FEB 261968

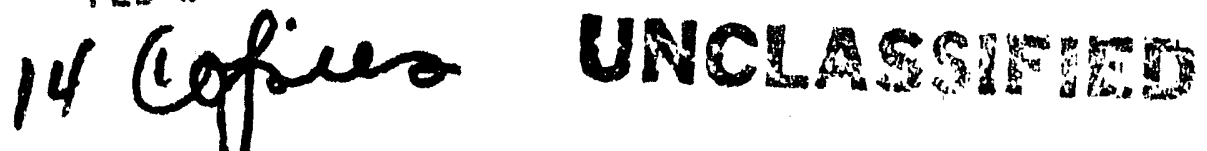

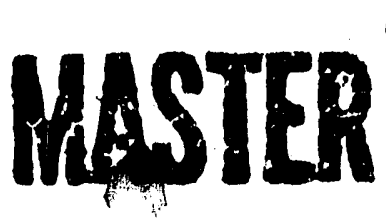

capy d.
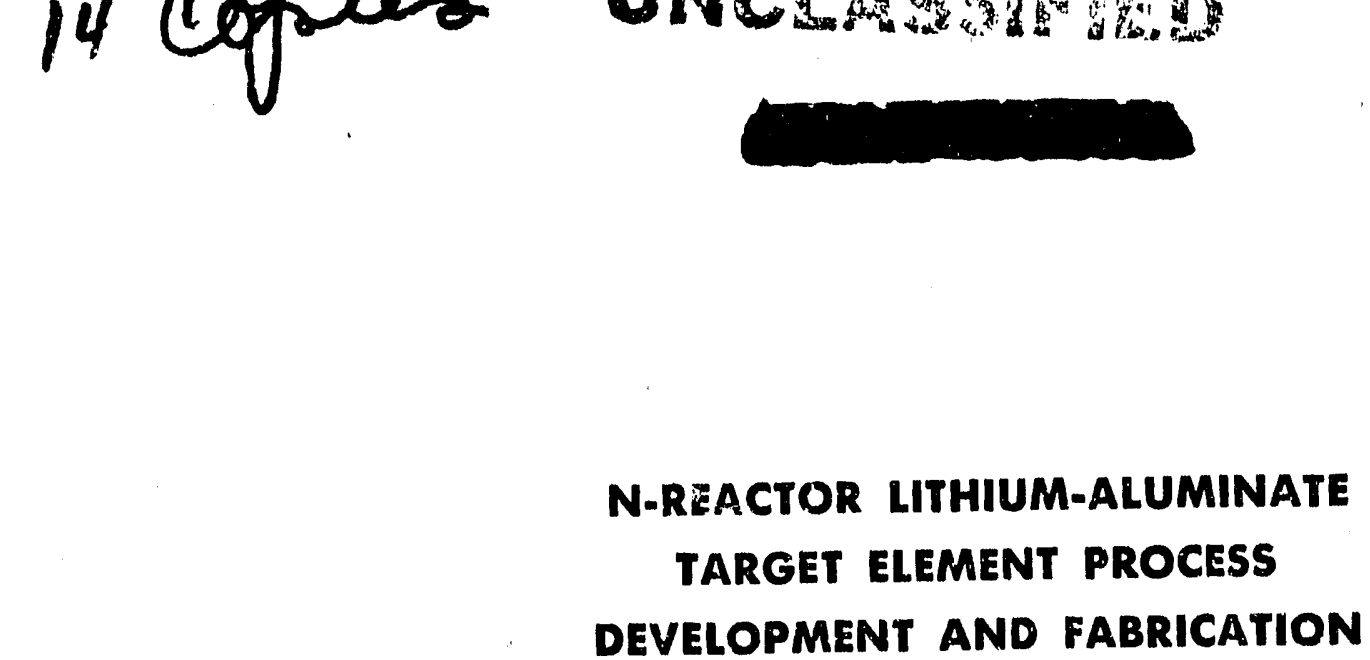

RL-GEN-1773

\title{
N-REACTOR LITHIUM-ALUMINATE \\ TARGET ELEMENT PROCESS \\ DEVELOPMENT AND FABRICATION
}

BY

C. H. SHAW

\section{N-FUELS ENGINEERING OPERATION \\ N.REACTOR FUELS SECTION \\ N-REACTOR DEPARTMENT \\ GENERAL ELECTRIC COMPANY}

$\sqrt{\text { DECEMBER 30, } 1967}$

CLASSILICATION CANSELLED

OR CHAIVGEO TO UNCLASSIFIED.

BY AUTHIORITY OF SP.M.Z. CG -

BY Sewnits 7. Savis DATE. $\frac{2-10-1292}{2-10-92}$

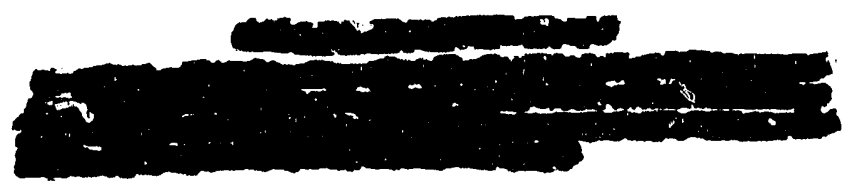

\section{UNCLASSIFES}

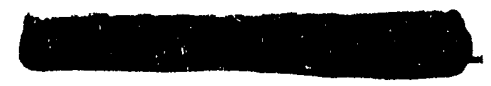




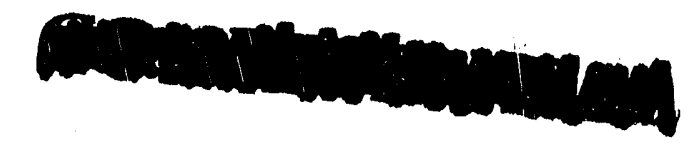

DOUGLAS UNITED NUCLEAR, INC.

RICHLAND. WASHINGTON

\section{NOTICE}

THIS REPORT WAS PREPARED FOR USE WITHIN DOUGLAS UNITED NUCLEAR, INC. IN THE COURSE OF WORK UNDER ATOMIC ENERGY COMMISSION CONTRACT AT (45-1) - 1857, AND ANY VIEWS OR OPINIONS EXPRESSED IN THE REPORT ARE THOSE OF THE AUTHOR ONLY. THIS REPORT IS SUBJECT TO REVISION UPON COLLECTION OF ADDITIONAL DATA.

\section{LEGAL NOTICE}

THIS REPORT WAS PREPARED AS AN ACCOUNT OF GOVERNMENT SPONSORED WORK. NEITHER THE UNITED STATES, NOR THE COMMISSION, NOR ANY PERSON ACTING ON BEHALF OF THE COMMISSION:

A. MAKES ANY WARRANTY OR REPRESENTATION, EXPRESSED OR IMPLIED, WITH RESPECT TO THE ACCURACY, COMPLETENESS, OR USEFULNESS OF THE INFORMATION CONTAINED IN THIS REPORT, OR THAT THE USE OF ANY INFORMATION, APPARATUS, METHOD, OR PROCESS DISCLOSED IN THIS REPORT MAY NOT INFRINGE PRIVATELY OWNED RIGHTS; OR

B. ASSUMES ANY LIABILITIES WITH RESPECT TO THE USE OF, OR FOR DAMAGES RESULTING FROM THF USE OF ANY INFORMATION, APPARATUS, METHOD, OR PROCESS DISCLOSED IN THIS REPORT.

AS USED IN THE ABOVE, "PERSON ACTING ON BEHALF OF THE COMMISSION" INCLUDES ANY EMPLOYEE OR CONTRACTOR OF THE COMMISSION, OR EMPLOYEE OF SUCH CONTRACTOR, TO THE EXTENT THAT SUCH EMPLOYEE OR CONTRACTOR OF THE COMMISSION, OR EMPLOYEE OF SUCH CONTRACTOR PREPARES, DISSEMINATES, OR PROVIDES ACCESS TO, ANY INFORMATION PURSUANT TO HIS EMPLOYMENT OR CONTRACT WITH THE COMMISSION, OR HIS EMPLOYMENT WITH SUCH CONTRACTOR.

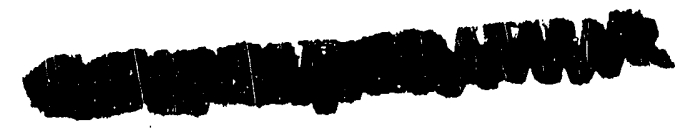


RL-GEN--1773

DE92 007667 ials

, l. )

N-REACTOR LITHIUM-ALUMINATE

TARGET ELEMENT PROCESS

DEVELOPIIENT ANL FABRICATION

By

N-Fuels Engineering Operation

$\mathrm{N}$-Reactor Fue1s Section

$\mathrm{N}$-Reactor Department

General Electric Company

Preparation Date: June 1967

Date of Issuance: $12 / 30 / 67$

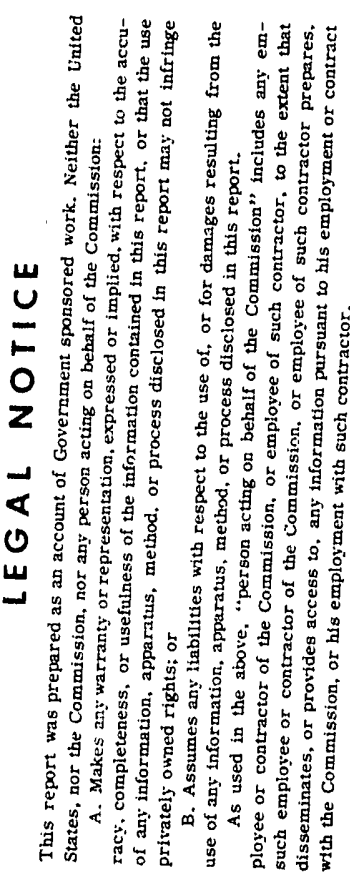

Work performed under Contract No. AT(45-1)-1350 between the Atomic Energy Commission and General Electric Company

HANFORD ATOMIC PRODUCTS OPERATION

RICHILAND, WASHIINGTON

GROUP 1

Excluded from automatic downgrading and dec?assification 


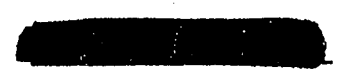

N-REACTDR LITHIUM-ALUMINATE

TARGET ELEMENT PROCESS

DEVELOPMENT AND FABRICATION

C. H. Shaw

\section{$\underline{\text { ABSTRACT }}$}

Fabrication of $\mathrm{IiAlO}_{2}$ target elements for the $\mathrm{N}$-Reactor Coproduct Demonstration Program required development of a suitable fabrication process consistent with installation of a minimum production facility on a limited time schedule. The most advanced manufacturing process developed and used within the facility and schedule constraints is described in detail. Major problems encountered in obtaining required component materials and development of the fabrication process are discussed and analyzed for impact on future programs utilizing LiA10 2 target elements. 
UNOBA

V

RL - GEN- 1773

TABLE OF CONTENTS

ABST'RACT

LIST OF FIGURES .

LIST OF TABLES

INTRODUCTION

MANUFACTURING PROCESS

General Process Description . . . . . . . . 2

Process Control Procedures . . . . . . . . 5

Facilities and Equipment . . . . . . . . . . 6

COMPONENT MATERIALS . . . . . . . . . . . . . . . 8

Lithium-Aluminate . . . . . . . . . . . . 8

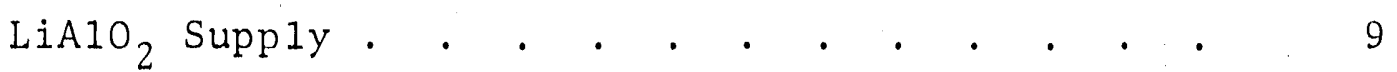

Isotope Control . . . . . . . . . . . . 11

Aluminum Cladding . . . . . . . . . . . 17

Zircaloy Components . . . . . . . . . . . 19

Cladding . . . . . . . . . . . . . 19

Support Hardware . . . . . . . . . . . 28

FABRICATION PROCESSES . . . . . . . . . . . . . . . 32

Ceramic (Sintered Product) Process . . . . . . 32

Receipt and Analysis of Powder . . . . . . 34

Characterization of Powder . . . . . . . . 34

Powder Conditioning . . . . . . . . . . . 44

Particle Sizing by Ball Milling . . . . . . 44

Addition Blending . . . . . . . . . . . 47

Pellet Pressing . . . . . . . . . . 48

Bakeout Lubricant and Binder. . . . . . . 52

Sintering . . . . . . . . . . . . . 53

Implications for the Future . . . . . . . 59

Assembly (Cladding) Process . . . . . . . . 59

Pellet Finishing Operations . . . . . . . 59

Ceramic Assembly into Aluminum Cladding . . . 59

Aluminum Assembly End Closure Welding . . . . 64

chisting 


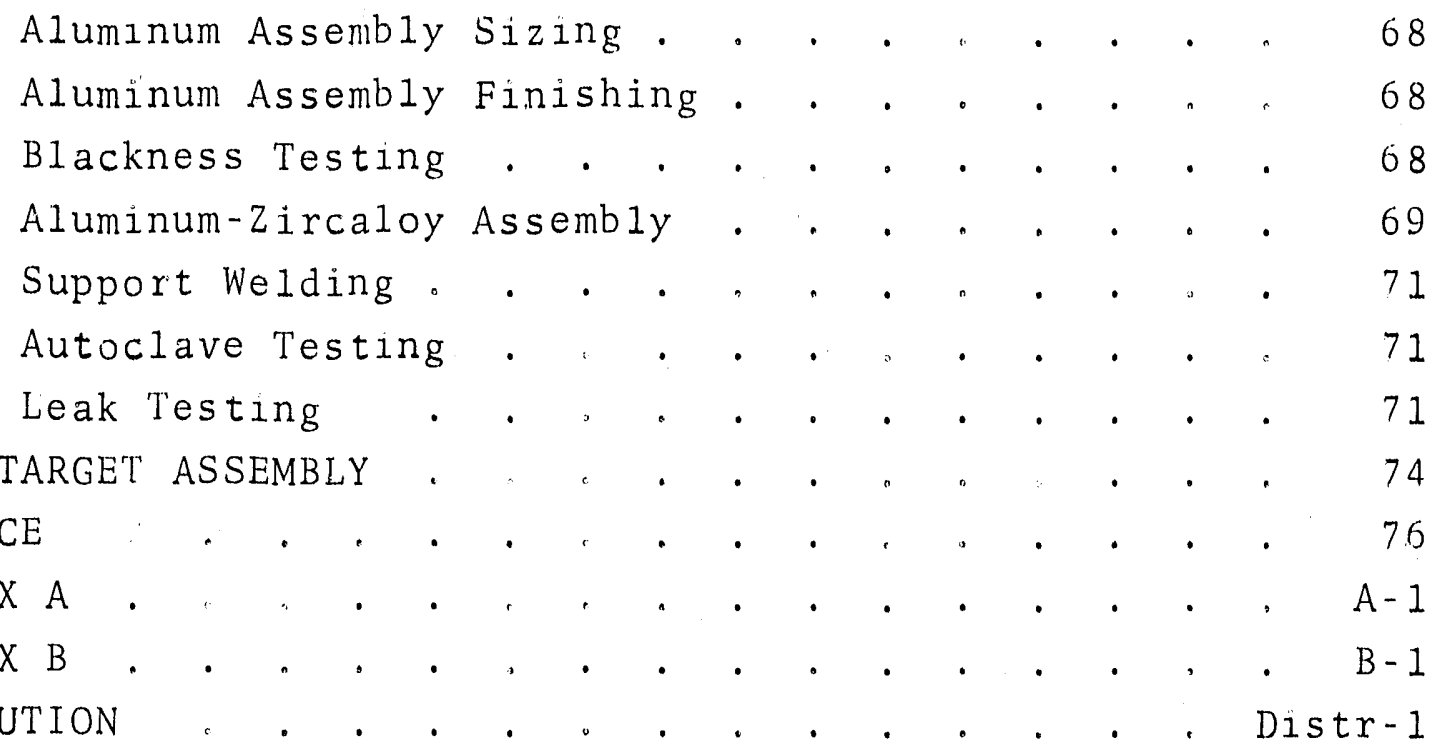

DRIVER - TAR

APPENDIX A

APPENDIX B

DISTRIBUTION 


\section{LIST OF FIGURES}

1 Coproduct Target Fabrication Process . . . . . . . 3

2 Cross Section of Coproduct Target Element . . . . 4

3 Subassembly Li ${ }^{6}$ Content Versus

305 Reactivity Results- . . . , . . . . . 14

Coproduct $\mathrm{LiAlO}_{2}$ " $\cdot$. $\cdot$. ' $\cdot$. $\cdot$. $\cdot$. $\cdot 14$

4 Target $\mathrm{Li}^{6}$ Content Versus 305 Reactivity

Results-Coproduct LiAlO 2 . . . . . . . . . 15

$5 \quad$ LiA102 Powder Li ${ }^{6}$ Content Versus

305 Reactivity Results . . . . . . . 16

6 Isotope Control Procedure. . . . . . . . . . 18

7 Defective Aluminum End Cap . . . . . . . . . . 20

8a Outer Surface of Clad at Point of . . . . . . 24

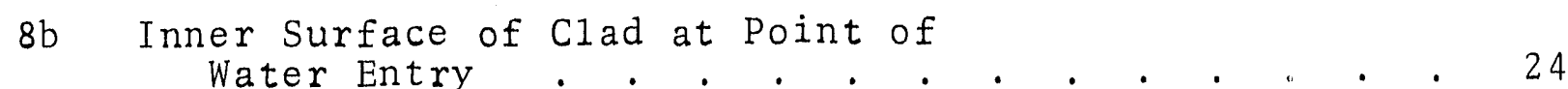

9 a Start of Larger Defect Area as Found by

$9 \mathrm{~b}$ Progressing Further into Defect. About 5 Mils , 25

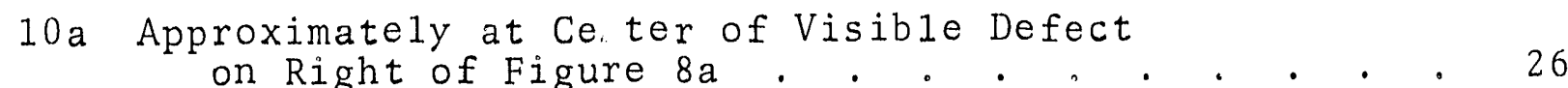

10b Root of Defect in View of Figure $10 \mathrm{a}$. Grain Size and Orientation Show Defect

Existed Prior to Final Drawing Operation . . . . 26

11 Water Path 。 . . . . . . . . . . . 27

12 "W" Spring (As formed) . . . . . . . . . . . 30

13 Rigid Support . . . . . . . • . . • • • . 31

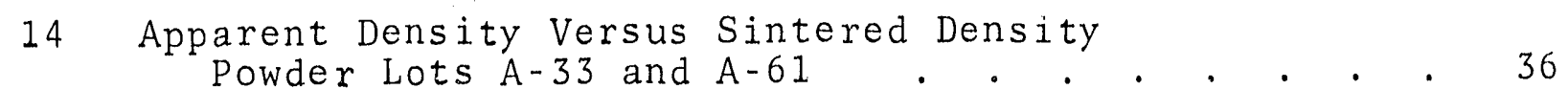

15 Average Particle Size Using Fisher Subsieve

Sizer Versus Apparent Density Using Scott

Volumeter for High As-Received Apparent Density. . 37

16 Green Pellet Density Versus Sintered Pellet

Density Powder Lot A-193 and PT-66 Powder. . . 38

17 Green Pellet Density Versus Powder Apparent

Density for Powder Lot A-193 
18 Powder Apparent Density Versus Adjusted

Sintered Density for Powder Lots

$\mathrm{A}-33$ and $\mathrm{A}-61 . .5 . .442$

19 Amount $\mathrm{CaCO}_{3}$ Addition Versus Sintered

Density Powder Jot A-41 . . . . . . . . . 45

20 Apparent Density Ve:sus Ball Mill Time

for Powder Lots A-33, A-51, and A-61. . . . 48

21 Green Density Versus Pressing Pressure

for Three Powder Lots. . . . . . . . . . 51

$22400{ }^{\circ} \mathrm{C}$ Bakeout -1 wt $\%$ Lithium Stearate

and 1 wt: Stearic Acid . . . . . . . . . 54

$23 \mathrm{LiAlO}_{2}$ Sintered Structure . . . . . . . . . 56

$24 \mathrm{LiAlO}_{2}$ Sintered Pellets . . . . , . . . . . 57

25 Centerless Belt Girinding Outside'

Diameter Finishing .. . . . . . . . . . . 60

26 Belt Sanding End Squaring . . . . . . . . . 61

27 Abrasive Saw to Stack Length . . . . . . . . 62

28 Glovebox Assembly Chamber . . . . . . . . . 65

29 Aluminum End Cap Welding . . . . . . . . . 67

30 Typical Production Zircaloy End

Closure Weld. . . . . . . . . . . 72

31 Typical Production Multiple Projection

Support We1d. . . . . . . . . . . . . 73

32 "W" Spring Stress Relaxation . • . • . . . . 75

\section{LIST OF TABLES}

1 Allowable Variation of Average Li ${ }^{6}$ Content

from Specification Nominal . • . • . • . . 12

2 Accuracy--Isotope Determination . . . . . . . 13

3 Process Evolution . . . . . . . . . . . . . 33

4 Additive Effects on Sintered Densicy . . . . . . 43

5 Binder and Lubricant Melting and Backing

6 Pellet Drying and Assembly Process . . . . . . 64

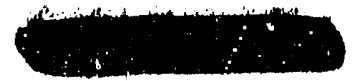




\section{H. \\ N-REACTOR LITHIUM-ALUMINATE \\ TARGET ELEMENT PROCESS \\ DEVELOPMENT AND FABRICATION}

C. H. Shaw

\section{INTRODUCTION}

The coproduct target element fabrication process used consisted of a typical sintered product process coupled with cladding and support hardware attachment operations to adapt the sintered product for use in the reactor. The facility and equipment utilized for production was minimized due to the short program duration. This minimization of capital expenditure and the limited time schedule were in many cases more restrictive on the process selected than established product criteria. The fabrication process utilized for a major portion of the demonstration program has been proven capable of producing a product within established criteria (1) with practical manufacturing operations. The process could, however, be refined in many areas from both an operating efficiency and control standpoint by investing additional process engineering development time and capital expenditures for the overall facility.

Quality and reproducibility of input LiAlo 2 powdor characteristics was the most significant problem encountered in the program. Development work to define and control the processing parameters necessary to produce LiA10 2 powder with consistent characteristics should be of first priority in any continued irradiation program utilizing LiAl0 2 targets. Supply of other essential components used in the program was more a matter of establishing reliable fabrication routes rather than basic development of material processes. 


\section{MANUFACTURING PROCESS}

The coproduct target element manufacturing process was basically made up of batching uperations. Individual components were fabricated in lots and assembled into the finished element. For purposes of process control, each target assembly was considered a unique $10 t$.

\section{GENERAL PROCESS DESCRIPTION}

A process flow diagram for coproduct element fabrication is shown in Figure 1. Target element details are shown in Figure 2 . The LiAlO 2 powder was pebble milled for particle sizing, appropriate binders were added to increase green strength, and the powder was then pressed into pellets. The green pellets were preheated for binder bakeout followed by sintering at $1325{ }^{\circ} \mathrm{C}$ for $14 \mathrm{hr}$. The sintered pellets were centerless ground, squared, and cut to stack length for assembly into aluminum cans. The aluminum clad assemblies were hydrostatical1y sized to the ceramic outside diameter, straightened, centerless ground, and assembled into the zircaloy cladding. The zircaloy clad assemblies were support welded and autoclaved followed by helium leak testing immediately prior to assembly with driver fuel. Each of the manufacturing process steps illustrated in Figure 1 is discussed under "Fabrication Processes."

The basic process for fabrication of sintered pellets was essentially that used for manufacture of most ceramic products. The process used did not provide for close dimensional control of the sintered product; however, sufficient development time was not available prior to production startup to optimize in this area. The decision to use secondary finishing operations was dictated by overall schedule commitments. Further refinements of the sintering process are advisable to minimize dimensional variation of the product in a sustained operation. 


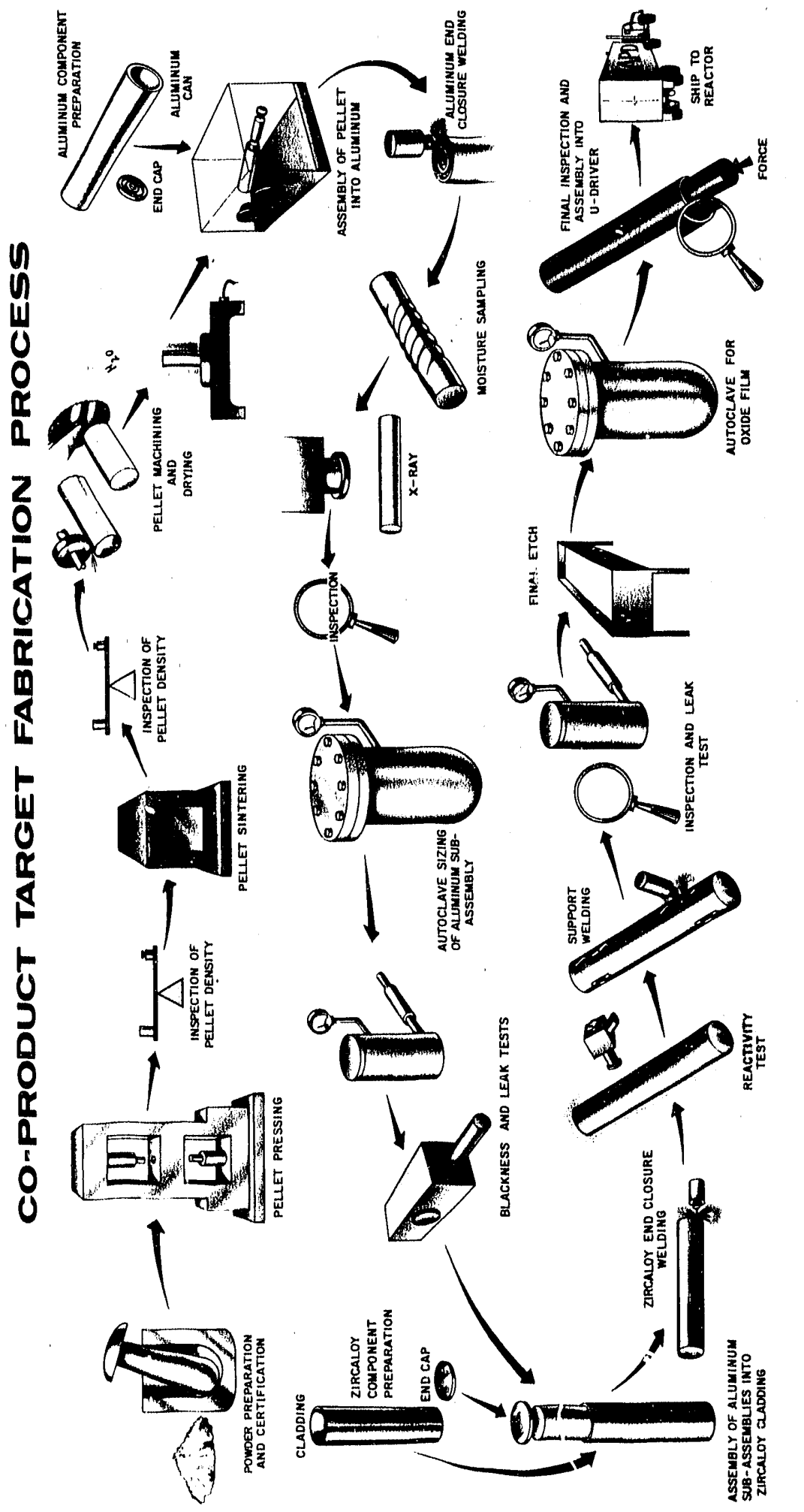

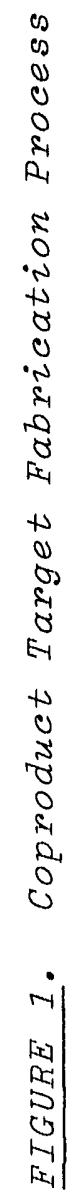



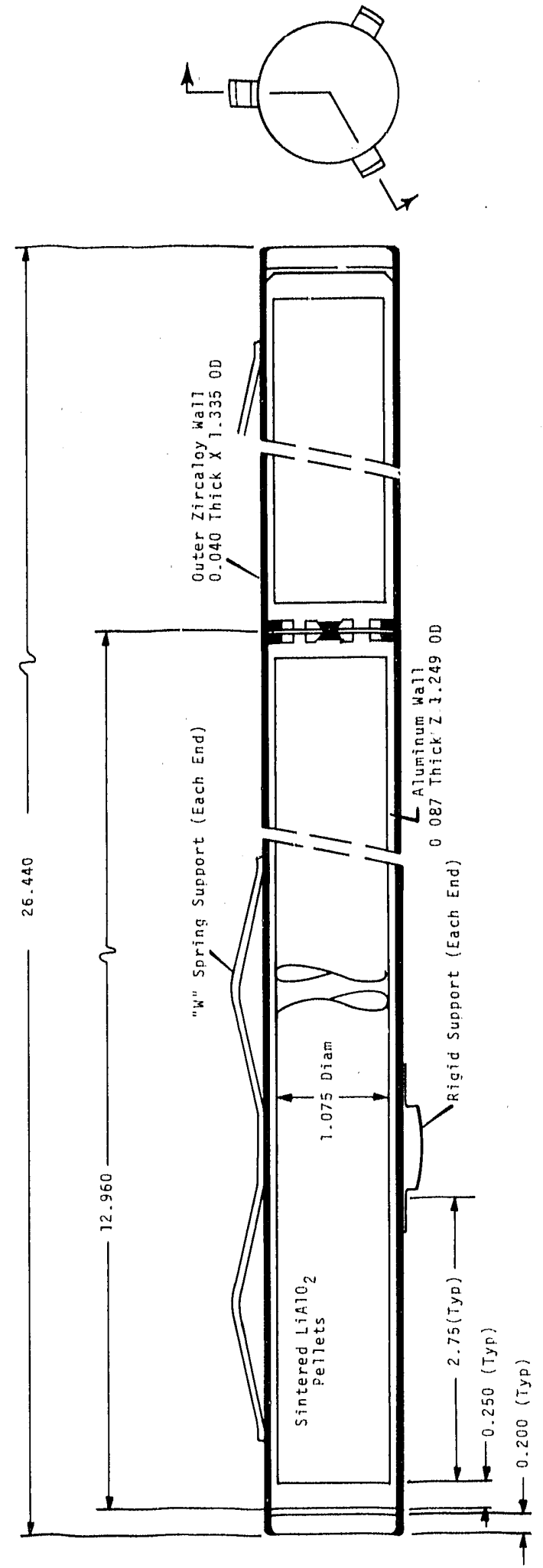

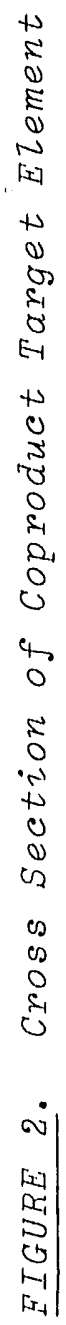

UNCLASSTFIED 
The assembly and cladding onerations used were not unusual for nuclear fuel. Glovebox assembly of the pellets into aluminum was required to minimize moisture pickup in the ceramic. The major technical consideration in the assembly area, other than physical integrity, was that the moisture level in the finished product had to be maintained less than $150 \mathrm{ppm}$. This moisture level was attained by drying the ceramic at $800^{\circ} \mathrm{C}$. The pellets were then immediately transferred at temperature to a controlled atmosphere (argon) glovebox for assembly in aluminum. The ceramic was not exposed to room air following the drying step. This particular portion of the assembly process dictated a batchtype of oporation. The glovebox operation was not limiting to production throughput in any manner when sufficient inventories of sintered product. existed to process reasonable size batches. PROCESS CONTROL PRUCEDUPES

Three basic documents were used for information to control the fabrication process. These documents discussed

- Operating Procedures (2) which were a combination of process and equipment operating instructions. The procedures were utilized directly by operating, personnel and were, therefore, che most restrictive.

- Quality Control Stanjards ${ }^{(3)}$, which detailed and limited those process and equipment parameters of major importance to product quality. The standards were used for auditing purposes by Ouality Control personnel, and were always less restrictive than the operating Procedures.

- Enginearing Specifications (4) which define those process requirements necessary to assure conformance to product criteria. The specifications were a combination of product and process requirements. The specifications were also used as a base for both the Quality Control standards and the Operating Procedures. 
Control requirements for coproduct target elements called for development of a material identification system to insure that the processing and materials history for each element could be traced. This requirement was met by the use of an alphanumeric identification number assigned each element. This identification number plus recorded manufacturing processing details associated with a given element were similar to those used for most nuclear fuel elements. This system is described in detail in Appendix A.

\section{FACILITIES AND EQUIPMENT}

The equipment and facilities to produce the coproduct target elements were installed with minimum capital expenditure. $(5,6)$ As stated under "GENERAL PROCESS DESCRIPTION," the limited time schedule dictated by the demonstration program required development of a practical compromise between installed equipment and the fabrication process used. The equipment used, however, performed quite satisfactorily and could be used for sustained operations. It is possible, with continued process development work, that the overal1 length of the production line could be shortened with resultant decreases in the number of equipment items required. This is not to say that the overall facility floor space would be reduced or that installed equipment cost would he reduced. To the contrary, a reduction of process steps, particularly in the pellet sizing area, would require the use of more sophisticated equipment to obtain reproducible control of the sintered product dimensions. A detailed listing of the major equipment items is included in Appendix $B$.

The most significant problems with fabrication equipment were related primarily to the characteristics of lithiun aiuminate and the product variability encountered. The aluminate powder is an abrasive and, therefore, all moving parts on the process equipment must be protected. The abrasive effects of: the powder were most evident on the pellet press, press tooling, 
blender bearings, grinder bearings, etc. Excess equipment capacity in these areas was necessary to allow for the extensive preventative maintenance required to protect critical equipment components.

Sintering furnace performance is a continuing problem due to lithium boil-off during the sintering operation. The lithium reacts with the furnace brick and globar heating elements dictating an average replacement of globars every seven weeks and furnace brick every three to four months. Attempts were made to improve globar 1 ife by pressurizing each unit with air. The air flow through the furnace provided some protection for the heating elements, but created significant temperature differences across the furnaces with resultant variation in sintered pellet density. Sca snging the furnaces did not, therefore, prove practical with the installed curnace designs. Engineering effort was then directed at testing and procurement of components ieast affected by the lithium. A simple change from the A. T. Standard type of globar to the S. G. spiral type provided a $300 \%$ increase in life.

Sintered densities were controlled $t 5 \%$ from specified nominal ( $78 \%$ of theoretical). This amount of variation, however, created numerous problems with the pellet sizing equipment. Pe1let reaction to abrasive saw blades and grinder belts is dependent on density and the amount of variation allowed in the product required tailoring of grinding equipment to each sintering lot; i.e., a different grade of blade was required for sawing $32 \%$ dense pellets than the one used for $74 \%$ dense pellets. 


\section{COMPONENT MATERIALS}

\section{LITHIUM-ALUMINATE}

Lithium-aluminate $\left(\mathrm{LiA1O_{2 }}\right)$ is produced by reacting 1 ithiumcarbonate $\left(\mathrm{LiCO}_{3}\right)$ and alumina $\left(\mathrm{Al}_{2} \mathrm{O}_{3}\right)$ at temperatures betweon 750 and $1000^{\circ} \mathrm{C}$. LiAlO, has two crystallographic forms. The low form, $\alpha$, transforms irreversibly to the high form, $\gamma$, above $60{ }^{\circ} \mathrm{C}$ with an accompanying $30 \%$ volumetric increase. The kinetics of the transformation increase with increasing temperature and the transformation occurs fairly rapidly at $900{ }^{\circ} \mathrm{C}$. The reaction can be accomplished by heating stoichiometric quantities of lithium-carbonate and alumina ejther as pressed compacts or powder mixtures.

Chemical purity of the aluminate is, of course, largely dependent on carbonate and alumina purity and use of clean processing equipment. The chemical purity of the final product is also dependent on the completeness of reaction and stoichiometry of the carbonate plus alumina. Nost of the aluminate used for the demonstration program had substoichiometric 1ithium contents with residual carbonate and alumina. Residual carbonate is undesirable if the material is subsequently heated above the reaction temperature due to reaction of the carbonate producing a partial pres sure of $\mathrm{CO}_{2}$. Residual alumina is also unclesirable due to effects on powder sinterability.

Control of the isotope ratio (Li ${ }^{6} / \mathrm{T}^{\circ} \mathrm{za}$. Li) in the lithium carbonate feed material was accomplishod by blending large batches of 1 ithium hydroxide monohydrate $\left(\right.$ i.ioll $\left.\cdot H_{2} O\right)$ to the required ratio. The hydroxide was then converted to carbonate and reacted to aluminate. This approach to isotope ratio control was used to simplify vendor certification procedures from hyclroxide to a 1 uminate since control of processing temperatures and product stoichiometry assured a given isotope level in the aluminate with

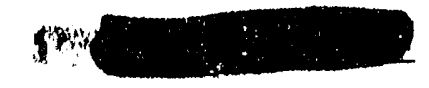


given hydroxide input. The problems encountered in establishing the supply of $\mathrm{LiAlO}_{2}$ with required isotope level are discussed below in more detail.

$\underline{\text { LiA10 }} 2$ Supp 1 y

Lithium-aluminate was produced, prior to HAPD usage, in small quantities by only one U.S. concern. This situation still exists. Other concerns expressed interest, but were not willing to perform the process development work and facility modifications required to produce material for a limited application. The primary supplier's experience in producing $\mathrm{LiAlO}_{2}$ was 1 imited to an occasiona 1200 pound lot which was offered to the ceramics indus try for a specialty glaze. Lithium content varied widely and impurities were controlled only as they affected the color of the product.

The material for the demonstration program represented more than a 100-fold increase in annual production and an entirely new magnitude of chemical control (7) in the product. The aluminate producer was not required to establish or maintain control of isotopic level except by segregation of the hydroxide feed material with various isotopic contents. Vendor performance in maintaining total lithium content in the product was quite good on all material produced. Control of specified impurity levels was more than adequate except for two elements, boron and fluorine. $(8,9)$

The universally accepted method of analyzing for lithium is by flame photometry. All lots of aluminate were analyzed and reported by both the vendor and Battelle-Northwest Chemical Anal. ysis section. While absolute agreement on any one lot was rare, the averages of values reported for all lots was surprisingly close considering the inherent lack of precision of the analytical method. 
No quantitative measure of boron content was available on initial production of aluminate. A spectrographic analysis for boron on a semiquantitative level was developed by Douglas United Nuclear Spectrographic Laboratory, and boron was found to occur sporatically in quantities up to $200 \mathrm{ppm}$. This level of contam. ination is subsequently reduced at least $50 \%$ by boil-off during the sintering operation. Boron contamination existed due to a cross.contamination problem in the reaction process. The problem was eliminated by emphasizing the need for complete separation of the aluminate from boron containing materials and contaminated equipment

The practical limits on fluorine content are not known. High fluorine content is potentially more serious than high boron, which only affects fuel reactivity and product yield. Fluorine can affect fuel integrity under irradiation and free fluorine or volatile fluorine compounds in the product separa. tions operation could prove detrimental to some items of equipment. (10) Based on the above general considerations, a limit of $25 \mathrm{ppm}$ fluorine was established for the aluminate. Again, as in the boron sase, analytical methods had to be developed to per. form fluorine analyses. Due to delays in obtaining analyses and che shortage of avallable powder, a number of powder lots were used which contained fluorine in excess of $25 \mathrm{ppm}$. This material was used because: (1) preliminary evaluation of product separa. tion operations indicated that no free fluoxine and very few, if any, fluorine compounds were released; and (2) a review of fun. damental fluoride chemistry showed that the fluorine content of the peliets should be significantly reduced during sintering Subsequent tests have shown that the fluorine content is reduced by at least a factor of 10 by sintering. The source(s) of fluo $r$ ine has not been determined, but 1 t is quite possible that a significant amount existed in the hydroxide used, and the reac. tion process was not performed at high enough temperatures to reduce the content by boil-off. 
Isotope Control

Procedures were required to establish anc then control spefied quantities of the $\mathrm{Li}^{6}$ isotope per unit of finished target element volume. Early in the program, isotopic ratio of the aluminate was adjusted by blending natural. lithium values with values of a lower $\mathrm{Li}^{6} / \mathrm{Li}^{7}$ ratio than was desired in the finished product. Total lithium and $\mathrm{Li}^{6}$ ratio analyses were made on each batch of aluminate received and materials proportioned to yield the desired $\mathrm{Li}^{6}$ content per unit target volume at $78 \%$ of theoretical density. This powder blending approach did not prove practical in that batch sizes were small and the inherent difficulties in mass spectographic determination of the $\mathrm{Li}^{6} / \mathrm{Li}$ weight ratio dictated use of maximum batch sizes to minimize the number of analyses required to certify the product. Isotopic ratio adjustment was therefore accomplishecl by solution blending large batches of lithium hydroxide to the desired level.

Adjustment in the hydroxide was believed possible since subsequent processing operations should not vary the ratio. The control problem was then reduced to control of total 1ith$i$ um as affected by the quantities of $\mathrm{Li}_{2} \mathrm{CO}_{3}$ and $\mathrm{Al}_{2} \mathrm{O}_{3}$ used in the reaction to $\mathrm{LiAlO}_{2}$, the boil-off losses during sintering, and the density of finished pellets.

The isotope control problem was primarily concerned with analytical ability to provide accurate analyses of the product at various points in the fabrication process. The level of $\mathrm{Li}^{6}$ can be obtained directly by the combination of chemical and mass spectographic analyses or indirectly by reactor determination of reactivity versus standards. The control requirements established by performance criteria are detailed in Table I. 
TABLE I. AlZowable Variation of Average ${ }^{6} i^{6}$ Content from Specification Nominal

Base Case

Li. $_{\text {Base }}^{6}$ Control

(Nom, $=6.07$

$\frac{\text { Base }}{\text { Individual }}$

Targets

Average of

a11 Targets

in a Reac-

tor to Column

Average of

a11 Tárgets

in the

Reactor

$$
\pm 10 \%
$$

Spike Case Nom $_{\hat{6}}=3.68$ $\mathrm{g} \mathrm{Li}^{6} / \mathrm{cm}^{3}$ of $\sim_{\text {LiA10 }}$ )

$\pm 15 \%$

$\pm 10 \%$
Poison Case (Nom. $=12.26$ $\mathrm{mg} \mathrm{Li} 6 / \mathrm{cm}^{3}$ of LiA10 2 )

$\%$

Chemical and mass spectrographic determination of the $\mathrm{Li}_{6}^{6} / \mathrm{LiAlO}_{2}$ weight ratio involves separate determination of the $\mathrm{Li}^{6} / \mathrm{Li}$ weight ratio (mass spectrographic) and the $\mathrm{Li} / \mathrm{LiAlO}{ }_{2}$ weight ratio (flame spectrometry). Each of these analyses is considered accurate to $\pm 7 \%$. The $\mathrm{Li}^{6} / \mathrm{LiAlO} 2$ weight ratio determined by the product of above analyses is considered accurate to $\pm 10 \%$. The accuracy of the $\mathrm{Li}^{6} \mathrm{LiAlO}{ }_{2}$ weight ratio determination could be improved by either improved accuracy on individual $\mathrm{Li}^{6}$, $\mathrm{Li}$ and $\mathrm{Li} / \mathrm{LiAlO}_{2}$ analyses, or by multiple analyses on a given sample. The Li6/Li mass spectrographic analysis is considered good at an accuracy of $\pm 5-7 \%$ due to the low Li ${ }^{6}$ content ( 3 wt $\mathrm{Li}^{6}$ in base case material). The Li/LiAlO 2 analysis is complicated by the time dependency of the analysis due to lithium reaction ith container materials. The Li/LiAlO 2 analysis is usually accurate to $\pm 5 \%$; however, the wide range of experienced values indicates the use of $\pm 7 \%$ for higher certainty.

Reactivity tests ( 305 T'est Reactor used for all testing) were used to relate a $\mathrm{LiAlO}_{2}$ reactivity measurement to the powder $\mathrm{Li}^{6} / \mathrm{LiAlO}_{2}$ weight ratio. Reactivity measurements for test $\mathrm{LiAlO}_{2}$ samples were obtained by comparing each sample to 
a $\mathrm{LiAlO}_{2}$ standard of known reactivity. The reactivity value obtained was then compared to a curve of reactivity versus $\mathrm{Li}^{6}$ content to obtain the $\mathrm{Li}^{6} / \mathrm{LiAlO} 2$ weight ratio. Three such curves are shown in Figures 3,4 , and 5 . The curves shown were used to test aluminum subassemblies, zircaloy clad assemblies, and input powder, respectively. Within curve accuracy, the only variable was the reactivity test measurement. A Li ${ }^{6}$ value (assuming correct curve) can therefore be obtained within $\pm 1 / 2 \%$. The curves were, however, generated by multiple analyses and contain inherent inaccuracies based on these analyses. Accuracy levels for the $\mathrm{Li}^{6}$ determination for the various powder cases (base, spike, and poison) are detailed in Table II.

\section{TABLE II. Accuracy--Isotope Determination}

Item Associated with Use of

Li 6 Versus Reactivity Curves

Subassembly and Target Curves (Figures 3 and 4 )

1. Li6 values (ordinate of curves) determined by multiple analyses.

2. Reactivity values (abscissa of curves) determined by multiple analyses.

3. Combination of Li $^{6}$ values and reactivity values of 1 and 2 above to obtain curve data points.

4. Individual sample reactivity measurements ( 305 Reactor drift test from standard). Note: This is accuracy of comparison between reactivity determined Li 6 values; that is assuming curves are correct.
Limitations of $\operatorname{Accuracy}(\mathrm{a})$ $\pm 1 / 4$ inhour or

$\pm 1 \% \mathrm{Li}^{6}$ (Base \& Poison Cases)

$\pm 1 / 2$ inhour or $\pm 21 / 2 \%$ Li 6 (Spike Case)

$\pm 31 / 2 \% \mathrm{Li}^{6}$ (Base \& Poison Case)

$\pm 41 / 2 \% \mathrm{Li}^{6}$

(Spike Case)

\pm 0.1 inhour or $\pm 1 / 2 \% \mathrm{Li} 6$ 


\section{TABLE II. (Contd)}

Item Associated with Use of

Li6 Versus Reactivity Curves

LiA10 2 Powder Curve (Figure 5)

5. Use of reactivity test value to assign real Lib content to material represented by sample.

Limitations of
Accuracy(a)

$\pm 4 \% \mathrm{Li}^{6}$ (Base \& Poison Case)

$\pm 5 \% \mathrm{Li}^{6}$ (Spike Case)

6. Li6 values (o: dinate of curve) determined by multiple analyses.

7. Reactivity values (abscissa of curve) determined by multiple analyses.

8. Individual sample reactivity measurements (305 Reactor drift test from standard). Note: This is accuracy of comparison between reactivity determined Li 6 values; that is assuming curve is correct.

9. Use of reactivity test value to assign rea $1 \pm 6 \% \mathrm{Li} 6$. Li6 content to material represented by sample. $\pm 23 / 4 \% \mathrm{Li}^{6}$

$\pm 1 / 2$ inhour or $\pm 51 / 2 \% \mathrm{Li} 6$

\pm 0.1 inhours or $\pm 1 / 2 \% \mathrm{Li} 6$

$\pm 6 \% \mathrm{Li}^{6}$

(a) These \pm values correspond to \pm 3 s limits.

The isotope control procedure developed, utilizing the analytical methods required with inherent inaccuracies, is charted in Figure 6. As-rereived powder was sampled for total $\mathrm{Li}$ and $\mathrm{Li}^{6}$ analyses and reactivity tested to establish the $\mathrm{Li}^{6} /$ LiA $10_{2}$ ratio. The purpose of these tests was to double check supplier lithium analyses and to detect any gross contamination by impurities of concern. The powder was also reactivity tested after sintering to establish the exact $\mathrm{Li}^{6} / \mathrm{LiAlO} \mathrm{O}_{2}$ value to be assigned the sintered product from that powder lot. This approach to powder certification provides maximum protection against a major material commitment prior to quantitative determination of quality. 


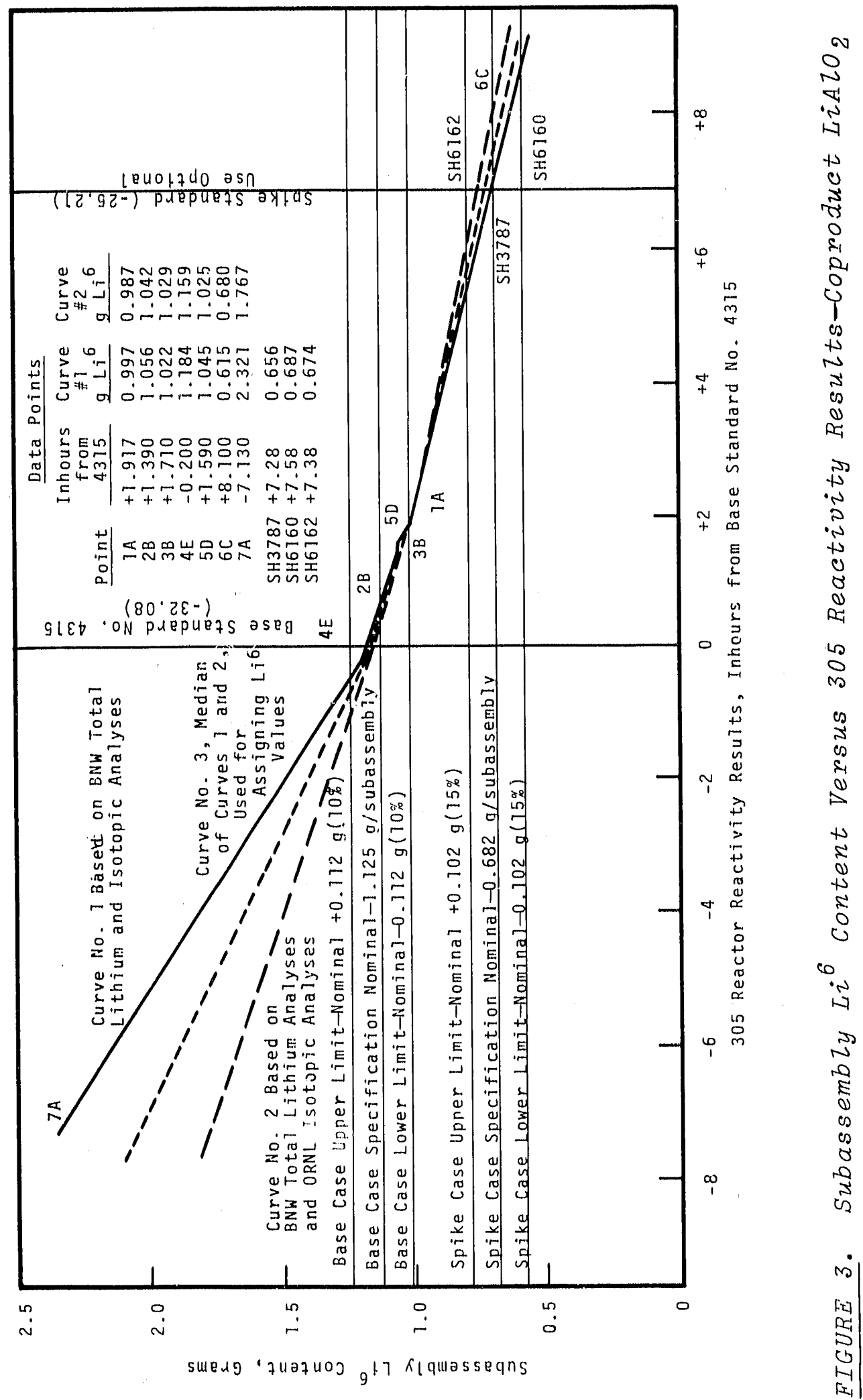



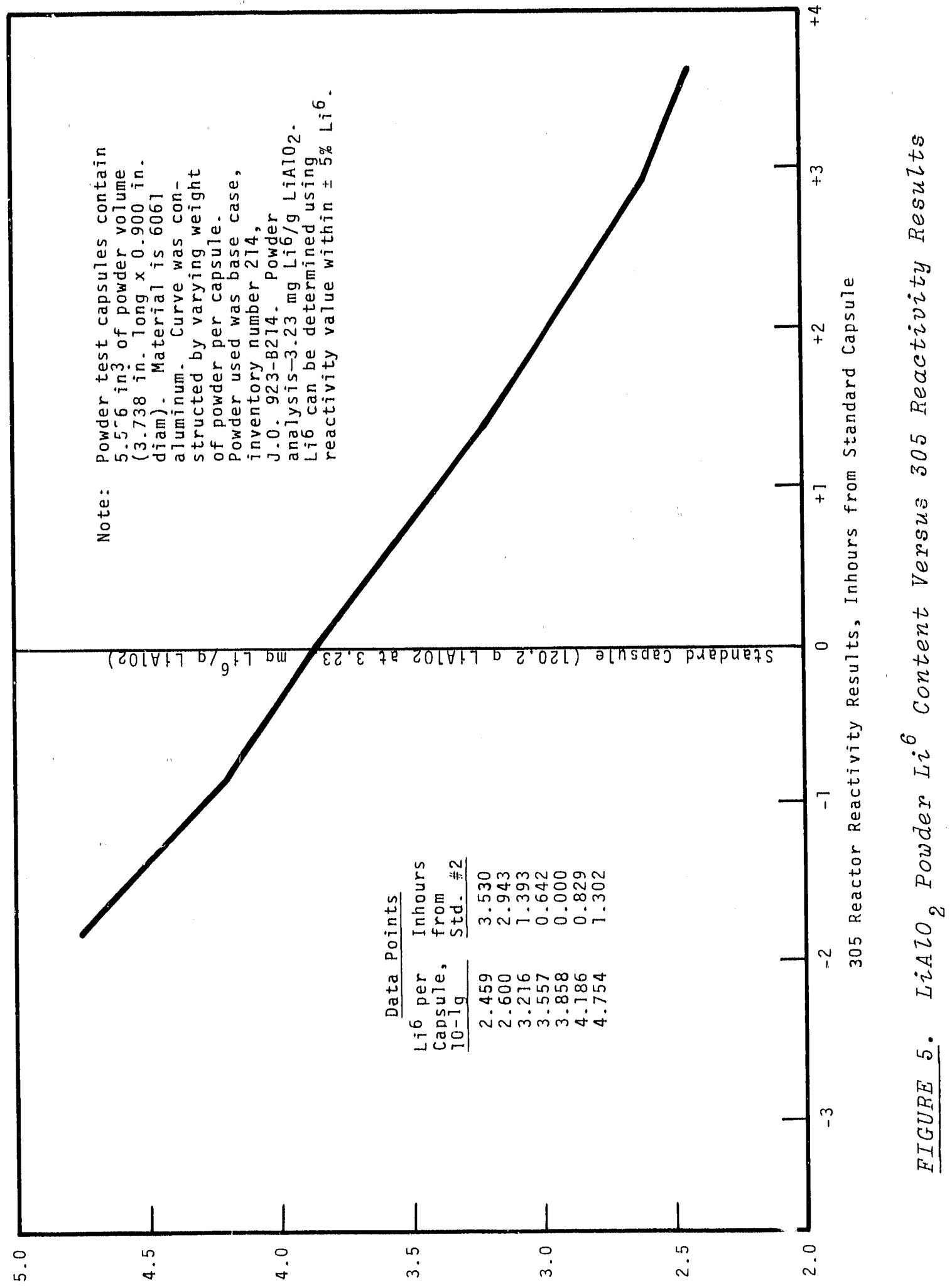

$1.01 \times 6$ '7uazuoj g17 18701 alnsdej 


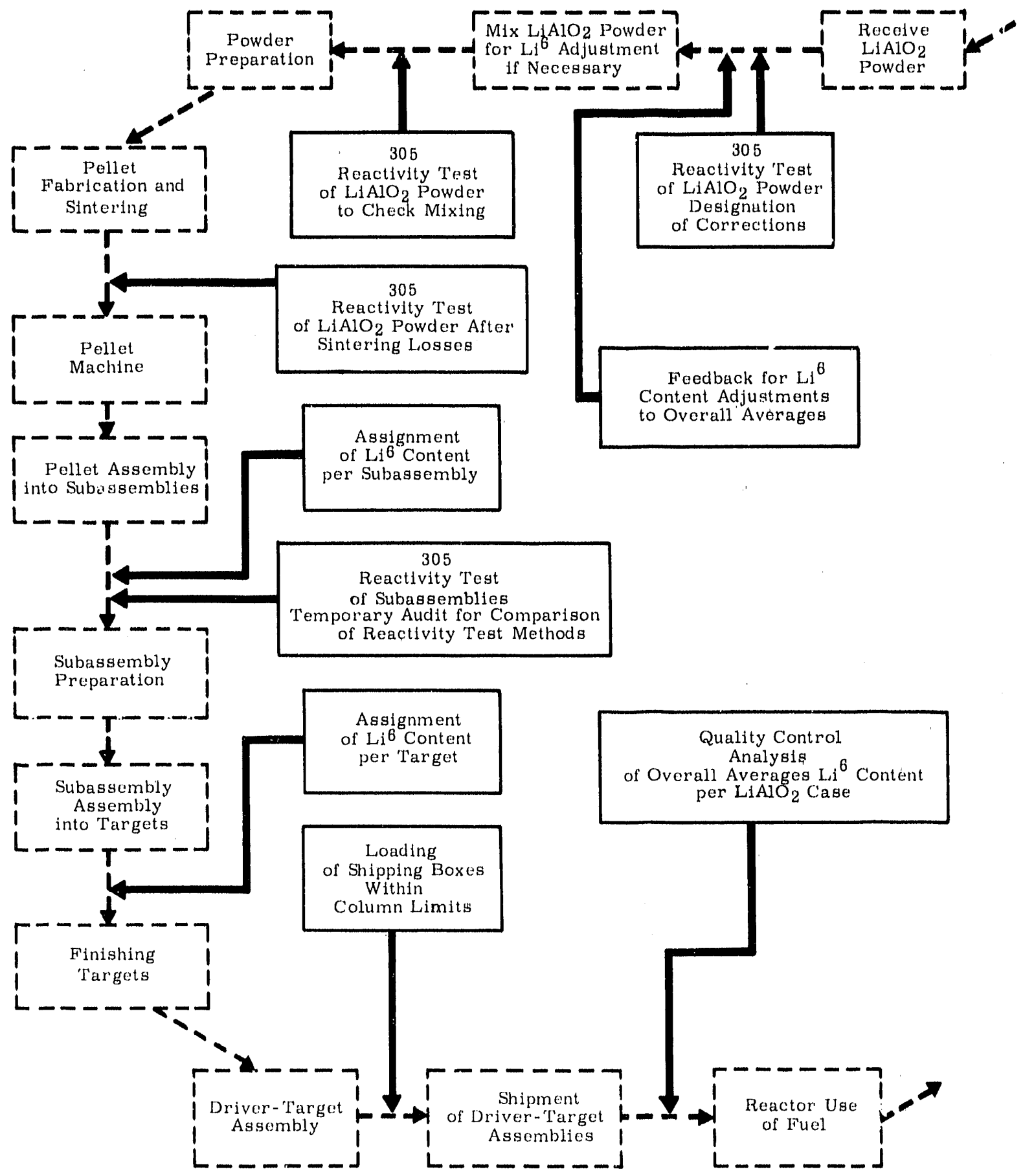

FIGURE 6. Isotope Control Prucedure 
ALUMINUM CLADDING

Aluminum was chosen for an intermediate cladding because it is impervious to hydrogen isotopes at operating temperatures, is compatible with other target components, and is fusible at the extraction temperature which permits automatic release of the gaseous irradiation products.

Aluminium cladding components were of no particular problem. The use of 1100 alloy tubing caused some delays in procurement because of a long term industry trend to the use of stronger alloys. Once a supply had been established, however, no further problems occurred in meeting schedule requirements.

The capability of impact forming of cans was established early in the program. The impact route proved adaptable to the length-wall thickness requirements ( 12.9 in. long $x 0.090$ in. wall) and provided significant cost reduction over the tubing doubleend closure alternative.

The need for nondestructive testing of end caps was further emphasized by defects detectea during the autoclave sizing process described in more detail under "FABRICATION PROCESS DETAILS." A typical end cap from one of the autoclave failures experienced is shown in Figure 7. Metallographic examination showed the defect to be an oxide inclusion not discovered by ultrasonic testing at the billet stage of processing.

ZIRCALOY COMPONENTS

Cladding

The zircaloy cladding dimensions were established by coolant flow requirements (outside diameter) and structural strength at operating conditions (wall thickness). In the early stages of component design, it was necessary to resolve the question on the relative advantages of free standing and internally supported (aluminum and ceramic components) cladding. The free standing 


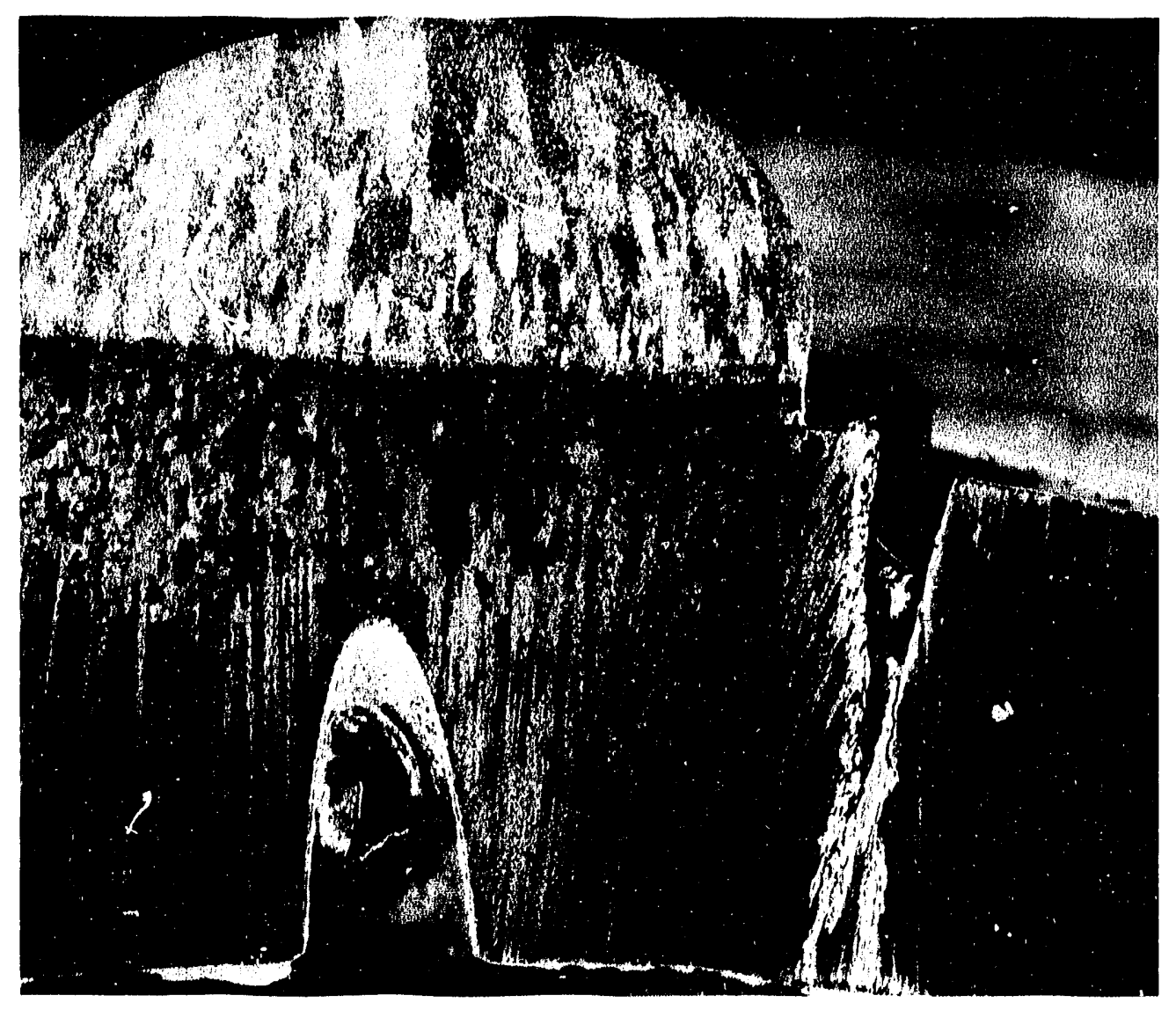

Neg $0670235-2$

EIGURE ?. Defective Aluminum End Cap

UNCLASS IFIED 
cladding concept provided operational advantages in that generous tolerances and allowances could be allowed on the internal components with no compromise of the zircaloy cladding integrity. In addition, the heavier clad provided greater freedom in methods selected for welding support hardware and end closures, Use of thin-walled tubing required control of the ceramic pellet and aluminum assembly dimensions to minimize clearances between the aluminum subassemblies and zircaloy cladding for adequate sup. port of the zircaloy. Assembly and finishing operations are therefore considerably more critical for the nonfree standing cladding.

The limiting wall thickness for free standing clad of decign outside diameter (1,335 in.) was calculated to be approximately 0.080 in. Empirical determinations of the limiting thickness showed it to be approximately 0.100 in due to ovality effects on stress distribution. The limiting wall thickness for nonfree standing cladding was empirically established by limiting tube collapse over a 0.120 in unsupported length (differential length between aluminum subassemblies and zircaloy cladding to accommodate differential thermal expansion) when exposed to autoclave conditions of $400^{\circ} \mathrm{C}$ and $1500 \mathrm{psia}$. A wall thickness of 0.040 in, nominal was selected on the basis of these tests.

The unit cost advantages of thinner wall tubes for target cladding persist until wall thickness becomes less than $3 \%$ of the tube outside diameter (approximately the ratio of minimum wall thickness target cladding). The selection of the cladding concepts to be used was therefore made by a comparison of the additional amount of zircaloy required for free standing clad versus the estimated additional operational cost associated with the nonfree standing clad. This comparison showed that a saving of approximately $\$ 500,000$ could be made by using thin wall 
tubing if suitable assembly and finishing processes could be developed to obtain the 0.006 to 0.010 in. diametral clearance requirement between the aluminum subassemblies and the zircaloy cladding. The assembly process was proven feasible and the thin wall cladding route was selected for the program.

Procurement of zircaloy cladding compnnents proved to be one of the major problems in meeting the demonstration program schedule. Procurement lead times for new tubing, produced by tube reducing extruded blanks to final size, proved to be approximately 12 months. The immediate cladding supply problem was resolved by reworking available excess $C$ and $K$ Reactor process tubes. Three methods of reducing tube diameter were employed (wall thickness held constant--outside diameter reduced from approximately 1.800 in. to 1.340 in.).A majority of the tubing was sized by multiple pass tube reducing. In addition, some $20 \%$ of the tubing was sized by free-sink drawing and single pass plug drawing (10\% each route). A11 material was annealed and straightented after the sizing operations.

Two major quality problems were encountered with the cladding: (i) folds on the tubing outer surface which are believed to have been caused by excessive reduction per pass in tube reducing extruded blanks to reactor process tube dimensions, (11) and (2) a pronounced tendency to warp when stress relieved in the final autoclaving step.

The fold problem was first discovered and identified as such when a leaker was detected after autoclaving. The zircaloy clad did not appear deformed and the leak may not have been detected except for a continued weeping which stained the exterior of the cladding. Location of the leak was remote from supports or end welds, and could not be attributed to any deviation in target fabrication processes. The clad of the failed target was sectioned and examined to identify the origin of the 


\section{UNCLASSHF}

defect. A second, smaller, defect about 4 in. axiály distant from the point of water entry was included in the examination. The attached series of photomicrographs (Figures 8 through 11) illustrate the nature of this defect as wel1 as a large number of similar defects in the cladding which have been found at receiving inspection. The high degree of axial alignment of similar visual defects plus the "worked" appearance, Figure 10b, of the metal adjacent to the discontinuity, suggests a defect originating early in the metallurgical history of the material. Possible causes are defects in the extrucled tube blank or toosevere reductions on the tube reducer resulting in pinching.

A11 of the tubing to be reworked to target dimensions was tested using a mass-spectrometer type helium leak detector. Tube ends were plugged and the tube was evacuated by a leak detector. A helium filled shroud was passed along the tube. As the shroud covered a leak, the detector would produce a signal and the leak location was marked. The defect section of the tube was later cut cut. Remajning sound sections over $6 \mathrm{ft}$ long were drawn to size.

U1trasonic testing was originally specified for inspection of the redrawn tube. Sensitivity was to be calibrated to a standard defect 0.050 in. long by $10 \%$ of tube wall thickness. An ultrasonic tester was assembled and calibrated to the standard defect size. At this level of sensitivity both extruded and redrawn material invariably yielded a defect signal. Zyglo and dye penetrant inspection of suspect areas failed to confirm tester results, and it was not possible with intensive metallographic examination to define any flaws in the tube wall. Measurements of surface finish of both frec-sink redrawn and extruded tubes showed that surface variations of the same order as the standard defect were causing spurious defect signals. At this point, the requirement for ultrasonic testing was removed; and a combination of $100 \%$ visual inspection of incoming cladding and helium leak testing of completed targets was initiated for control of material quality. 


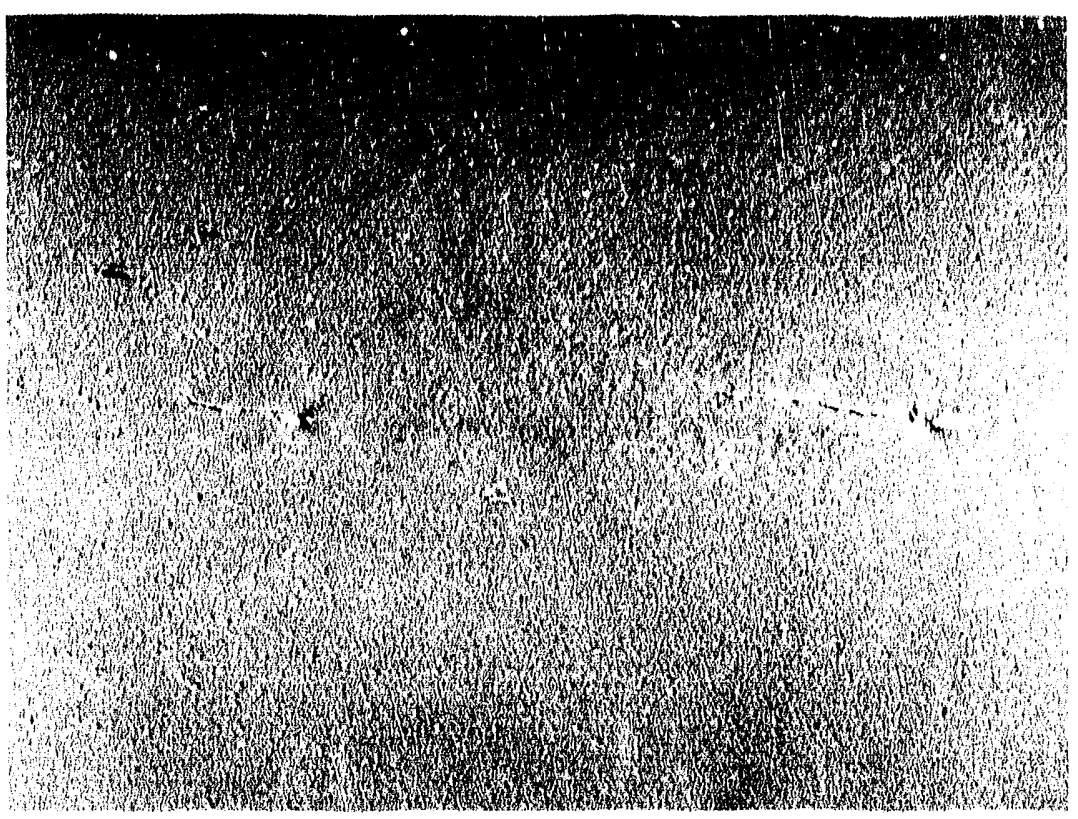

$\operatorname{Neg} 467-5147-A$

FIGURE 8a. Outer Surface of Clad at Point of Water Entry

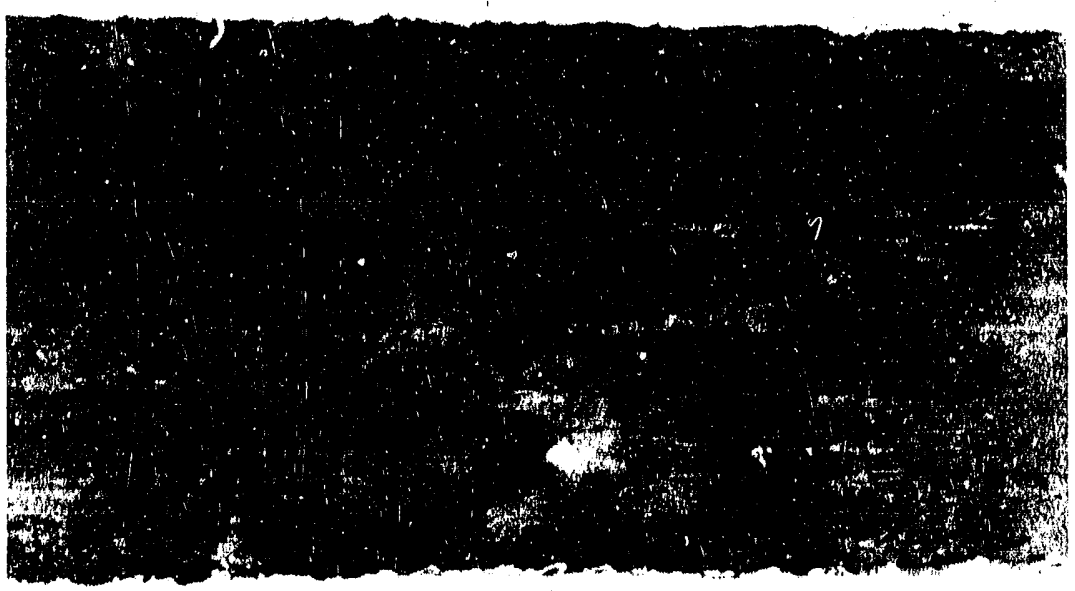

Neg 467-5147-B

$5 X$

PIGURE 8b. Inner Surface of c'lad at Point of Water Entry 


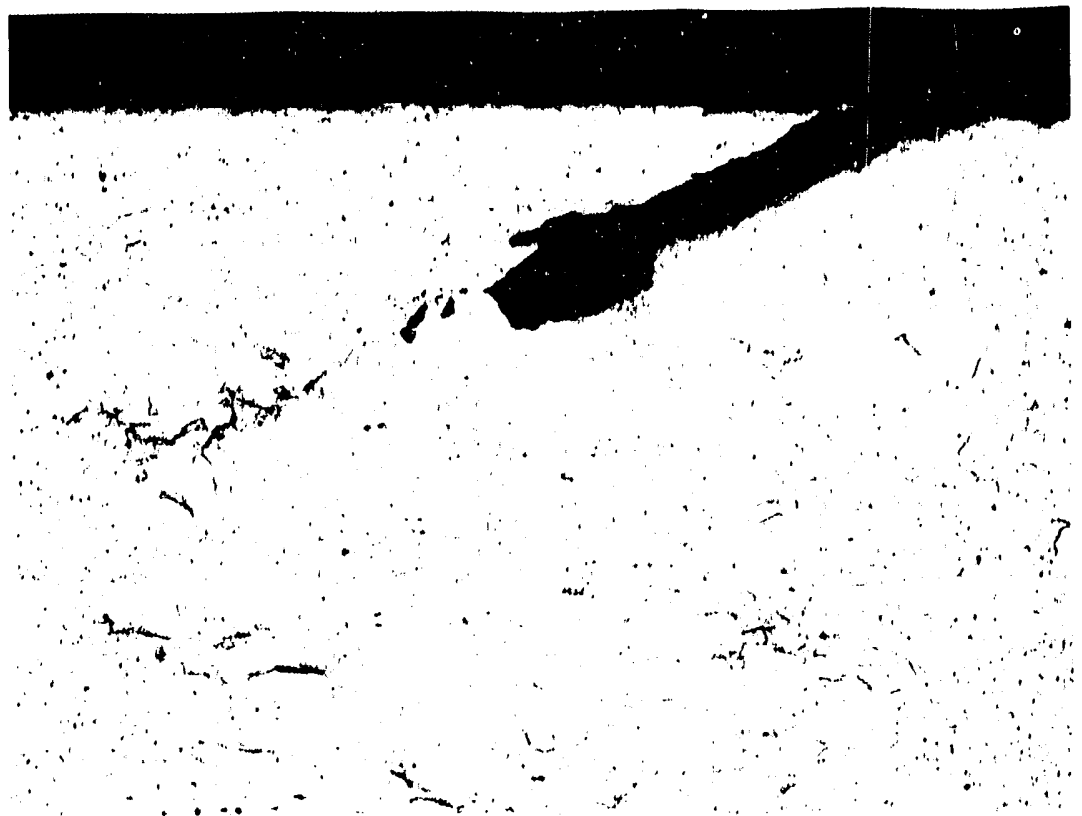

Neg $467-5148-A$

FIGURE 9a. Start of Larger Defect Area as Found by Polishing from Bottom of Figure 8 a

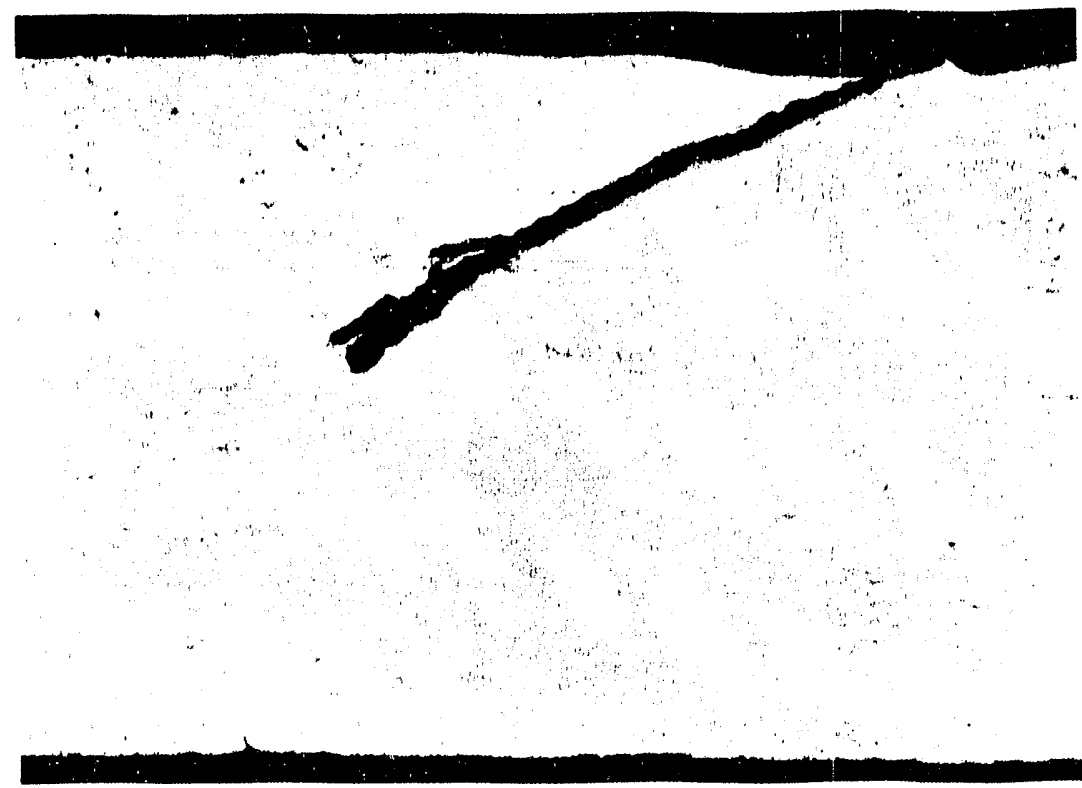

Neg $467-5148-F$

FIGURE 9b. Progressing Further into Defect. About 5 mils from Figure $9 a$ 


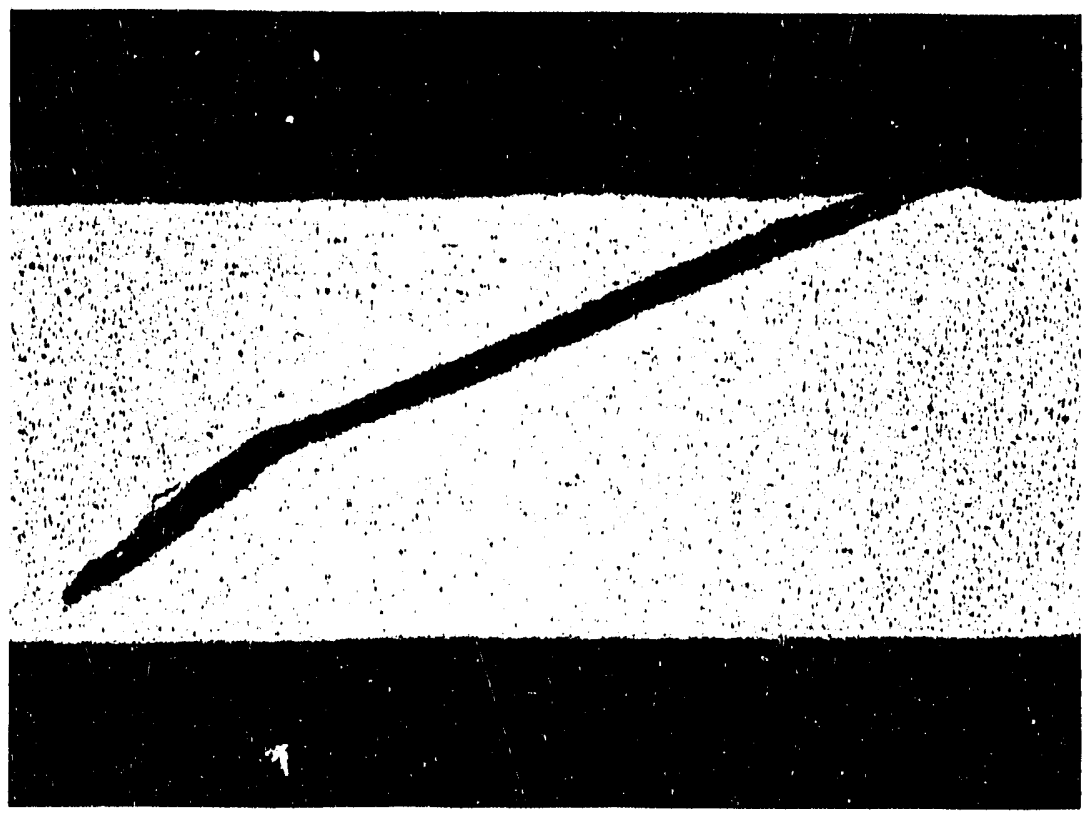

Neg 467-5148-C

FIGURE 10a. Approximately at Center of Visible Defect on Right of Figure 8 a

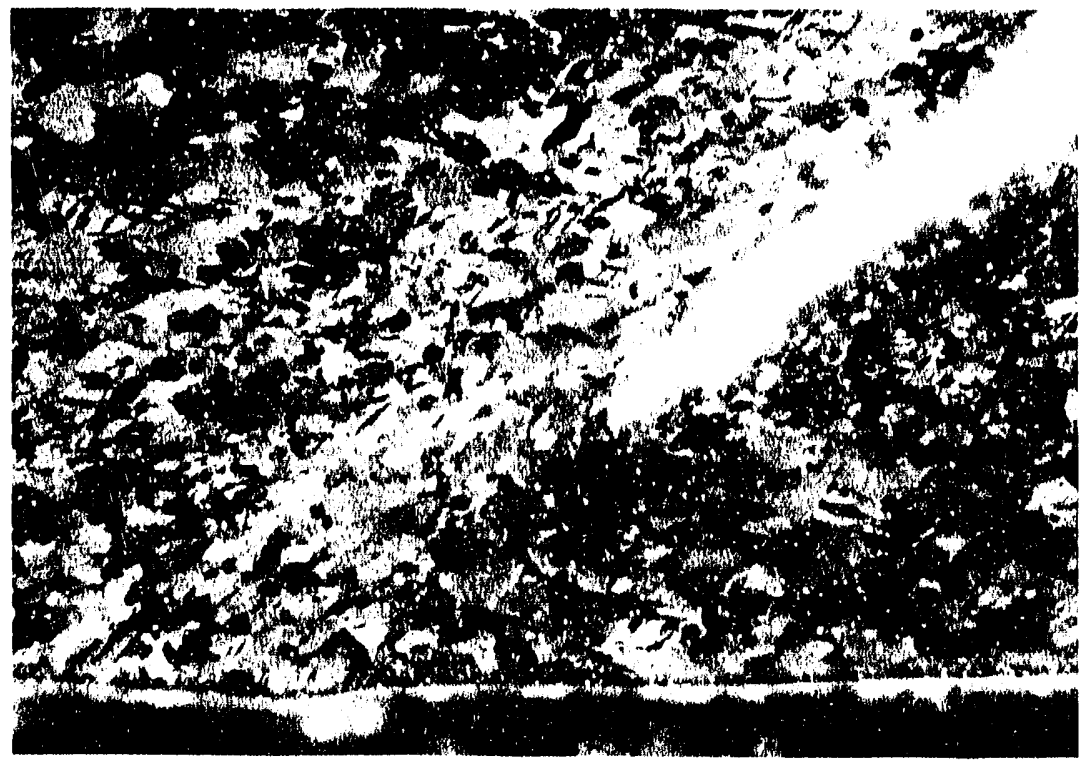

Neg 467-5.148-G

$250 X$

FIGURE 10b. Root of Defect in View of Figure 10a. Grain Size and orientation Show Defect Existed Prior to Einal Drawing operation

UNCLASS I F IED 


\section{UNCLASSHFED}

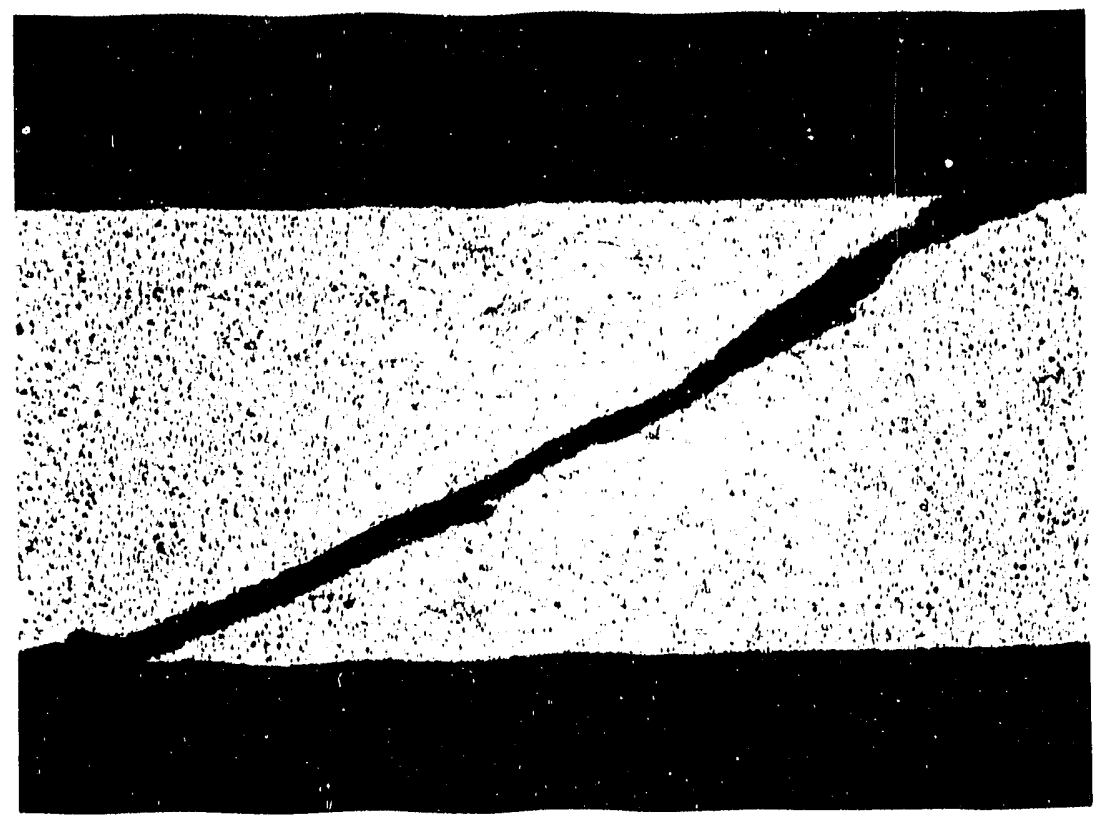

Neg $467-5148-D$

$50 X$

FIGURE 11. Water Path

The definitive testing method for clad integrity is the helium leak detector. The optimum application of this technique is to closure-weld a helium-backfilled target under helium atmosphere and immediately test for leaks. In practice, some time must elapse between closure welding and testing. There was a certain amount of material in-process between stations because supports were welded on the target, prior to testing, to insure that support welding had not compromised cladding integrity. Targets which had not been tested within $48 \mathrm{hr}$ of closure welding were, in the interest of increased leak test reliability, held under vacuum for $30 \mathrm{~min}$ and then exposed to helium atmosphere at ambient pressure for $15 \mathrm{~min}$ immediately prior to testing.

Examination of the path of water entry through the zircaloy clad points to the possibility that the component may have been helium-tight when leak tested. The combination of hydriding at the base of the fold plus the strain, induced by external

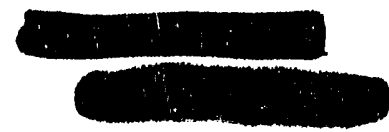


pressure and the internal assembly clearance, could extend the notch the final small increment required to produce complete penetration. A final repressurization and leak test after autoclaving was initiated to make the detection of failed targets less dependent on immediate visual inspection after tho targets are removed from the autoclave. A total of 17 defective target elements were detected in this manner.

A severe problem with zircaloy clad target assembly warp was experienced during initial stages of production and, to some degree, a 11 during the program. Initially, this warp problem was attributed to stress relaxation during autoclaving when cold straightening or similar operations were performed as a finishing step on the zircaloy tubing. Use of hot straightening and/or annealing steps following straightening effectively reduced the component warp problem although some warp of the assembly continued to occur with autoclaving.

Support Hardware

The first support design for coproduct ceramic targets was an extrapolation of the "buggy-spring" support used on the inner fuel of Mark I fuel assemblies. Proportional thickness of the zircaloy-2 strip spring material was 0.026 in., resulting in a $0.023 \mathrm{in.}$ maximum thickness after fabrication and final etch. The supports were to be "hard-sized" in the driver inside diameter.

Very early in the program, measurements of the elastic strain in the sized support assembly showed that the "springback" was just sufficient to assure that the supports would najintain contact with the ariver inside dianeter at operating temperatures. Hydraulic testing at temperature showed that, as the annulus increased because of the unfavorable differences in temperature and thermal coefficient of expansion between driver and target, the "hard-size" feature of the supports was diminished and the supports became springs with a very low 
load-to-deflection characteristic. The target was froo to vibrate in the coolant stream, and fallures occurred by fretting of the driver clad or by fatigue of the supports.

Attempts to obtain higher spring stiffness by increasing strip thickness were not successful. 'The thicker strip could not be formed, without cracking, to the "buggy-spring" shape with the coproduct annulus dimensions.

Forming the thicker strip to a hoight in excoss of annulus dimensions, "interference fit," was successful; but spring stiffness was not yet sufficient to avoid failures of the type mentioned. Doubling the number of supports per target and using a nominal diametral interference of $0.050 \mathrm{in}$. gave more satisfactory performance in flow loop tests and in-reactor, but the support system was completely redesigned to employ two rigid supports and one (or two) interference-fit supports at each end of the target. The prototype design, using two of the "buggy spring" supports in axial alignment and two inelastic supports spaced radially $120^{\circ}$ at each end of the target, performed satisfactorily both in test loop charges and in-reactor. The two buggy-spring supports were therefore replaced by a single spring support (See Figure 2).

The new spring support ("W" spring) was developed by optimizing the required compromise between springback, spring constant, and load at annulus. (13) spring and rigid support details are shown in Figures 12 and 13 . 'lhe spring design was less demanding of material formability than the "buggy-springs" and could be formed by commercial fabricators. Zircaloy strip was furnished to component manufacturers in the interest of insuring consistent spring characteristics.

'The rigid target supports were' not material sensitive: providing corrosion resistance was adequate. These supports were produced from commercial sources of plate or wire. 
30

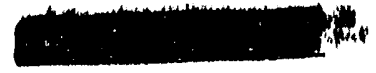

RL-GEN- 1773
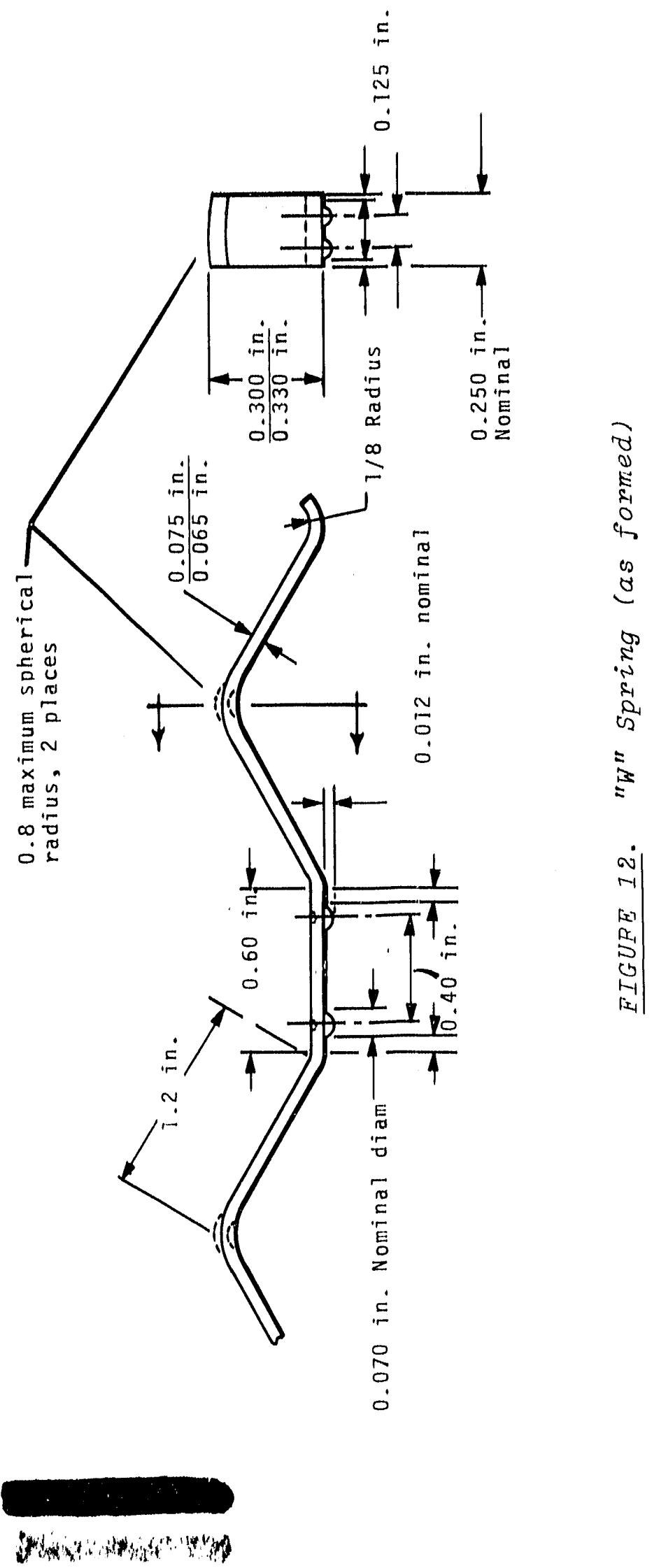


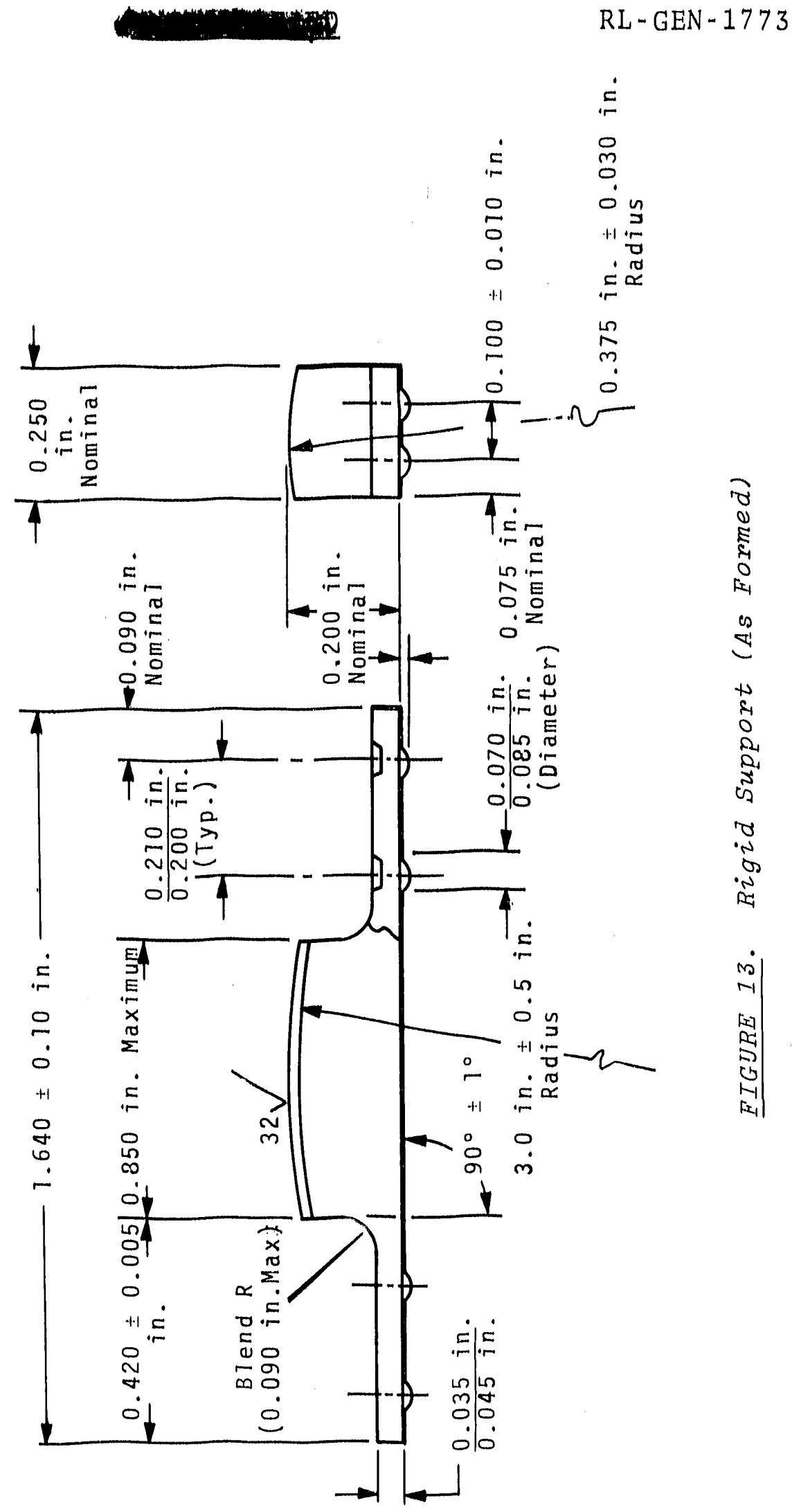

UNCLASSIFIED 
RL - (iLN -1.773

\section{FABRICATION PROCESSES}

\section{CERAMIC (SINTERED PRODUCT) PROCESS $(14)$}

The sintering process was established around two basic criteria:

- The process had to produce a target core with physical. characteristics capable of withstanding finishing operations and reactor processing.

- The process had to produce a consistent density in the product to maintain control of the $\mathrm{Li}^{6}$ isotope level per un it of core volume.

The ceramic process was, therefore, directed primarily at achieving a consistent sintered clensity.

The pellet fabrication process was originally developed by $B N I$. $(15,16)$ This development covered the processing of eight LiA1O 2 powder batches, where each batch was an individual LiAlo 2 conversion kiln load. Because these batches had consistent fabrication characteristics, it was assumed that they were typical of powder to be received on a continuing basis. Based on the capability experienced with these powders, a sintered density requirement of $78 \pm 5 \%$ of theoretical density $\left(2.62 \mathrm{~g} / \mathrm{cm}^{3}\right)$ was specified for production of LiAlo, peliets for the demonstration program. This density range wa: found to produce mechanically stable pellets, and was considered easily attainable. Therefore, $\mathrm{Li}^{6}$ content on input powders was specified to provide the desired $2 i^{6}$ content in $78 \pm 5 \%$ dense pellet production.

The powder materials used for process development did not prove totally representative of the feed matorial received during the program. Sizable quantities of powder were received which did not react consistenty to the sintering process and

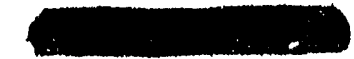


numerous problems with a low density product occurred during the first few months of production. The overall program time schedule did not permit more specific control of the aluminacarbonate reaction process for feed material uniformity. Therefore, development work was concentrated on the sintering process for maximum flexibility in processing powder with varying characteristics to the specified sintered density range. The evolution of the process as a result of this development work is illustrated in Table III.

\section{TABLE III. Process Evolution}

\section{Process Step}

1. Receipt and Analys is of

Powder

2. Characterize powder

3. Condition
Power

4. Bal1 mill powder for particle size 5. Blend Additions
into Powder

6. Press Powder into Pellets

7. Bakeout Lubricant and Binder

8. Sinter Pellets
Original process at Start of PT-NR-75

Chemical analyses on $1 y$

Not done originally

$600 \pm 10{ }^{\circ} \mathrm{C}$ for 2 hr, minimum

$7 \pm 1 / 4 \mathrm{hr}$ or given number of revolu-

tions based on mill load size.

1 wt: each of 1ithium stearate lubricant and stearic acid binder blended for $1 \mathrm{hr}$.

$40,000 \pm 1,000$ psi compaction pressure

$400 \pm 15^{\circ} \mathrm{C}$ for 2 hr, minimum

$1325 \pm 5{ }^{\circ} \mathrm{C}$ for
Fina 1 Process

Chemical \& reactivity analyses

Pretest to determine green density and sinterability characteristics.

$600 \pm 25^{\circ} \mathrm{C}$ for 2 $\mathrm{hr}$, minimum

Mill to specified bulk density (particle size), no time requirement.

1 wt $\%$ 1ithiumstearate 1 ubricant blended 15 min. 1 wt\% DIW as binder blended in $45 \mathrm{~min}$ more.

Same as originally

$600 \pm 25^{\circ} \mathrm{C}$ for 2

hr, minimum

$1325 \pm 5{ }^{\circ} \mathrm{C}$ for 14 hr, minimum 
A detailed review of the major process steps is included in the following discussions.

Receipt and Analysis of Powder

A11 powder used for the program was reacted using a rotary kiln. Each kiln load was termed a batch of powder. On receipt, each powder batch was sampled for the following analyses:

1) apparent density, 2) total lithium, 3) spectrographic semiquantitative, and 4) fluorine. Each fifth batch underwent the following additional analyses: 5) isotopic $\mathrm{Li}^{6}$, 6) water, 7) carbon, and 8) X-ray diffraction. Analyses 2, 3, and 5 were performed to insure that the powder conformed to appropriate Engineering Specifications. The remaining analyses were performed to gather engineering data. Results of these analyses are detailed in other reports in this area. $(17,18)$

Characterization of Powder

Problems with feed powder variability were encountered early in the production startup phase. Initial engineering effort was clirected at insuring that strict conformance to the established process was being maintained. Secondly, tests were performed in an attempt to determine why powder lots were different. $(19,20)$ The above work, including a review of the reaction process, did not reveal the cause(s) of variability. As a result the decision was made to develop the fabrication process around the assumption that feed material variation would occur.

Process development efforts revealed that sintered density was a function of:

- average particle size

- green (as-pressed) density

- an accumulation of other factors which herein is called inherent sinterability.

Figures 14 through 16 demonstrate these relationships to sintered density. Figure 14 shows how sintered density increases

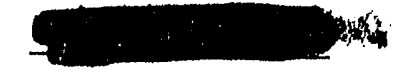


with decreasing particle size for a given powder lot. The general relation shown in Figure 14 is considered typical of al1 powder lots; however, the location of the curve may be shifted up or down for other powder lots depending on the green density and inherent sinterability characteristics. Figure 15 is included to show how average particle size varies with apparent density. This curve is fairly constant for powders of similar particle geometry, composition, and structure; however, variations to this curve will be discussed in the bal1 milling section of this report. The apparent density measurement operation was much simpler to perform than subsieve sizing.

Figures 14 and 16 illustrate the effect of inherent sinterability. Both figures show that under identical conditions of average particle size and green density, different powder lots will sinter to different densities. This phenomenon was attributed to the $\mathrm{LiAlO}_{2}$ production process and to the combinations and levels of impurity content in the powders. It is believed that the presence of some compounds during sintering provides reactions and intermolecular motion which aid the sintering process. The number of impurities normally present in Li. $10_{2}$ makes difficult any determination of those elements which affect inherent sinterability. Therefore, in order to establish processing conditions, a sample of each powder lot was pretested to determine sinterability. The pellet fabrication process was then specified for particular powder lots to provide the sintered density desired.

The sinterability pretest establishes the sintered density a particular powder lot will develop from a given particle size and green density. Pretests were usually performed on as-received powder; however, the same results could be obtained 


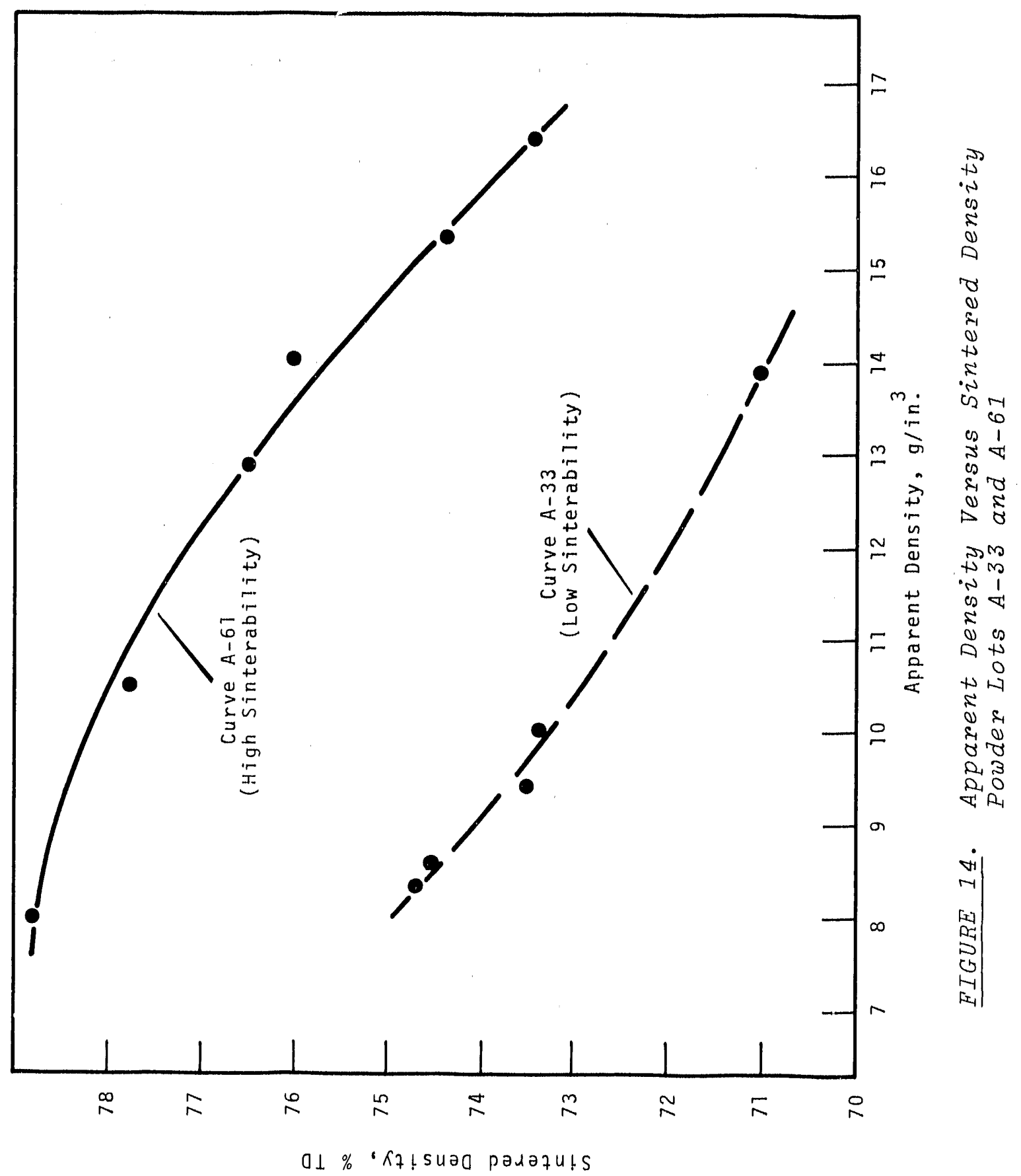




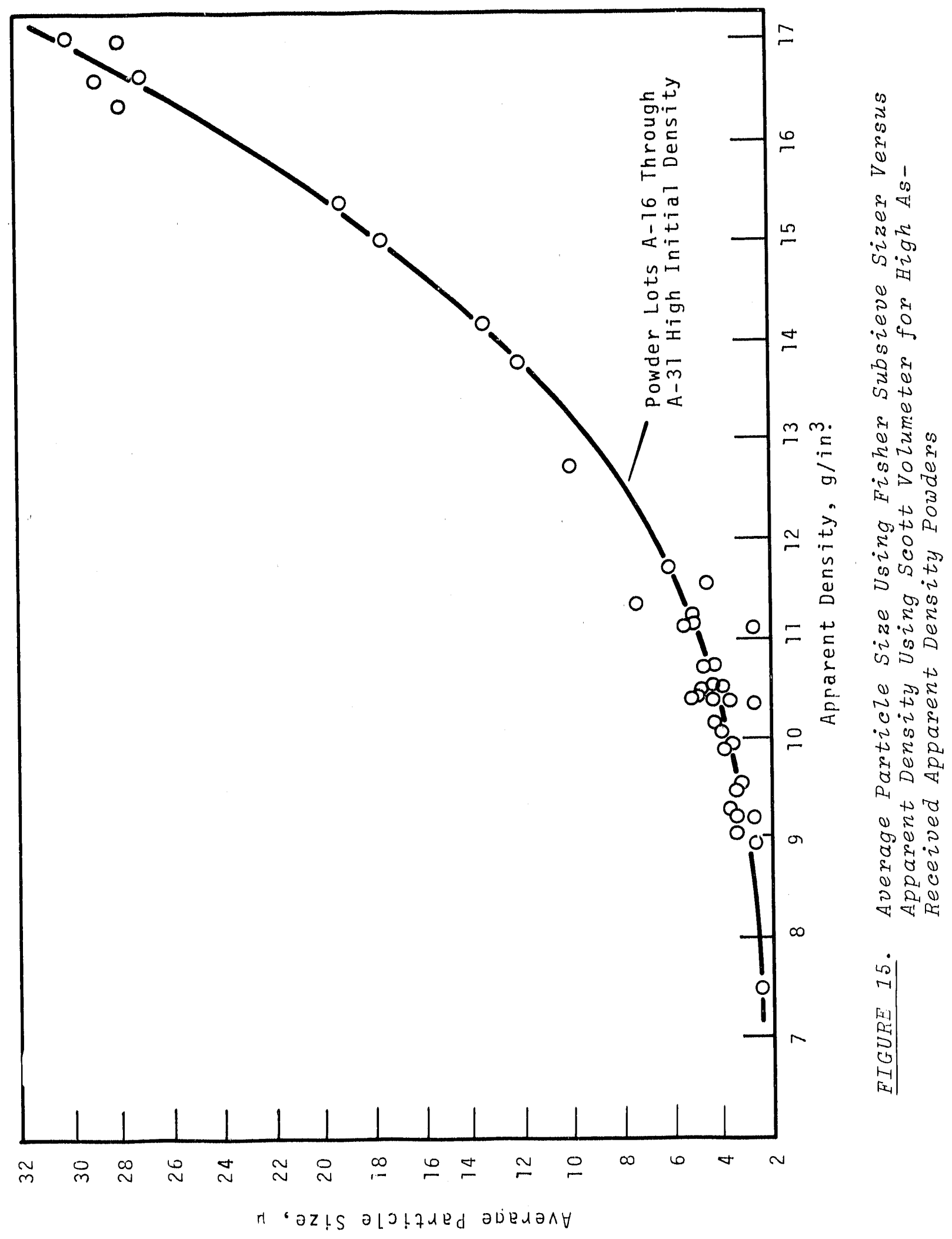




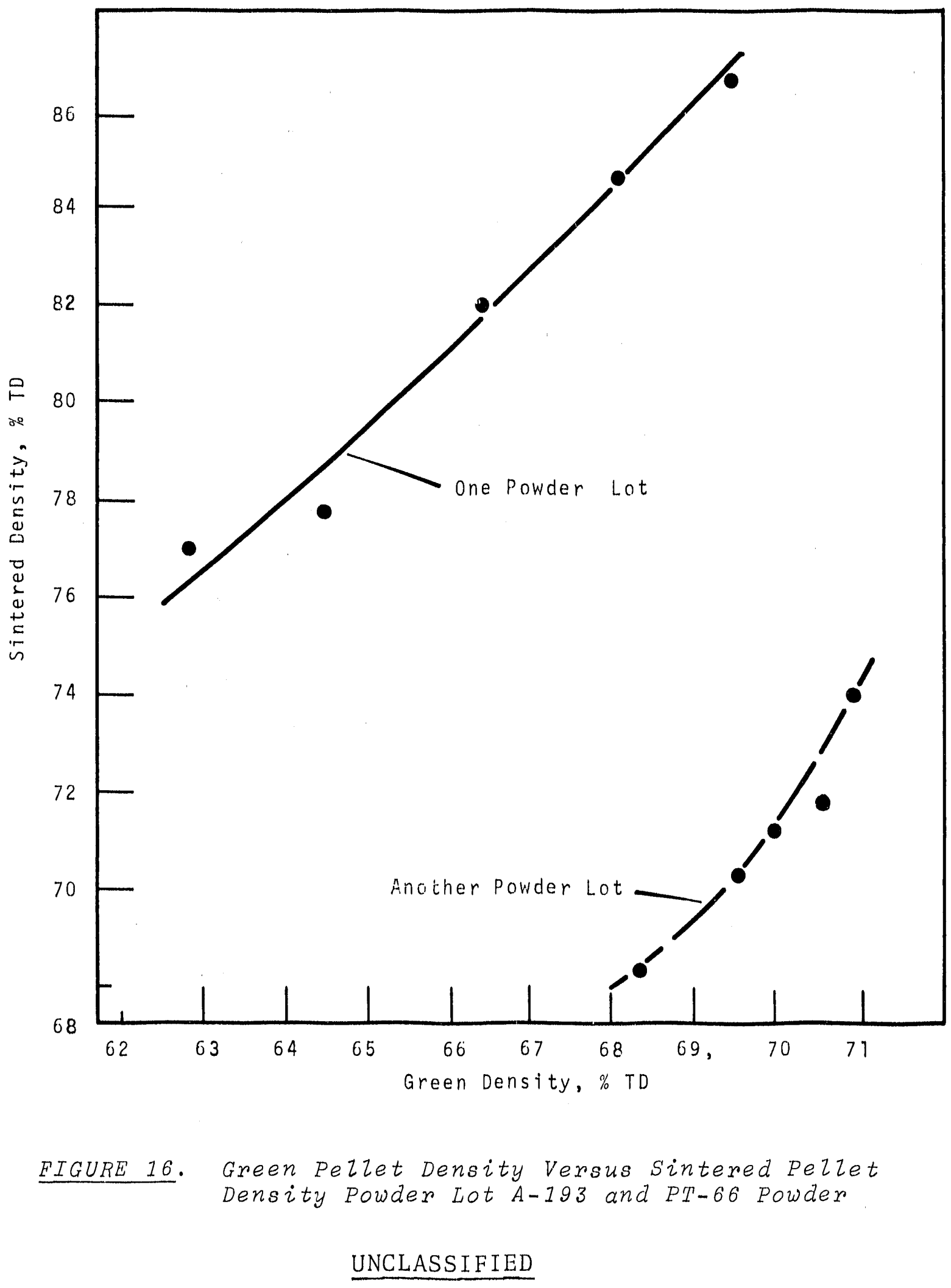


from ball milled powder. Given a pretest bulk density, green density, and resultant sintered density, the powder was then rated as to sinterability and was assigned a set of process conditions for fabrication into pellets. The powder sinterability rating was calculated by the following formula:

$$
S=\left(S D_{0}-G D_{0}\right)\left(B D_{0}\right) \text {, }
$$

where $S$ is the powder sinterability rating, $S_{0}$ is the pretest sintered density, $\mathrm{GD}_{0}$ is the pretest green density, and $\mathrm{BD}_{0}$ is the pretest bulk density. The sintered and green density terms are percent of theoretical density $\left(2.62 \mathrm{~g} / \mathrm{cm}^{3}\right)$, and the bulk density is grams per cubic inch. This combination of units provides a convenient range of sinterabilities for comparison. For example, of the powder lots so characterized, Powder Lot A-108 had the lowest sinterability rating of 26 , and Powder Lot $A-70$ had the highest sinterability rating of 190 .

Given the pretest information, it is possible to calculate the sintered density which will be developed from a given average particle size, as indicated by bulk density. Referring to Figure 14, it can be seen that the sintered density versus apparent density curves are nearly linear. 'The green density versus apparent density curve of Figure 17 is of the same general shape with lower slope. A curve (Figure 18) of sintered density minus green density versus apparent density is obtained by subtracting the green density curve from the sintered density curve. The curves in Figure 18 are most nearly 1 inear, and the assumption of 1 inearity is used to predict the sintered density obtainable from a given powder apparent density. The accuracy of such prediction is considered to be $\pm 1 \%$ of theoretical density. 


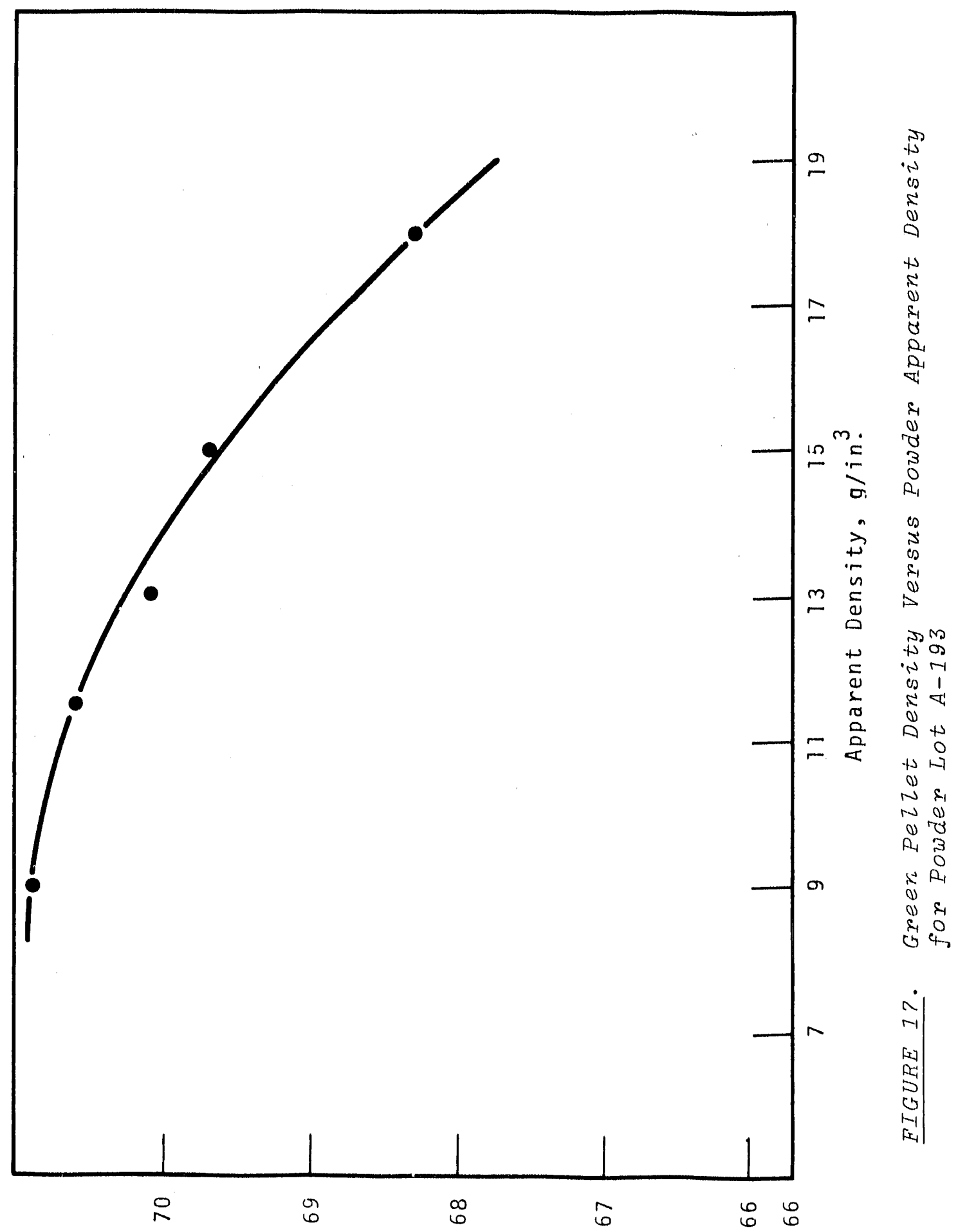

$0 \perp \%$ ‘र

UNCLASS I FIED 


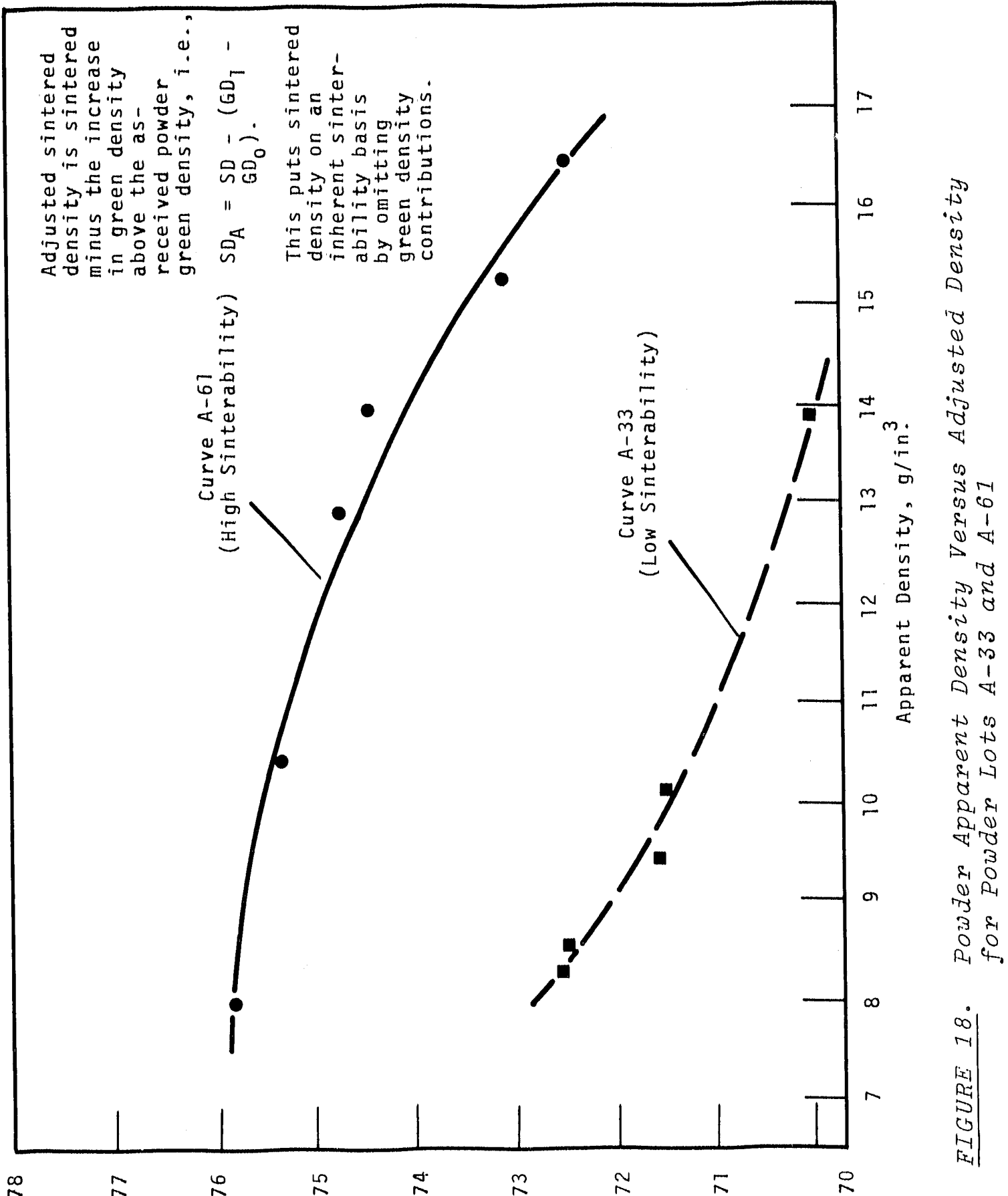

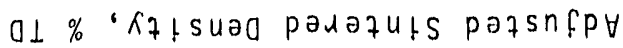


The final particle size chosen for the processing of a given powder lot depends on many considerations, including:

a) The time required for particle size reduction at ba 11 miling

b) The pellet pressing production rate obtainable, and the press die-set wear rate, from a given powder particle size

c) The desired sintered density as dictated by Li $^{6}$ control procedures

d) The anticipated effects of the process used on sintered pellet quality, particularly as to effects on peliet machinability.

Consideration of items $a, b$, and $d$ a 11 tend towards larger particle sizes. Less miling time is required for larger particle sizes; pellets can be pressed faster with larger particle sizes; and, generally, pellets produced from larger particle sizes had better machinability characteristics. These considerations must be compromised with item $c$, since sintered density varies inversely with particle size. Once a particle size is selected for a powder lot, the sintered density which can be obtained is calculated. If the calculated density is below requirements, steps are taken to provide the incremental density necessary.

The incremental. density can be provided for by either or both of two means: 1) increasing green pellet density, and 2) use of sintering agents. Cireen density increases were found to be feasible by the means explained below:

- Precompaction--as much as $2 \%$ density increase was obtaincd by precompacting powder at $40,000 \mathrm{psi}$ and crushing for repressing.

- Increased pressing pressure--as much as $0.5 \%$ density increase was obtained by pressing at 45,000 psi with existing die-set design $(40,000$ psi norma1). The 
potential oxists for a $1.5 \%$ clonstey fincroaso by prossing at a maximum of 60,000 psi, with a moditiod dio-sot dostgn.

- Molting tho stoaric acid bindor-groon donstity incroasos from 3 to $6 \%$ were obtained by molting the binder in the powclor prior to pressing. Large gains in greon pollot strength were another bonefit.

- Roplacing stoaric acid binder with diondzed wator (DIW) - an estimatod $3 \%$ increaso of theoretical density was obtained by substituting DIN for stearic acid. Large gains in green pellet strength were also achievod.

Sintered density increases obtained from the use of sintering agents were found to bo much larger and more easily obtained than those resulting from increased green density. Five different additives were added to powder prior to the bal1 miling station to cletermine their effects on sinterability. Typical results of tests employing 1 wto of each additive are presented below in Table IV. As indicated from control powder results, the test powder lot was one of low sinterability.

\section{IABLE IV. Additive Effeats on Sinter Density}

\begin{tabular}{|c|c|c|}
\hline Additive & $\begin{array}{c}\text { Green Density, } \\
0.07 \mathrm{o} \\
\end{array}$ & $\begin{array}{c}\text { Sintered bensity. } \\
\text { o'ld }\end{array}$ \\
\hline Calcium Carbonate $\left(\mathrm{CaCO}_{3}\right)$ & $68^{1 .}$ & 77 \\
\hline Potassium Carbonate $\left(\mathrm{K}_{2} \mathrm{CO}_{3}\right)$ & 68 & 66.5 \\
\hline Lithium Silicate $\left(\mathrm{Li}_{2} \mathrm{SiO}_{3}\right)$ & 67.5 & 72 \\
\hline Sodium Silicate $\left(\mathrm{Na}_{2} \mathrm{SiO}_{3}\right)$ & 67 & 70 \\
\hline Magnesium Oxide (MgO) & 68 & 72 \\
\hline $\begin{array}{l}\text { Control (normal without } \\
\text { additives) LiAlO } 2 \text { Powder }\end{array}$ & 68 & 72 \\
\hline
\end{tabular}


'tho significant incroaso in sintorod clonsity obtainod by the uso of $\mathrm{CaCO}_{3}$ promptod further devolopment work with this additive. Higure 19 shows typleal sintered donsity variation with Caco 3 concentration. The slope of the curve varios with powder lots; 1.0. , to obtatn a 4 to $5 \frac{0}{0}$ incroaso in sintered clenstty ma requitre $\mathrm{CaCO}_{3}$ additions of: $5 / 16$ to $11 / 1 \mathrm{wt} \%$.

'the effect of $\mathrm{CaCO}_{3}$ on sintered density is beliteved due to intermolocular motion created cluring decompostition of the $\mathrm{CaCO}_{3}\left(\mathrm{~d} 9000^{\circ} \mathrm{C}\right)$ to the oxide $(\mathrm{CaO})$ followed by several possible complexes of the oxide with avaliable alumina and lithLum-aluminate.

\section{powder Conditioning}

As-received powder was first passed through a sot of crossed grate magnets to remove tramp iron picked up in manufacture. The powder was then loaded into conditioning containers to a miximum clepth of $3 \mathrm{in}$. for furnace heating at $600^{\circ} \mathrm{C}$ for $3 \mathrm{hr}$, minimum. The conditioning process step was originally intended to increase powder sinterability and reduce moisture content. It is now believed that conditioning was of valuo only in reducing overall moisture content, burn-off of some impurities, and improving reaction to ball miling. Conditioning effects on sintering can be detrimental if temperatures are allowed to approach the $\alpha-\gamma$ transition temperature of the LiAlO 2 since $\gamma$-LiAlO 2 is less active cluring sintering. The continued use of conditioning is questionable and tests to cvaluate elimination of this process step are advised with sustained operations.

particle sizing by Ball Militing

'l'he ball milling process was one in which the LiAlo 2 powder was tumbled with grinding media in large closed jars. 'The

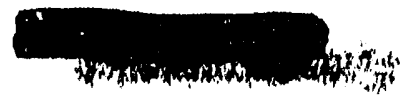




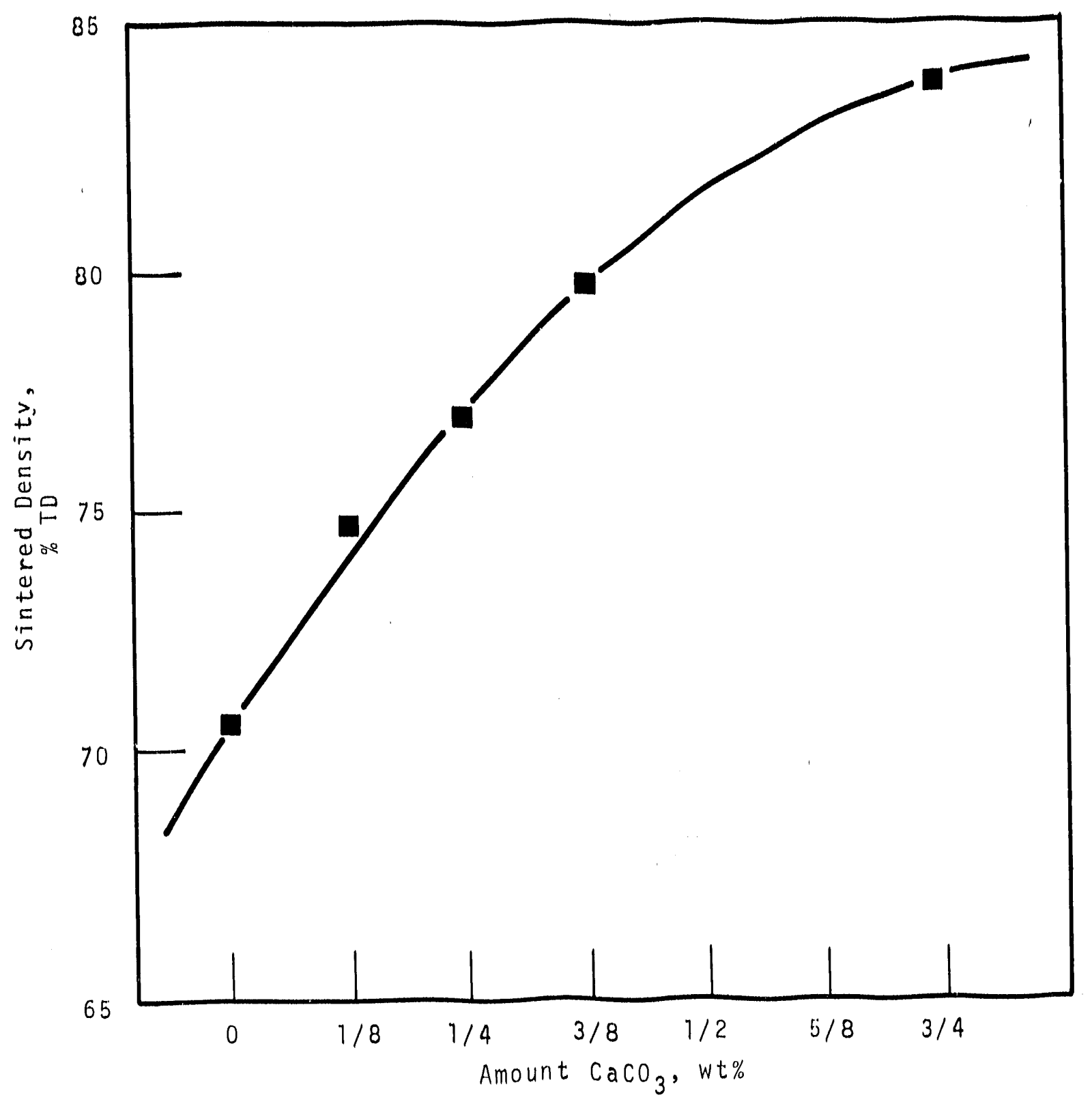
FIGURE 19. Amount CaCo3 Addition Versus Sintered
Density Powder Lot $A-41$ 
grinding media used was high density alumina ceramic of various configurations, and the jars were porcelain lined. Particle size is reiluced by the crushing action of the media on the powder particles. The ball milling of $\mathrm{LiAl}_{2}$ was along estab. lished industry recommendations for bal1 miling (21) Bal1 milling results in reduced average particle size as we 11 as a modified particle size distribution, i.e., a modified distribution of particle sizes by weight percent of the whole. The rate of particle size reduction was found to depend on:

a) The percent of mill volume charged

b) The type of grinding media

c) Mil1 jar $\mathrm{rpm}$

d) The particular powder lot

e) The initial particle size.

Conditioned powder was ball milled to reduce average par ticle size. The smaller particle size was necessary to attain the desired sintered density in that pellet green density increased directly with reduced particle size, and sintered density increased directly with green density (see Figures 14 and 16).

The original process development called for control of sintered density by miling only a portion of the powder as required to obtain a given sintered density. The disadvantage of this procedure was that milling different portions of the various powder lots produced powders of varying particle size distributions. Particle size distribution and average particle size would therefore have to be controlled together to attain desired sintered densities from powder lots of differing sinterability. characteristics. Considering these control complications, the bal1 milling process evolved to one of miling $100 \%$ of the powder for a constant time. This process eliminiated variable particle size distributions between powder lots. The milling 
time was established at $7 \mathrm{hr}$, which generally provided the minimum particle size for most lots.

Milling for $7 \mathrm{hr}$ proved to be undesirable from the production time standpoint and the variable average particle sizes obtained. During production of start-up material, the average particle size obtained for various powder lots under constant milling conditions varied from 2.35 to $13 \mu$. This particle size variation produced 3 to $4 \%$ variation in sintered density and caused considerable variation in other fabrication characteristics, i.e., grinding, sawing, etc.

The development of ball miling as used for the demonstration program was initiated from tests to determine ball milling times for various apparent densities (Figure 20). Figure 20 clearly illustrates that powder lots differ in particle size reduction rate and the time required for a particular lot to reach a given particle size is dependent on initial particle size. Based on this analysis, particle size was specified after characterization of each powder lot, and milling was per. formed until the desired particle size was reached. Particle sizes generally selected ranged fl $m 4$ to $10 \mathrm{\mu}$. The most fre quently used size was $10 \mu$ which requires from $1 / 2$ to $21 / 2 \mathrm{hr}$ milling time, depending on the powder lot. This milling process did not produce any significant variation in sintered density.

Addition Blending

After ball milling, those material additions required for pellet pressing were blended into the powder. Calcium carbon. ate $\left(\mathrm{CaCO}_{3}\right)$ as a sintering agent, may also be added at this station; however, $\mathrm{CaCO}_{3}$ was normally added during ball milling to decrease particle size and to insure uniform distribution throughout the powder. $\mathrm{CaCO}_{3}$ added prior to miliing is more 


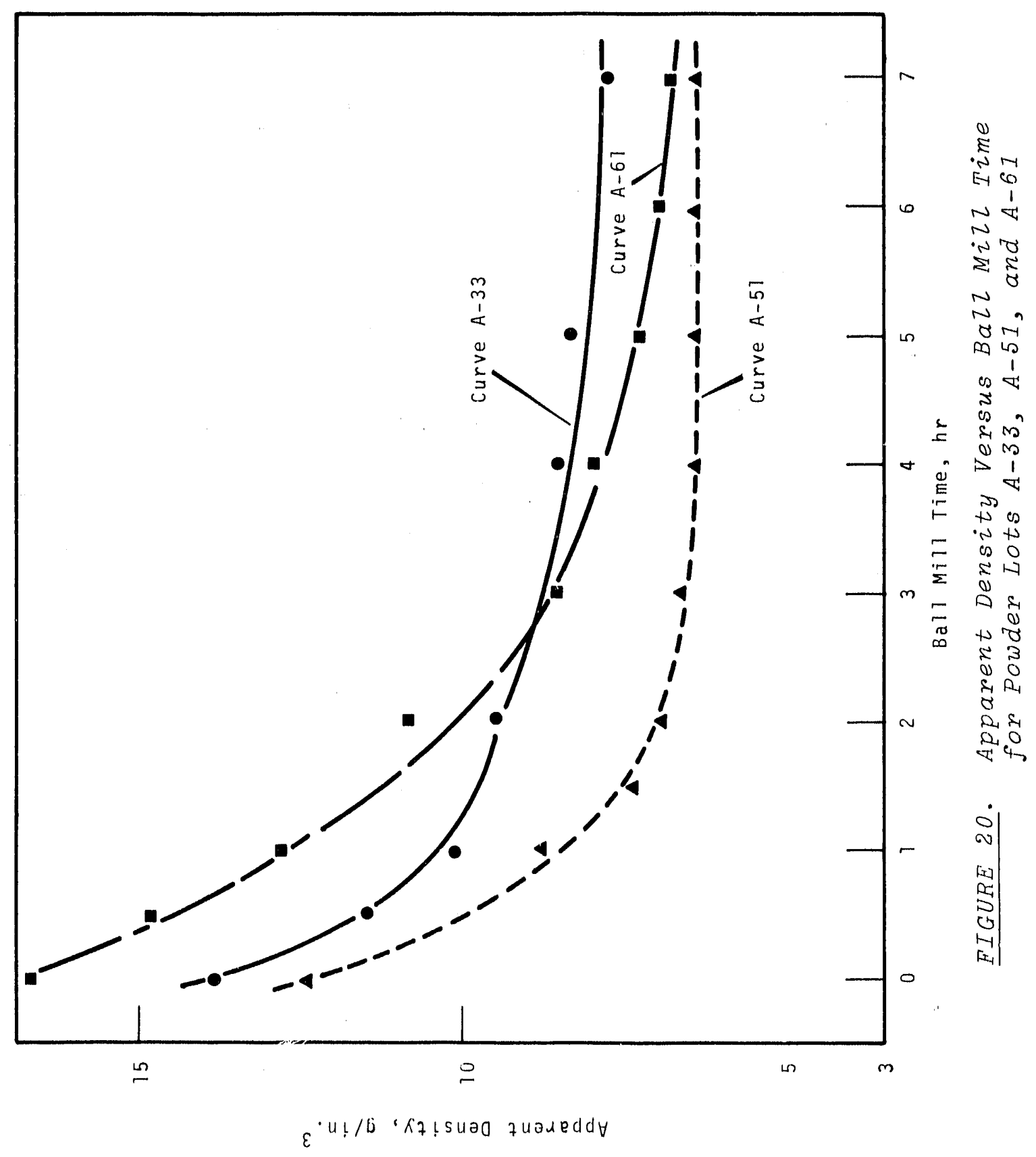


effective, per given weight of addition, than when added during blending. Those additions required for pellet pressing were lithium-stearate $\left(\mathrm{LiC}_{18} \mathrm{H}_{35} \mathrm{O}_{2}\right)$, which was used as a die lubricant; stearic acid $\left[\mathrm{CH}_{3}\left(\mathrm{CH}_{2}\right){ }_{16} \mathrm{CO}_{2} \mathrm{H}\right]$, which was originally used as a binder; and dionized water (DIW), which was developed as an alternate to stearic acid.

The lithium stearate serves to 1) aid (through lubrication) the flow of powder particles during the pressing operation, 2) minimize the buildup of internal stresses which result in cracked green pellets, 3) reduce die-set wear, and 4) reduce pellet ejection forces at completion of the pressing operation. The function of stearic acid or DIW additions was to increase green strength in pressed pellets. Blending practice has been to load the $\mathrm{LiAlO}_{2}$ powder plus all additions in to the blender without specific metering of one component into the other. A blending time of 1 hr has proven sufficient for thorough mixing. The lithium stearate must be blended in the powder for at least $15 \mathrm{~min}$ prior to addition of the DIW. Forty-five minutes additional blending time is then required. This procedure was required because the DIW wet the powder, and adequate mixing of the lithium stearate was not possible.

\section{Pellet Pressing}

The pellet pressing operation compacted the blended $\mathrm{LiAlO}_{2}$ powder into the approximate size and shape desired in the final LiA $1 \mathrm{O}_{2}$ product. The sintered derisity in the finished peilets was directly dependent on the green density developed from pressing. Green (as-pressed) pellets were produced by compacting blended powder within a die-set at 40,000 psi pressure. This pressure generally developed a green density of 60 to $70 \%$ of theoretical density. 
Pellet pressing was regulated to meet the following requirements:

- Green pellets had to be of sufficient green strength to withstand handling without chipping or cracking.

- The desired green density had to be consistently obtained.

- Pellets had to be produced at the fastest rate possible while maintaining pellet quality.

Pellet green strength was a function of the powder average particle size, compaction pressure, powder moisture content, cycle dwell time at high pressure, and the speed of pellet ejection from the die. A precise measure of green strength was not developed during the Coproduct Program; however, major differences in green strength were readily apparent. Subjectively, green strength increases directly with average powder particle size and powder moisture content (DIW content). Development of maximum green strength was compromised by the fact that die wear also increases with increasing average particle size, and pellet ejection forces increase with increasing powder moisture content. Die wear rate was usually judged of secondary importance compared to pellet quality and pellet production rates.

The optimum moisture level in the powder was at that point where the powder slowly "creaks" and "groans" while at high pressure. No noise was discernible when insufficient water was present. A loud "screech" occurred when the moisture level was excessive. These less than qualitative measurements emphasize the "art" approach to pellet pressing. In most cases, 1 Wt: of DIW was considered optimum for powder of a ball milled apparent density of 13 to $14 \mathrm{~g} / \mathrm{in} 3^{3}$. The green strength provided by DIW was directly related to the quantity of DIN per unit of particle surface area. Powders of smaller average

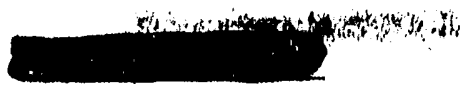


particle size (greater total surface area) required more DIW for optimum green strength than did powders of large average particle size (smaller total surface area).

Green strength increased with increased cycle dwell time at high pressure $(40,000 \mathrm{psi})$ up to a maximum of 5 to 6 sec of dwe11. The powder compaction occurred very rapidly in the first second of high pressure and, thereafter, proceeded more slowly. This phenomenon could be audibly detected during the pressing cycle. The "creaking" sound occurred rapidly at first and then diminished to silence. The "creaking" was indicative of the powder particles building up compressive stress to a certain level at which the powder compacted. This buildup and release of stress continued until the pressure was no longer able to overcome the compressive stress within the powder. To insure acceptable green strength, pellets were pressed with a two second minimum cycle dwell at high pressure. Under optimum conditions, acceptable pellets were produced with as low as one-half second high pressure dwell time. Manipulation of high pressure dwell time was one technique commonly used to control green strength, i.e., a way to increase the green strength without adding DIW to the powder was to increase the high pressure dwell time.

Pellet green strength varied inversely with the ejection speed from the die. Green pellets incur compressive strain at the high pressure portion of the pressing cycle. As pressure is released, the compressive strain is released and the pellet expands. The rate of pellet expansion varies directly with the speed of pellet ejection, and pellet green strength decreases directly with the rate of pellet expansion. The acceptable speed of ejection was facilitated by using die bodies with an ejection taper. Standard pellet dies contained 
an ejection taper of 0.014 in per inch of length along the 1 ast 1 to $11 / 4$ in of the die cavity. These dies allowed for a maxi. mum acceptable ejection speed of approximately $1 \mathrm{in} / \mathrm{sec}$ which resulted in a 0.005 to 0.010 in. diametral expansion of the pellet. Expansion can be maintained less than 0.005 in. with slower ejection speeds; however, the ejection speed used in prac. tice was the fastest speed which produces crackfree pellets of acceptable green strength. This speed varied between blender loads of powder as the average particle size and moisture content varied.

Pellet green density was held consistent throughout a powder lot by providing uniform preparation for pressing and by mantaining the die-set in good condition. With a given average particle size, particle size distribution, and blending additions, the powder will press to a green density which is depen dent on the pressing pressure used. Pressing pressure can vary with the condition of the die and punch set; $i$.e, punches, that are galled or loaded up with powder: or lithlum stearate, require much of the applied pressure to overcome friction within the die. set This loss of pressure to friction reduces the compaction pressure with resultant reductions in green density. Green den. sity versus applied pressure for three typical powdex lots is shown in Figure 2i.

Excess lithium stearate and/or moisture content within the powder also had a reducing effect on green density. High mois. ture content resulted in increased green strength, to that point where the force required to overcome shear strength of the powder boundary layer was significant compared to the force applied to the powder. The same phenomenon occurs with exces. sive lithium stearate. The force of friction at the boundary layer (die powder interface) liquefies the lithium stearate which produced a sticky pellet surface, and also developed a very high green surface strength which increased required force for a given density 


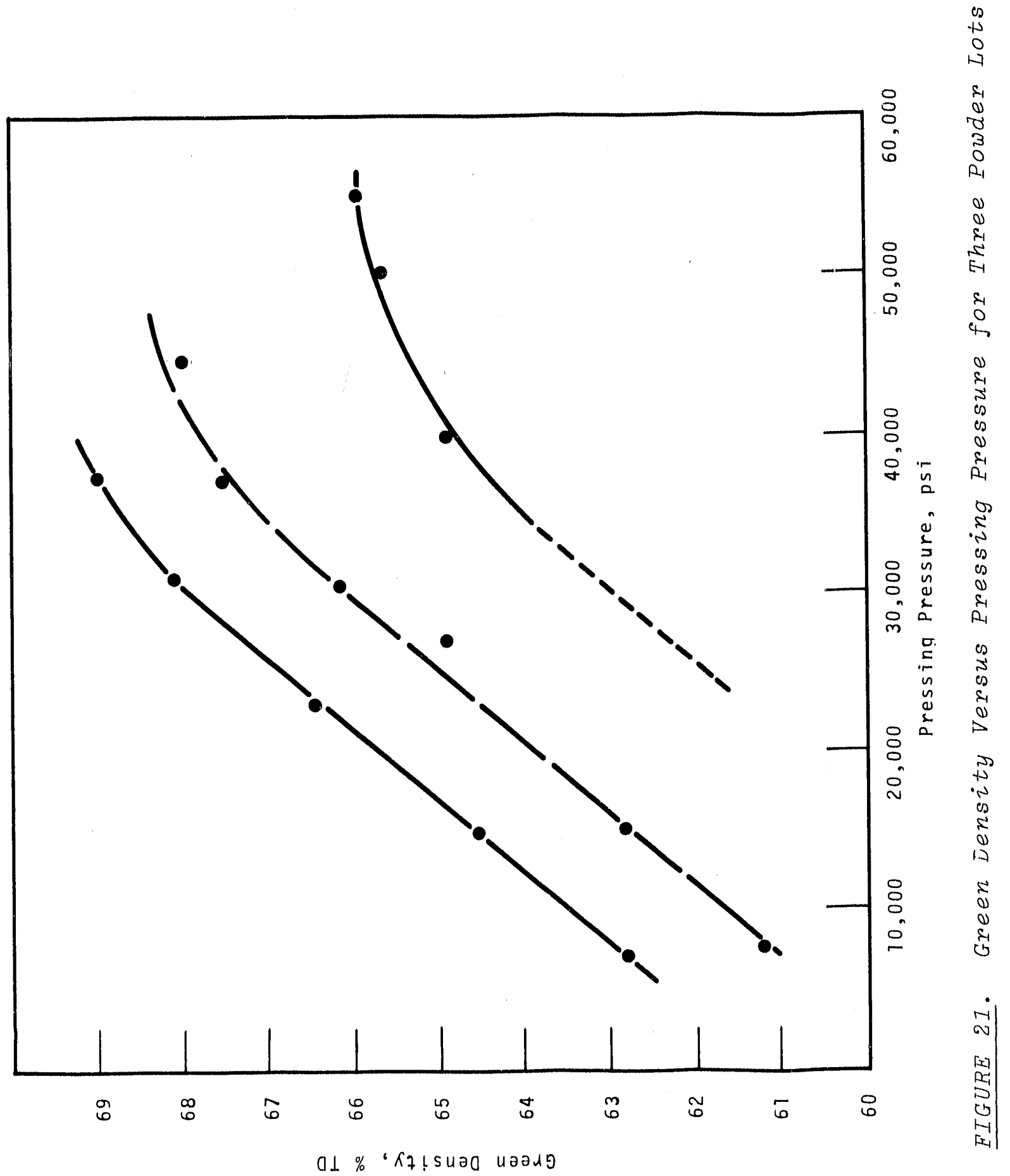


Pellet pressing rate was dependent on green strength and average particle size of the powder. When the powder was milled to an apparent density of 13 to $13,5 \mathrm{~g} / \mathrm{in} 3$. (corresponds to average particle size of 9 to $11 \mu$ ) or greater, pellet press. ing rates were significantly increased, $1 . e$, an average par ticle size of 3 to $4 \mu$ established a maximum pellet pressing rate of 2 pellets/min versus 5 pellets/min obtained with an average particle size of 10 to $11 \mathrm{\mu}$. The relationship between pellet pressing rate and average particle size was a function of press toolıng design. The tolerance gap between the punch and die cavity allowed powder leakage around the punch during pressing. This leakage was a function of particle size and pressure losses due to associated friction vary accordingly.

The pellet size produced during a major portion of the demonstration program was 2.75 in. 1 ong $x 1.165$ in. $O D$. Peilets were pressed in lengths up to $31 / 2$ in.; however, the higher length to diameter ratios did not prove practical for produrtion purposes, The green pellet diameter selected was based on typical shrinkage values during sintering. The die bore size was selected to provide sintered diameters 0.025 to 0.030 in. Larger than the finished outside diameter to allow for centerless grinding.

Bakeout Lubricant and Binder

The bakeout process provided for the controlled decomposi. tion and removal of moisture and organics from green peliets. The evolution of gases occurs at a rate which is dependent on the temperature and quantity of moisture and organics in the pellets. This rate must be controlled to prevent bursting of green pellets. Green pellets were baked out prior to sintering

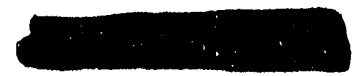


since the sintering temperature would cause rapid evolution of gases with resultant pellet decomposition. Table V lists data pertinent to the bakeout of water $\left(\mathrm{H}_{2} \mathrm{O}\right)$, lithium stearate $\left(\mathrm{LiC}_{18} \mathrm{H}_{36} \mathrm{O}_{2}\right)$, and stearic acid $\left[\mathrm{CH}_{3}\left(\mathrm{CH}_{2}\right)_{16} \mathrm{CO}_{2} \mathrm{G}\right]$. The additives are listed in the relative order of bakeout initiation and completion.

TABLE V. Binder and Lubrioant Melting and Boiling l'emperature

$\begin{array}{ccc}\text { Compound } & \text { Me1ting Point, }{ }^{\circ} \mathrm{C} & \text { Boiling Point, }{ }^{\circ} \mathrm{C} \\ \mathrm{H}_{2} \mathrm{O} & 0 & 100 \\ {\left[\mathrm{CH}_{3}\left(\mathrm{CH}_{2}\right)_{16} \mathrm{CO}_{2} \mathrm{H}\right]} & 80 & 380 \\ \mathrm{LiC}_{18} \mathrm{H}_{36} \mathrm{O}_{2} & 220 & -\end{array}$

Lithium stearate and stearic acid turn brown upon melting. Figure 22 shows the cross sections of pellets baked for various times at $400^{\circ} \mathrm{C}$. The dark areas indicate the depth at which melting of either organic occurred. Visual examination indicates that the majority of the stearic acid was baked out after $10 \mathrm{~min}$ of heating; however, between 1 and $2 \mathrm{hr}$ were required to drive off most of the lithium stearate. Using the visual examination approach illustrated in Figure 22 , tests were performed which proved that a $600^{\circ} \mathrm{C}$ bakeout temperature could be used on a shorter time cycle and thus eliminate thermal shock when transferring the pellets into sintering furnaces idling at $800^{\circ} \mathrm{C}$. Visual observation of pellet cross sections provided only a gross measure of additive removal. Residual carbon content analyses from each pellet shown in Figure 22 showed that approximately $90 \%$ additive removal occurred. The remaining additives were effectively removed in the sintering operation without any detrimental effects on the pellets.

Sintering

The sintering operation increased pellet density, pellet strength, and pellet surface quality. The sintered density of 


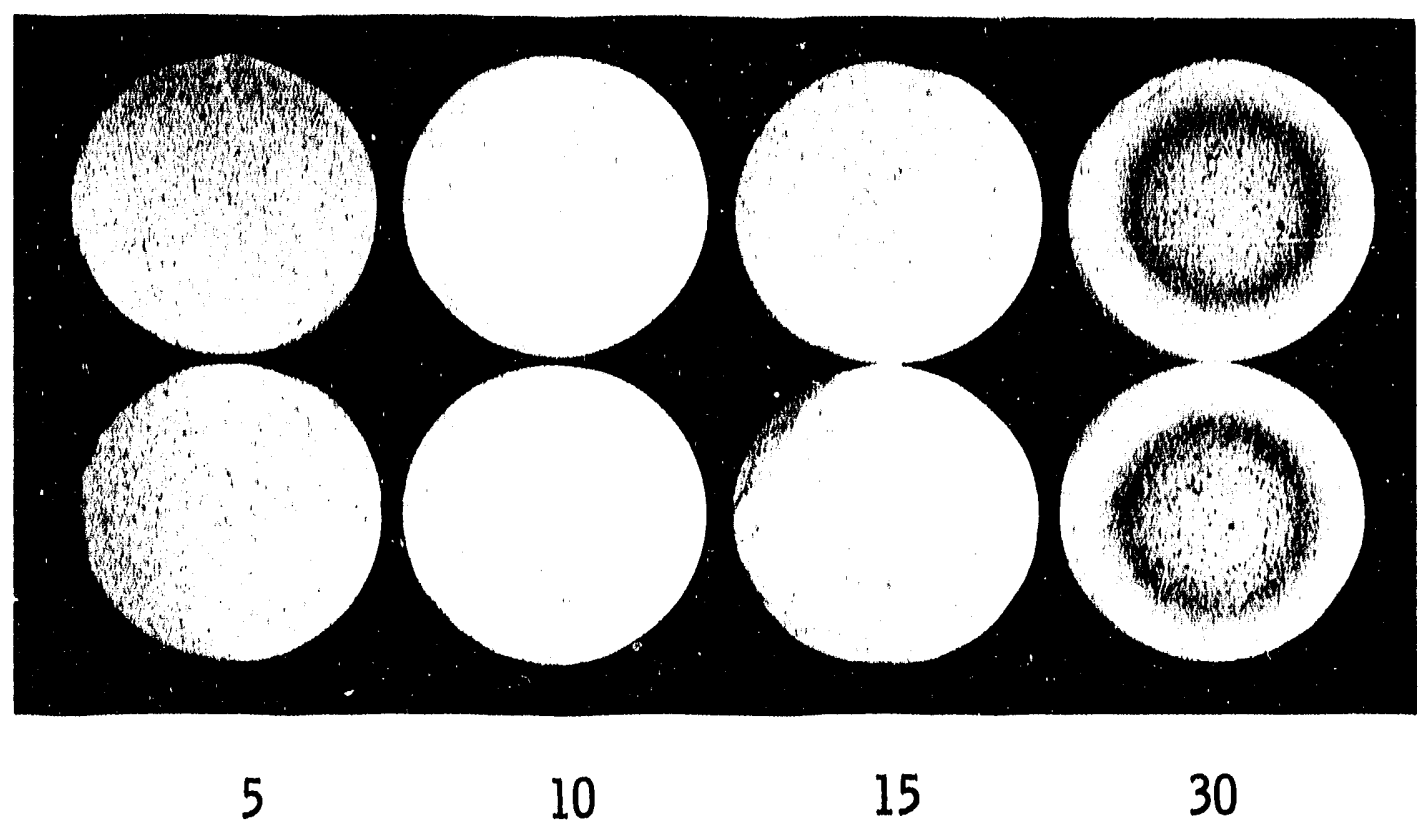

T'ime, min

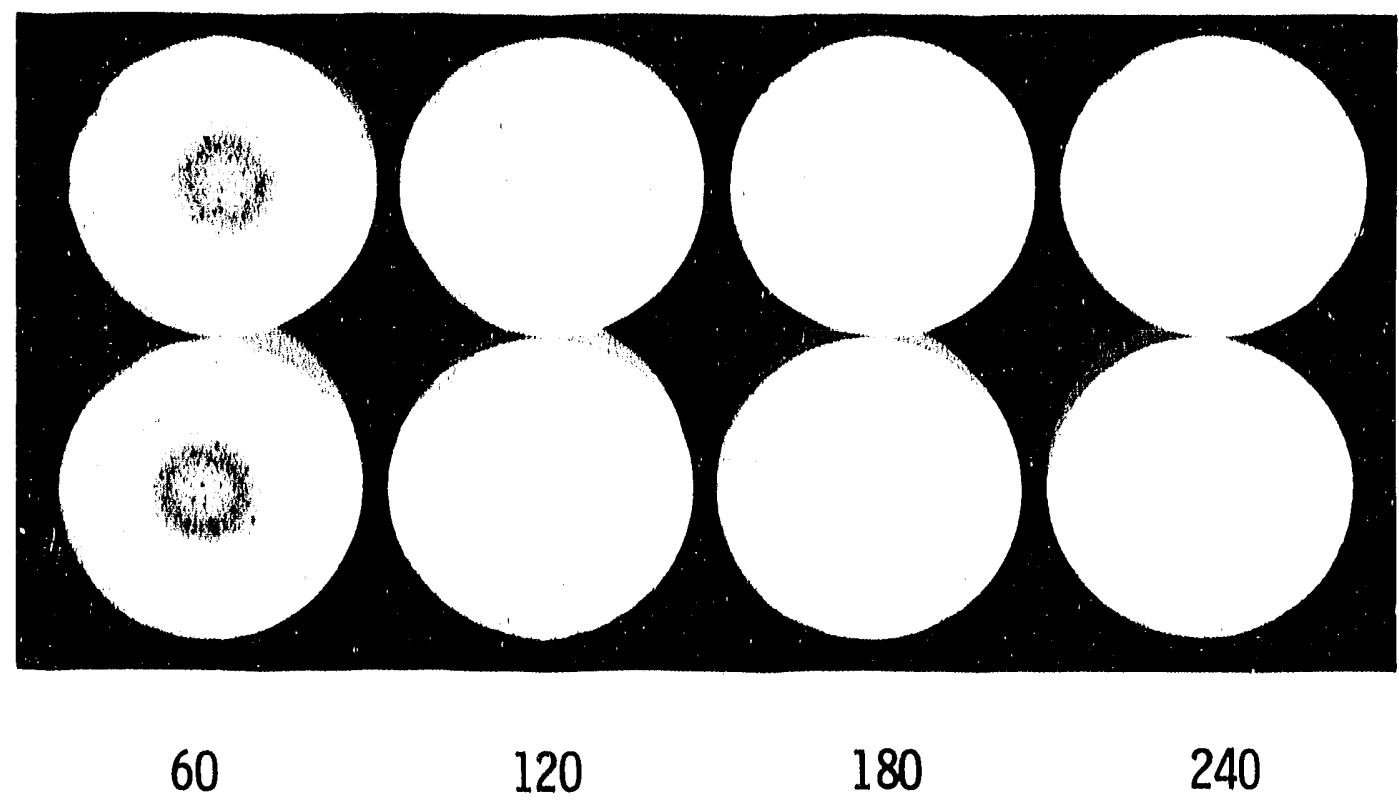

T'ime, min

Neg $0661890-1$

FIGURE 22. $400{ }^{\circ} \mathrm{C}$ Bakeout--1 wt\% Lithium stearate and 1 wt\% steario Aoid

UNCLASS I FIED 
RL-GEN-1773

finished peliets directly affects the $L 1^{6}$ content per unit of LiAlo, volume (also $\mathrm{Li}^{6}$ content/unit of target volume). Al1 pellet Eabrication process steps pritor to sintering were directed towards development of the desired sintered density.

Green LiAlO 2 pellets were sintered by heating to a temperature approaching the melting point of $\mathrm{LiAlO}_{2}$. At this temperature the LiAlO 2 particles are in more intimate contact, the effectiveness of surface tension reactions is increased, plasticity is increased, and there is the possibility that better mechanical interlocking is produced by the infiltration of a fluid network comprised of some compound(s) present which are in the liquid phase at sintering temperature. The effectiveness of the sintering process is believed enhanced by any reactions occurring which produce intermolecular motion. A typical sintered structure is shown in Figure 23. The rounded edges of vold spaces contained in the sintered structure shown suggest the presence of a liquid matrix during sintering.

The sintering process was performed in air at 1325 and $1335^{\circ} \mathrm{C}$ with times varying from 12 to $17 \mathrm{hr}$ at temperature. Sintering was performed in batch type furnaces heated by silicon carbide globar elements. One of the major sintering problems was maintenance of a constant sintering temperature throughout the furnace heating zone. Although considerable care was taken to provide more globar current to the front and rear heating zones and insulation of all access openings, thermal gradients still existed in the furnace and a 3 to $5 \%$ sintered density variation often occurred in a furnace load.

A variety of sintered pellet qualities were experienced during the Coproduct Program. Figure 24 illustrates the appearance of certain pellet types which are attributable to definite 


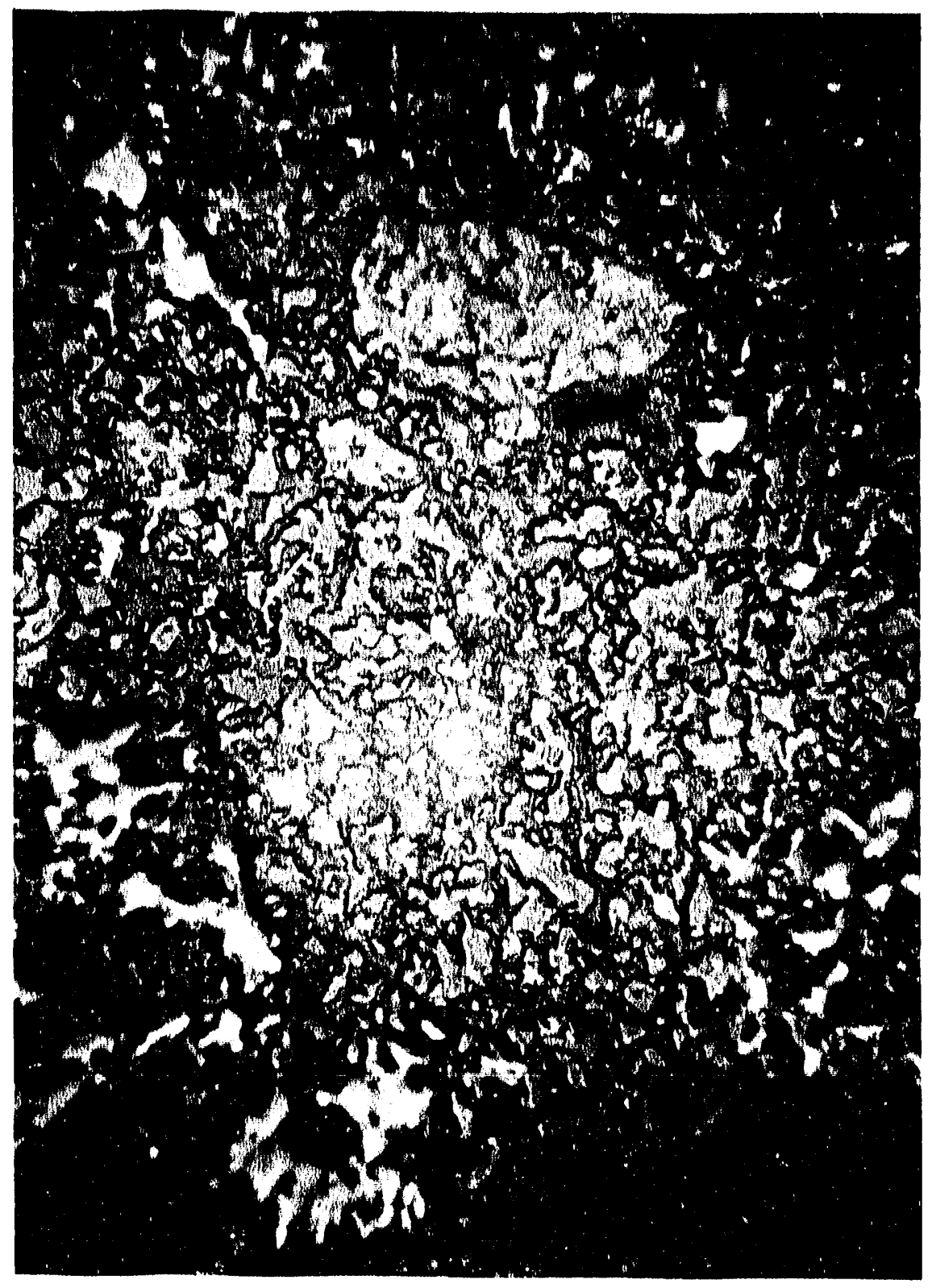

Neg $566-0264-B$ 

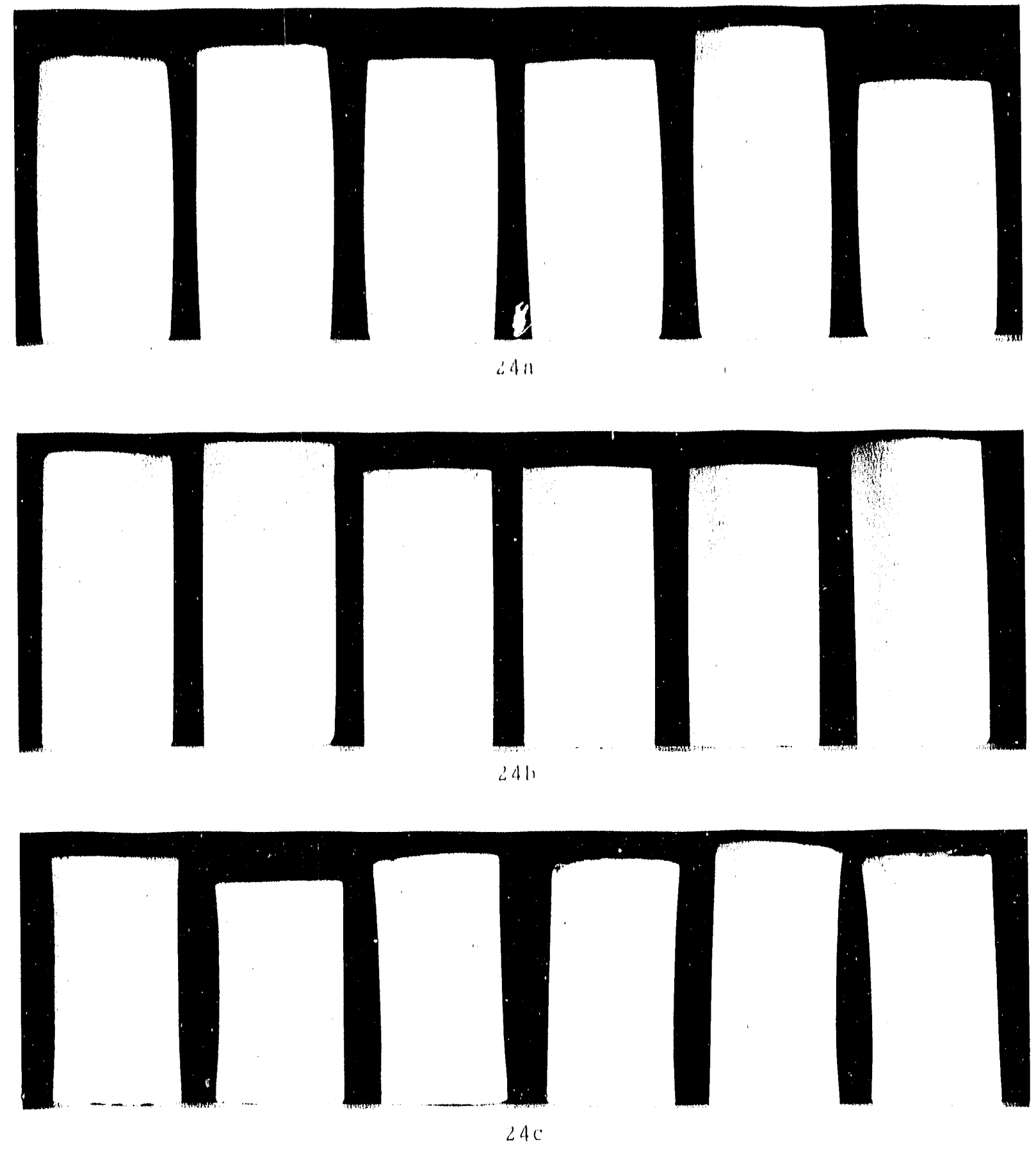

Neg $0663160-2$

FIGURE 24. LiAlo 2 Sintered pellets

UNCLASSIFIED 
causes. The barrel. shaped pellets of Figure 24 a can be the result of: 1) bar:el shaped green pellets due to "bellied" die iner or 2) incomplete sintering. In the event a worn die liner was used, pellets will probably be of acceptable density. Straight green pellets which emerge barrel shaped from sintering have not received sufficient heating during sintering. Typical1y, pellet ends sinter first as they experience longer exposure to sintering temperature than do pellet centers. When barrel shaped pellets are produced from a sinter run, they can be further sintered by recycling. Figure $24 \mathrm{~b}$ illustrates the appearance of normal pellets which have passed through the shape of those in Figure $24 a$, but have received sufficient exposure to sinter completely. Figure $24 \mathrm{c}$ shows the typical shape of pellets which have been densified by $30 \%$ or more during sintering. These particular pellets had a green density of $62 \%$ of theoretical and a sintered density of $85 \%$ of thecretical (a $37 \%$ increase). The "hour-glassed" pellets indicate a greater than normal amount of liquid phase present during sintering. This effect can be induced by using $\mathrm{CaCO}_{3}$ or other agents which promote sintering.

Sintering has proven to be effective in volatilizing undesirable impurities in the $\mathrm{LiAlO}_{2}$. The :e is generally a $50 \%$ reduction in boron content and a $90 \%$ reduction in fluorine content during sintering. Unfortunately, lithium is also vaporized during sintering. The lithium loss has been measured at 2 to $4 \%$ of the original lithium content. This loss is accounted for in the procurement of powder and the adjustment of $\mathrm{Li}^{6} \mathrm{con}$ tent prior to powder processing. Lithium loss varies directly with exposure time to sintering temperature; therefore, increased loss must be accounted for when pellets are resintered or sintering times are changed. 


\section{Implications for the Future}

The $\mathrm{LiAlO}_{2}$ fabrication process has two major shortcomings. one is that process development proceeded on an empirical basis, with a minimum amount of underlying development as to the causes of variable $\mathrm{LiAlO}_{2}$ fabrication characteristics. The second shortcoming is that the process is engineering oriented, i.e., the process requires substantial engineering input as opposed to a standardized production process. These shortcomings are a direct result of limited time availability for process development work. The process could be continued as now defined, as successfully demonstrated by the Coproduct Program; however, certain changes would be desirable prior to application to a long-term production situation. A sustained manufacturing situation should include the following recommended actions:

a. The $\mathrm{LiAlO}_{2}$ preparation process (conversion from LiOH to LiA $10_{2}$ ) should be investigated to provide procurement specifications to insure $\mathrm{LiAlO}_{2}$ of uniform fabrication characteristics. The desired goal would be to receive powder which would consistently achieve a desired sintered density $\pm 1 \%$ under constant processing conditions. Such powder would eliminate the present requirement for vari. able processing conditions, and would further benefit the $\mathrm{Li}^{6}$ control problem by yielding a consistent sintered density.

b. Process refinement or simplification is desirable so that production functions could assume those duties performed by Quality Control and Engineering for demonstration purposes.

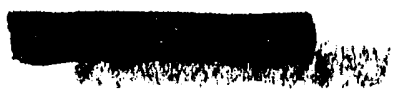




\section{ASSEMBLY (CLADDING) PROCESS}

The assembly cladding process was an adaptation of the ceramic target for irradiation in the $\mathrm{N}$-Reactor environment. This portion of the process was therefore directed at:

1) encapsulation of the ceramic pellets into aluminum for hydro. gen isotope containment and postiradiation handiing, and 2) assembly of aluminum clad assemblies into zircaloy cladding to provide required resistance to corrosion in high temperature pH-10 water. The assembly process was therefore directed primarlaly at physical integrity. A review of the major process steps is included in the following discussions.

Pellet Finishing Operations

Sintered pellets were checked for conformance to density specifications and then processed through three finishing opera. tions including: 1) centerless belt grinding for outside diam.

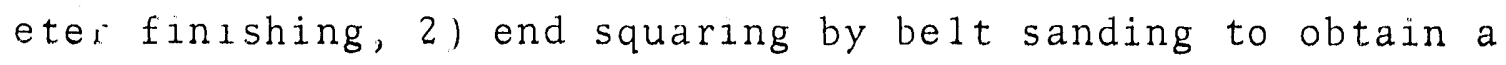
flat mating surface between pellets, and 3) abrasive sawing to pellet stack length for assembly into aluminum cladding compo. nents. These operations are shown in Figures 25,26 , and 27 .

The major problem encountered in these operations was variable pellet density. Pellet reaction (material removal rate) to abrasive finishing equipment is affected primarily by densicy Centerless grinding in particular, was extremely sen. sitive to this characteristic and grinder set up was checked and in most cases modified for each significant change in pellet density

Ceramic Assembly into Aluminum Cladding

The most critical assembly problem in the various assembly operations was assuring that the molsture content of the ceramic was less than $150 \mathrm{ppm}$ in the aluminum clad assembly. The pellet drying and aluminum canning process utilized was based on the 


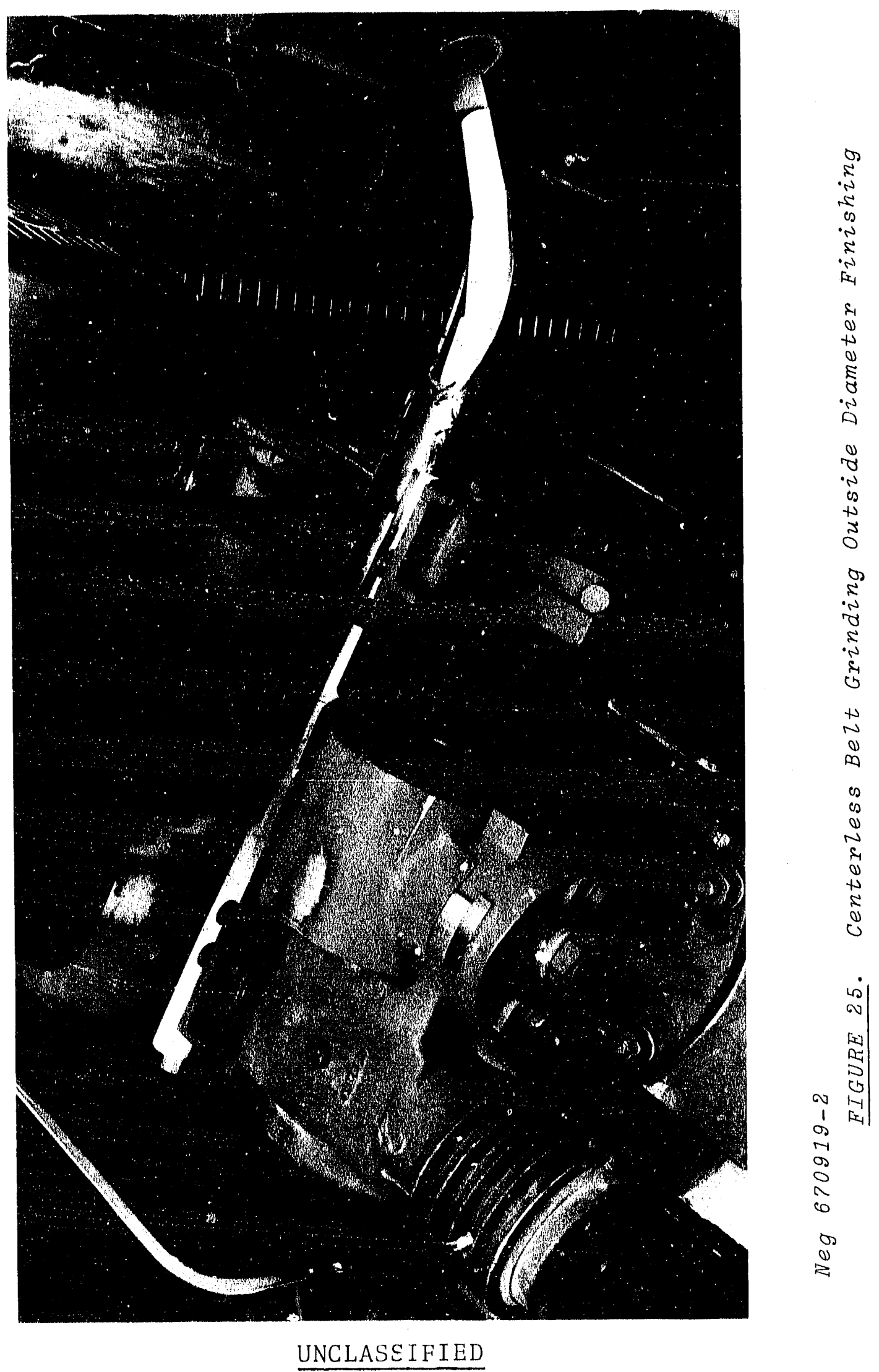




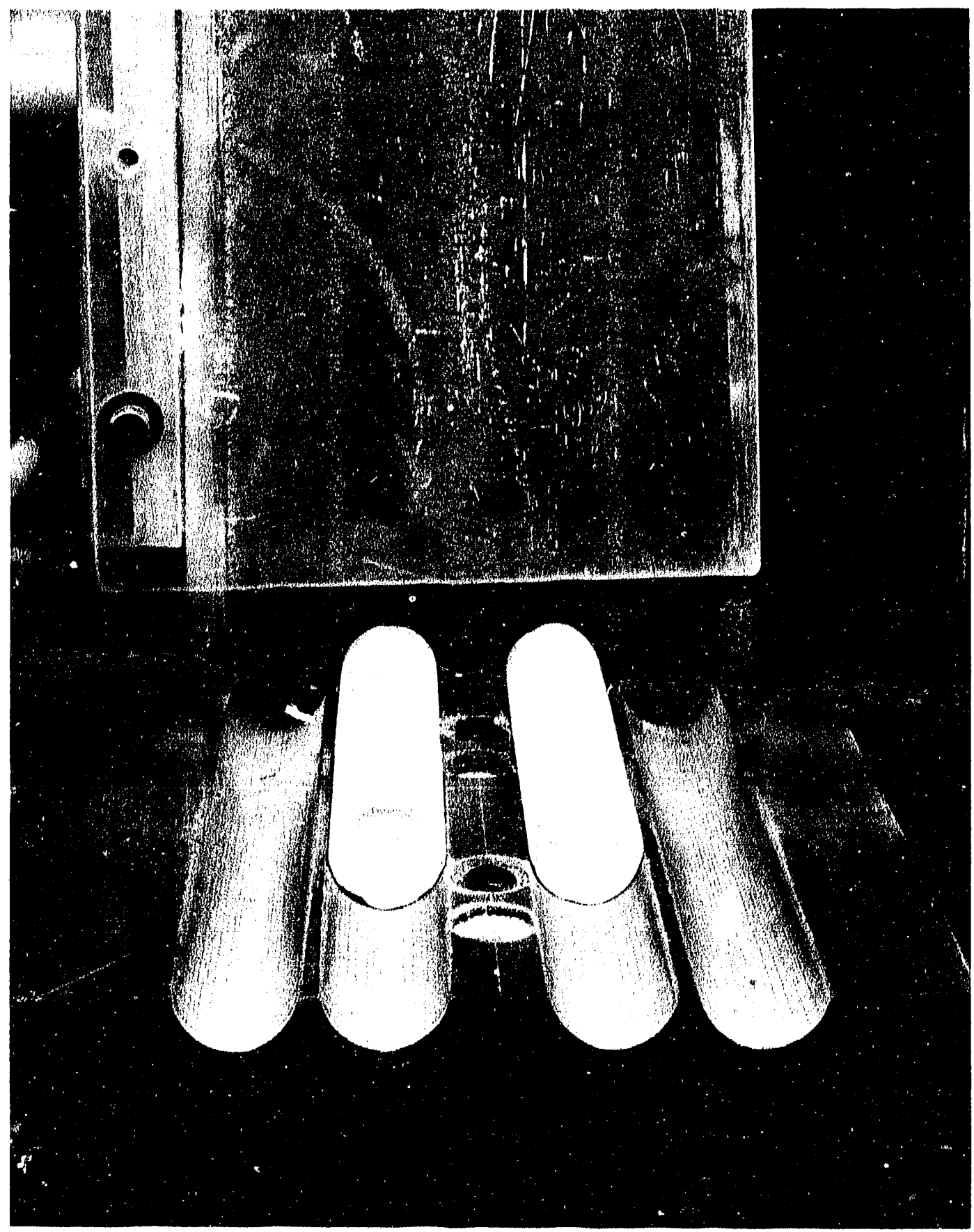

Neg $670919-3$

FIGURE 26. Belt Sanding End Squaring 

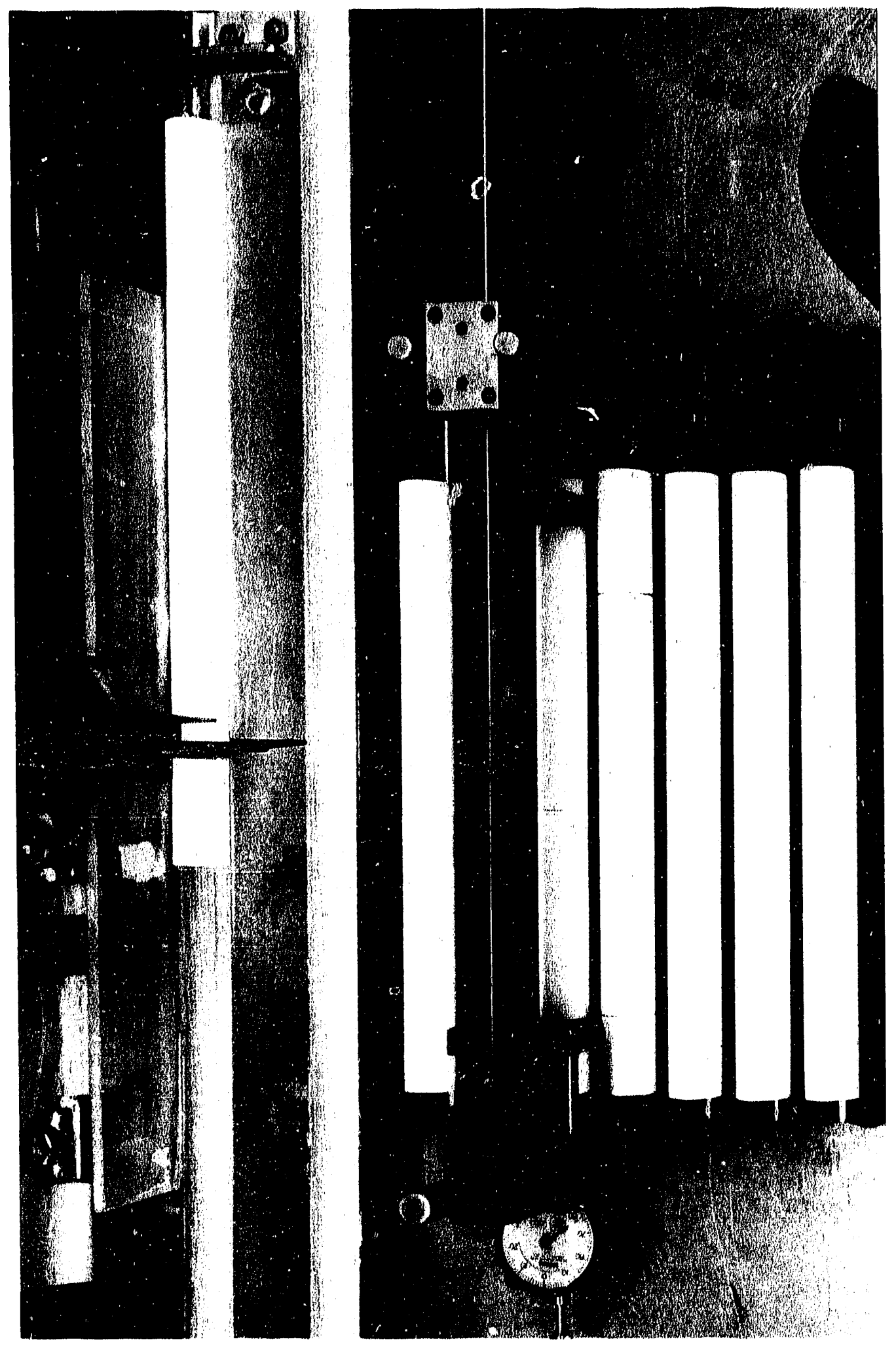

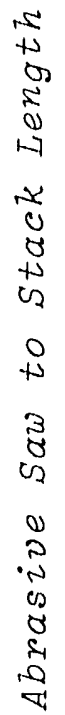

嚾?

Wrom

$\therefore \quad x_{x}$
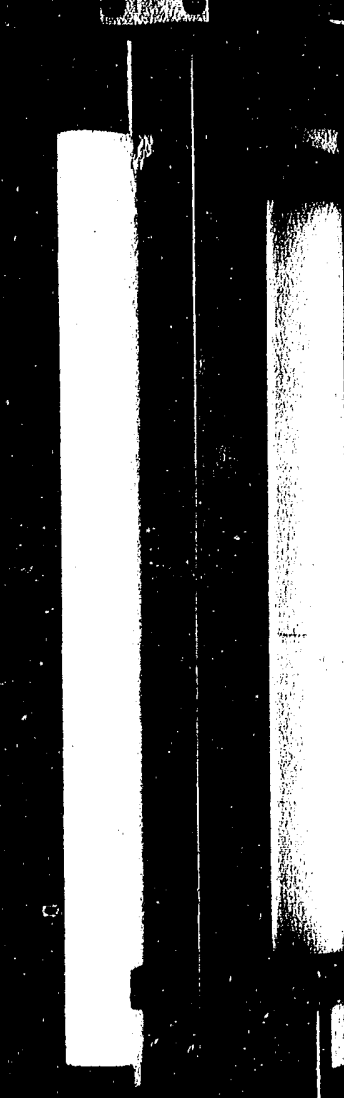

7

-

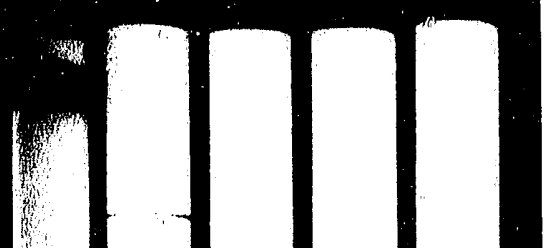

ve

?

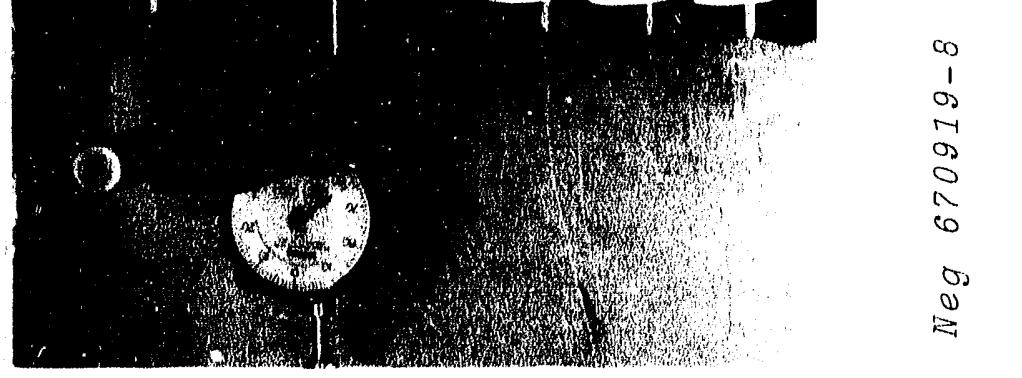

UNCLASS IFIED 
following developed ceramic-moisture relationships:

a. 500 to $600^{\circ} \mathrm{C}$ is sufficient to drive all moisture from the $\mathrm{LiAlO}_{2}$ regardless of initial moisture content, i.e., pellets soaked in water prior to drying did not exceed moisture levels typical of standard production peliets.

b. Moisture adsorption by the $\mathrm{LiAlO}_{2}$ will not occur above $500{ }^{\circ} \mathrm{C}$.

c. Dried $\mathrm{LiAlO}_{2}$ adsorbs moisture at the rate of $1 \mathrm{ppm} / \mathrm{min}$ from a "dry" atmosphere (4 to 6 ppm leve1). This emphasizes the importance of controlled exposure time after cooling below $500^{\circ} \mathrm{C}$.

d. The $\mathrm{LiAlO}_{2}$ moisture adsorption rate is high initially, but the increase declines asymptotically as ambient conditions are approached. Maximum moisture content which can be reached is not known. The maximum content would not be limited by the atmosphere moisture level if unlimited exposure time was allowed.

e. Different reaction batches of $\mathrm{LiAlO}_{2}$ adsorb moisture at different rates. No correlation was found between other $\mathrm{LiAlO}_{2}$ characteristics and the rate of moisture adsorption. Moisture adsorption rate is considered a function of the types and amounts of various chemical compounds in the $\mathrm{LiAlO}_{2}$.

f. No correlation was found between pellet density and moisture content or rate of moisture adsorption.

'the assembly process used is summarized in l'able VI. 'th is process, using the maximum exposure times, consistently produced canned $\mathrm{LiAlO}_{2}$ moisture levels of $75 \mathrm{ppm}$ or less. Normal production practice quite often reduced exposure times with resultant lower moisture levels. 'lhe average moisture content for all target assemblies produced during the demonstration program was below $50 \mathrm{ppm}$.

'The glovebox assembly chamber referred to in T'able VI is shown in Figure 28 . 


\section{IABLE VI. Pellet Drying and Assembly Prosess}

\begin{tabular}{|c|c|c|}
\hline Process Step & Exposure Time & $\begin{array}{l}\text { Maximum Atmospnert } \\
\text { Moisture Content }\end{array}$ \\
\hline $\begin{array}{l}\text { a. Furnace Drying } \\
\left(650 \text { to } 850^{\circ} \mathrm{C}\right)\end{array}$ & 2 hr minimum & Room Air \\
\hline $\begin{array}{l}\text { b. Pellet transfer } \\
\text { (furnace to glovebox } \\
\text { cooling chamber) }\end{array}$ & 90 sec maximum & Room Air \\
\hline c. Cool pellets in chamber & 45 min maximum & $\begin{array}{l}100 \mathrm{ppm} 1 / 2 \mathrm{hr} \\
\text { after charging } \\
\text { (argon) }\end{array}$ \\
\hline d. Assemble into aluminum & 90 min maximum & $600 \mathrm{ppm}$ (argon) \\
\hline $\begin{array}{l}\text { e. Glovebox in-process } \\
\text { storage (capped-unwelded } \\
\text { assemblies) }\end{array}$ & 60 min maximum & $600 \mathrm{ppm}$ (argon) \\
\hline $\begin{array}{l}\text { f. Preweld in-process stor- } \\
\text { age (capped-unwelded } \\
\text { assemblies) }\end{array}$ & 60 min maximum & Room Air \\
\hline
\end{tabular}

'T'wo alternative methods of controlling pellet moisture content were investigated. Pellets were vacuum dried versus $800^{\circ} \mathrm{C}$ furnace drying. Holding time in vacuum proved excessive to attain moisture levels below $150 \mathrm{ppm}$. Pellets were assembled at $750^{\circ} \mathrm{C}$ into aluminum cans at $200^{\circ} \mathrm{C}$. This hot assembly approach was quite successful in holding moisture levels below $50 \mathrm{ppm}$. 'The hot assembly process offers the potential for reduced capital investment and lower operating maintenance is a sustained operating case.

\section{Aluminum A'ssembly End Closure Welding}

The Coproduct l'arget aluminum subassembly end closure weld is made with the tungsten inert gas process using an ac power supply. $(22,23)$ The ac power supply was chosen over ac because

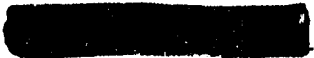




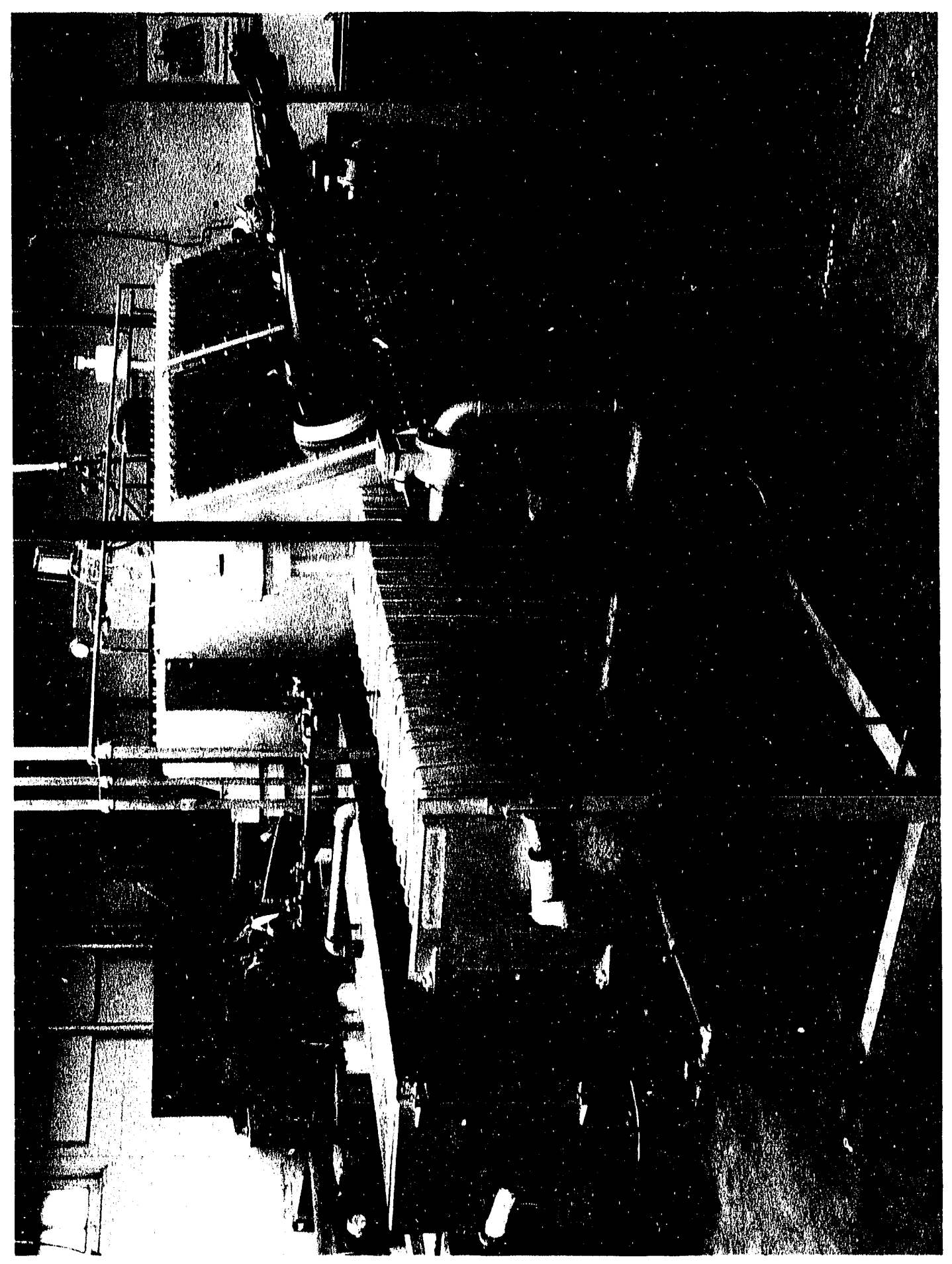

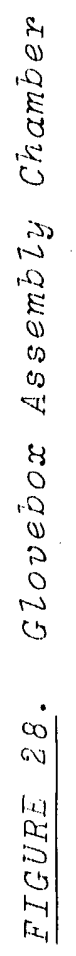

0
-1
1
-1
0
0
0
0
0
0
0
0 
ac does provide some degree of cleaning by cathodic etch during the welding process. Figure 29 shows a cross section of the aluminum end cap and welds. 'lhe step in the cap outside dianeter allows the welding arc to provide a cleaning action between the feying surfaces. 'l'he Number 55 drill hole in the center of the cap is a venthole to allow escape of entrapped atmosphere as the cap heats during welding. 'lhis precludes blowout of the outer weld. The vent hole is sealed after the main closure is complete. Success of the vent hole closure process depends upon the speed with which the closure can be completed. The $0.25 \mathrm{in}$. center section is fused into a smoothly rounded dome. The step in the clad inside diameter provides positioning and thins the wall of the can to provide a thermally balanced weld joint.

Rotation speed of the aluminum subassembly was 6 to $7 \mathrm{rpm}$ during welding of the outer weld joint. A semiatomatic programmer provides a dwell time before rotation starts after initiation of the weld cycle. During the dwell time the current is increased from zero to $150 \mathrm{~A}$. After the 0.1 to $1.0 \mathrm{sec}$ dwe 11 time, rotation of the work piece starts and the current is decayed automatically to $95 \mathrm{~A}$. 'The weld is completed at $95 \mathrm{~A}$. at completion of the weld, the operator initiates the stop cycle which decays the current to approximately 20 A before the weld contactor is opened. Decay time is $120^{\circ}$ of rotation maximum.

The work piece was not rotated during the vent hole weld. 'The electrode is positioned directly over the vent hole during welding. 'lhe current program provides current slope control to $150 \mathrm{~A}$ and decay slope to approximately $20 \mathrm{~A}$. 'lhe seal weld was completed in 3 to $3.5 \mathrm{sec}$. 


\section{UNCLASSMUUD}
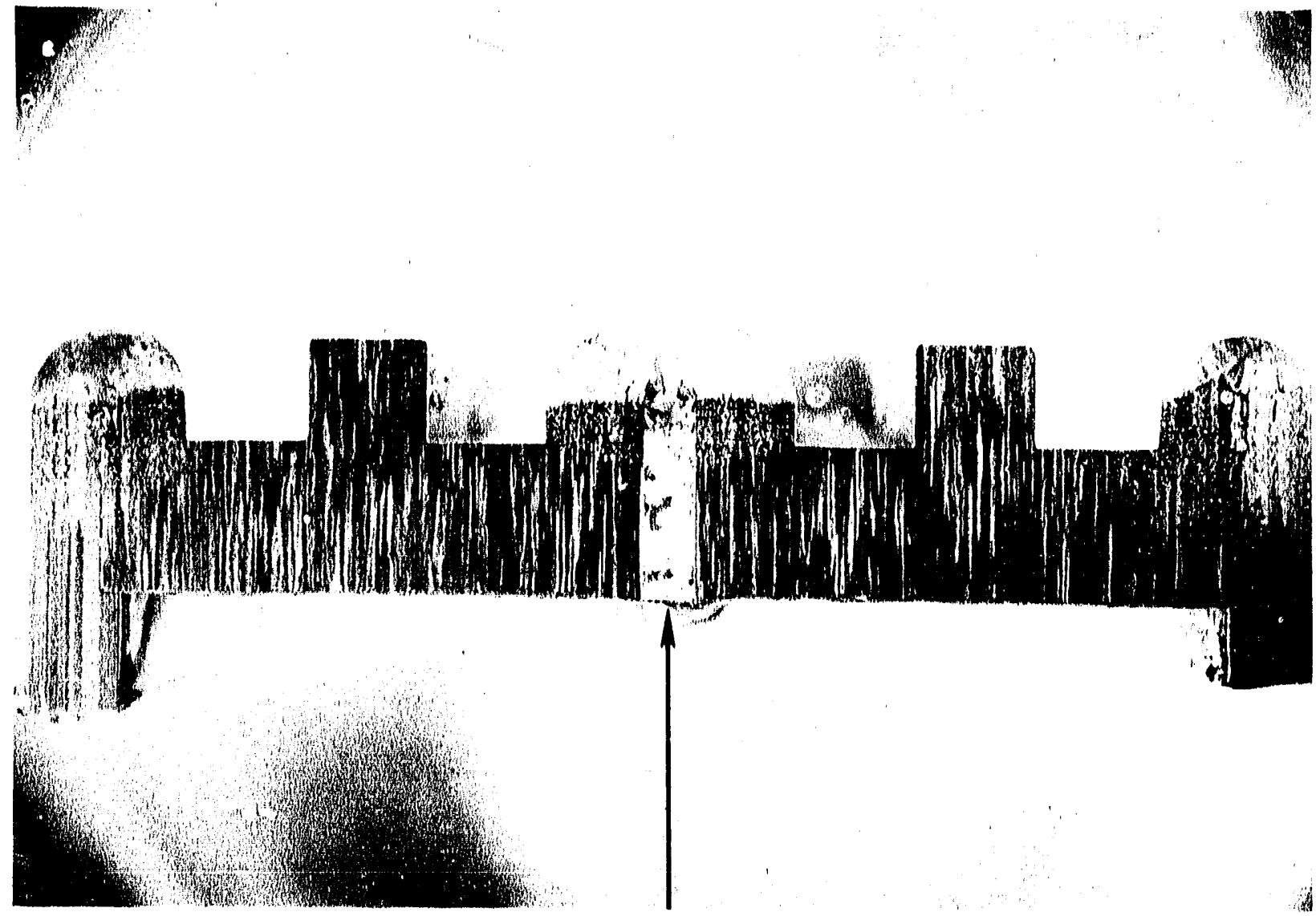

Neg 566-6027-B

Vent llole

FIGURE 29. Aluminum Eind C'ap Welding UNCLASS IFEDE 


\section{Aluminum Assembly Sizing}

'tho aluminum assomblies wore hydrostaticaliy sized followIng end closure welding to reduce the assembly clearance betweon the aluminum clad inside diameter and the pellot outside diameter. The sizing operation was performed at autoclave conditions of $2500 \pm 50 \mathrm{psia}$ and $150+50-10{ }^{\circ} \mathrm{C}$ for a period of: 15 min minimum. Sizing to minimizo clearances in the fintshod target assembly was necessary to eliminate potential zircaloy cladding collapse due to system pressure which could affect: support performance.

Various mechanical sizing methods (die sizing, spin or roll forming, etc.) were evaluated versus the hydrostatic method. In genera1, most mechanical methods created problems in maintaining a low mosture lovel in the ceramic. In addi. tion to processing advantages, the inherent ability of the autoclave to detect defect pellets and welds was a characteris tic judged necessary for overall product quality Aluminum Assembly Finishing

The sized aluminum assemblies are straightened to $0.010 \mathrm{ln}$. IIR maximum and belt centerless ground to eliminate surface irregularities and to size the outside diameter to fit the available zircaloy cladding components. This grinding operation essentially eliminates ovality and the assembly outside diameter variation was $0.003 \mathrm{cn}$. maximum.

Aluminum assemblies were helium leak tested after grinding to assure that no pinholes or cracks were opened cluring the grinding process. 'l'he leak testing procedure is described in detail in a latter section.

Blackness l'esting

'To insure that aluminum assemblies containing significantly different levels of Li $^{6}$ did not become intermaxed in the process, 
a "blackress" tester was used to tost $100 \%$ of the material procossed against known standards. The "blackness" tester is essentialiy a device for measuring tho relative noutron adsorption characteristic of each assembly. (24) An assembly was placed between a known neutron source and a noutron counter. 'The neutron count was then compared with that obtained from a known standard to establish the $L i^{6}$ level. The tester was proven capable of detecting the three enrichment levels of: interest (spike, base, poison) and providing a qualitative measure of conformance to tolerance ranges. The tester only provided a general indication of enrichment level and could not be used to establish the actual $\mathrm{Li}^{6}$ content of assemblies. The 305 'lest Reactor was the only proven method for establishing quantitative $L i^{6}$ values and no definite correlation with the "blackness" tester was possible.

Alum inum-Zircaloy Assembly

'The assembled target element is a mechanical assembly with no bond between the lithium-aluminate, aluminum, or zircaloy components. Assembly and thermal expansion clearances were provided in the target design to allow for differences between component in-reactor operating temperatures and thermal expansion. A basic mechanical design analysis of the target, under extreme-case conditions of assembled dimensions and in-reactor enviromment, indicated that the pellet-aluminum subassembly Ilight expand enough longitudinally to incur more than 0.100 in. length interference with the zircaloy end caps. (17)

'This condition could be experienced in a target located at a position of maximum heat generation ( $4.4 \mathrm{~kW} / \mathrm{ft}$ ) with minimum allowable longitudinal assembly and thermal expansion clearance $(0.080 \mathrm{in.})$. In this case the longitudinal expansion of the aluminum was calculated to be 0.065 in. more than the zircaloy, 
and the 1 thtum-aluminate 0.080 in. more than the aluminum; resulting in an equivalent forced intorforence of $0.145 \mathrm{in.}$ betweon the aluminum and the zircaloy end caps. 'The equivalent force on the zircaloy ond caps as caused by the internat interference, by the pressure increase due to reduction of assembly and expansion gaps by thermal expansion, by the pressure derived from gas generation within the ceramic, and by the external pressure of reactor coolant was calculated to be $372 \mathrm{psi}$. 'The resulting stressing of the zircaloy cladding would then be a factor of four less than the yield strength of the cladding. Irradiation experience to date has proven the target to be mechanically stable at design conditions.

The assembly clearance between the aluminum assembly outside diameter and the zircaloy cladding inside diameter was established at $0.006 \pm 0.003$ in. for standard operating procedures with a $0.012 \mathrm{in}$. maximum. Assembly clearances less than 0.006 in. have not been practical because of minor surface irregularities in the aluminum and/or zircaloy. Aluminumzircaloy assembly is a selective assembly operation. The aluminum assembly outside diameter is dependent on both the zircaloy cladding inside diameter and the fabrication method used for producing the zircaloy cladding. The fabrication method is of: importance in that the cladding inside diameter surface finish varies significantly between free-sink drawing and plug drawing. Assembly problems would be minimized with a standard fabrication route for a 11 zircaloy cladding components.

The zircaloy end closures are made with the tungsten inert gas process using a de power supply with helium as the inert gas. A typical weld cross section is shown in ligure 30 . Holium was also introducod into the target assembly at this time to improve the overall reliability of helium leak testing after atutoclaving. 


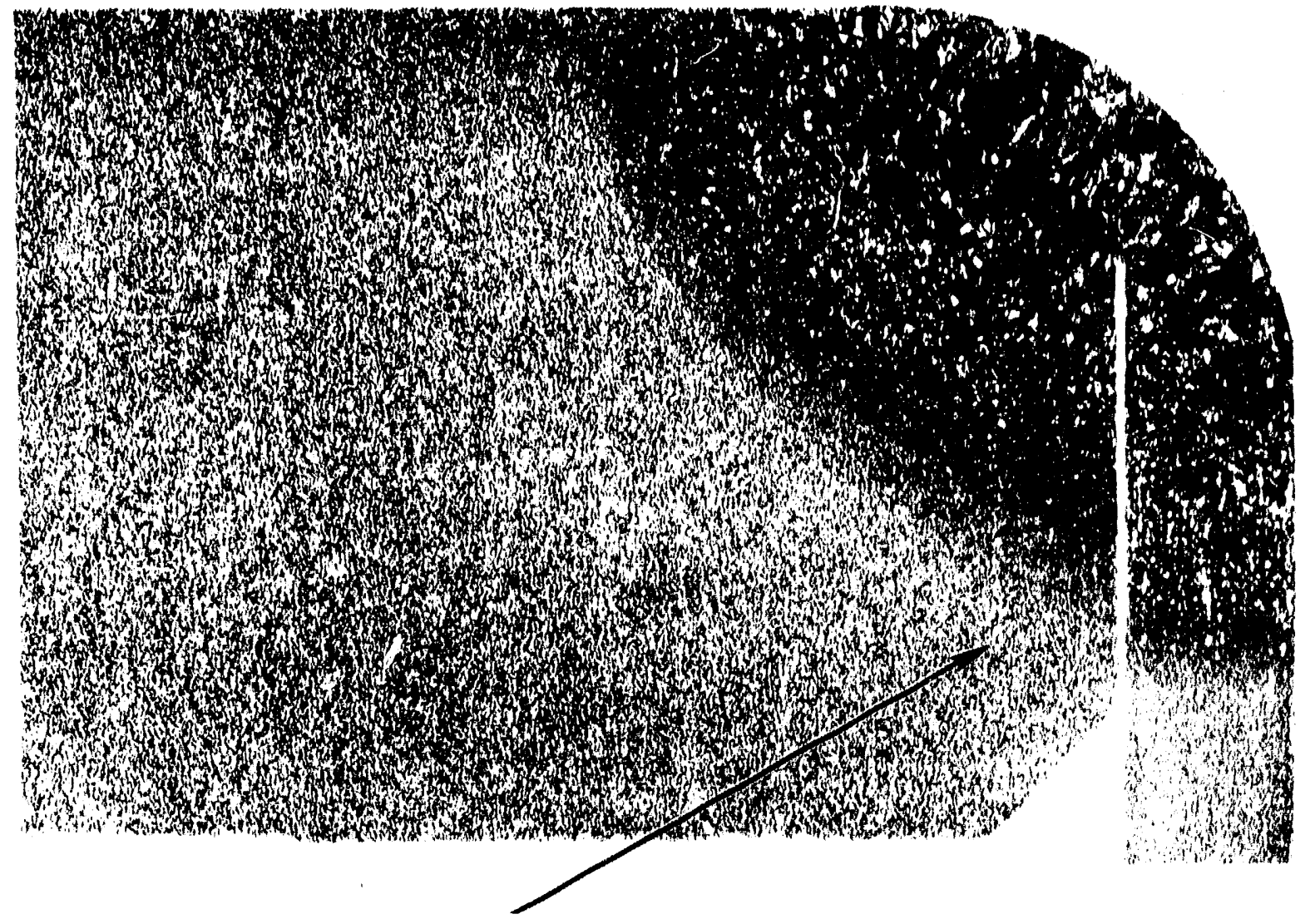

Limit of Heat Affected Zone

Neg 566-6102-A

FIGURE 30. Typiaal production ziroaloy End Closure weld

UNCLASS I FIED 


\section{UNCLASSIFED}

RL-GEN-1773

Support Welding

Self supports for the coproduct target element are projection welded to the zircaloy clad following end closure welding. The weld projection arrangement (multiple), illustrated in Figures 12 and 13, was developed for use with a spike welder powder supply to obtain maximum weld shear strength with minimum cladding penetration. Weld penetration was of particular concern since a bond could be developed between zircaloy and aluminum which was not compatible with postirradiation processing. The normal shear strength developed per weld tab was 600 pounds. A typical weld cross section is shown in Figure 31.

Autoclave Testing

The target assemblies were nitric-hydrofluoric etched ( $0.001 \mathrm{in}$. removal per surface) and autoclaved to detect cladding penetrations and to assess the corrosion resistance of the zircaloy cladding. A superheated steam cycle was used: $400^{\circ} \mathrm{C}$ at $1500 \mathrm{psi}$. The high temperature and pressure cycle was used also as a final test of the structural characteristics of the assembly in an environment in excess of reactor conditions, i.e., excessive diametral assembly clearances between the aluminum subassemblies and the zircaloy cladding were easily detected after autoclaving due to cladding collapse.

Leak Testing

Autoclaved targets were helium leak tested to assure clad and weld integrity. The targets were placed in an evacuation chamber, held at a low pressure for a minimum of $30 \mathrm{~min}$, and the chamber was then backfilled with helium at a pressure of 1 to 2 psi for $15 \mathrm{~min}$. The targets were then leak tested along with a leak test standard. The leak standard was : rocessed through the complete cycle with an assembly lot of targets to assure against equipment malfunction. 

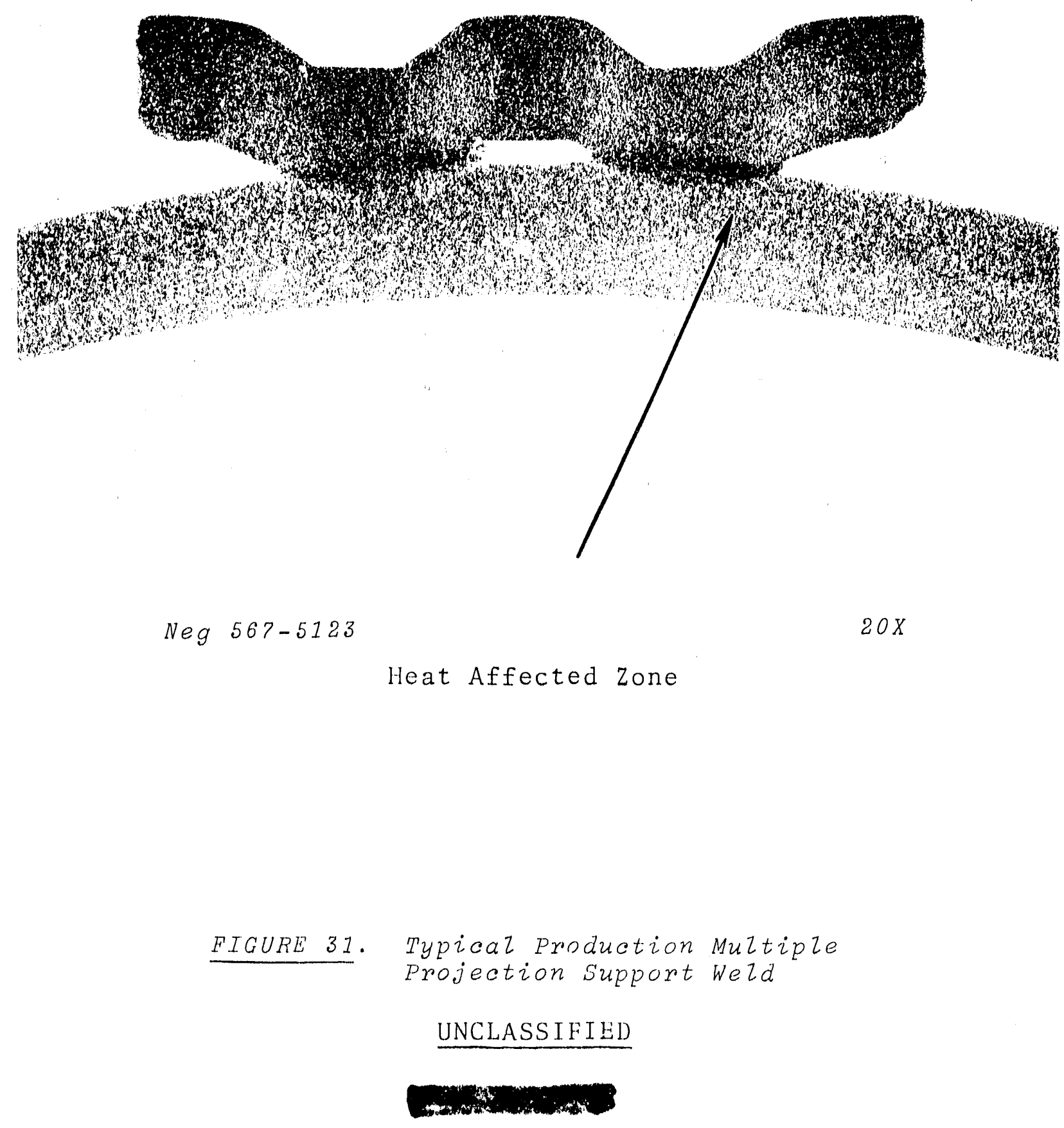


\section{DRIVER-TARGET ASSEMBLY}

Assembly of the target element into the driver fuel was performed consistent with two major criteria:

- The annuli between the target outside diameter and the driver fuel inside diameter had to be within established tolerances.

- The "W" support spring characteristics had to be assured and maintained within the limits required to prevent breaking of contact between any of the support components and the driver cladding under the action of the maximum hydrodynamic forces expected during residence in the reactor.

Maintenance of an acceptable annulus variation was dependent on a number of inter-related variables including: target outside diameter, solid support height, driver inside diameter, and target cladding defection due to the spring load in the support weld areas. Therefore, the assembly process utilized required measurement of the rarget outside diameter in the support location and grinding of the solid supports to a height compatible with specific driver fuels grouped by insià diameter.

The "W" spring force required to assure target stability during reactor service was established at $301 \mathrm{~b}$. The support system utilized called for cold assembly in the plastic range with a resultalit loss of developed spring load due to stress relaxation at operating temperature. Stress relaxation of the Mark II "W" springs is generally as shown in Figure 32 . To insure against significant changes in stress relaxation characteristics, sample springs were tested from each lot of supports, where lots are defined by strip rolling process lots or feed material. In addition, each assembly is tested cold for developed spring load following assembly. This testing

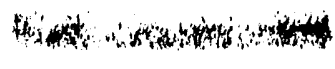




\section{UNCDASBIFH}

is performed by loading the target element against the "W" spring with a fixture designed for this purpose with empirically defined limits for developed load-deflection curves. $(25,26,27)$

The fuel assemblies were then shipped with the "W" springs in the top-center position to eliminate the possibility of handling damage. No attempt was made to orient the spring location during irradiation.
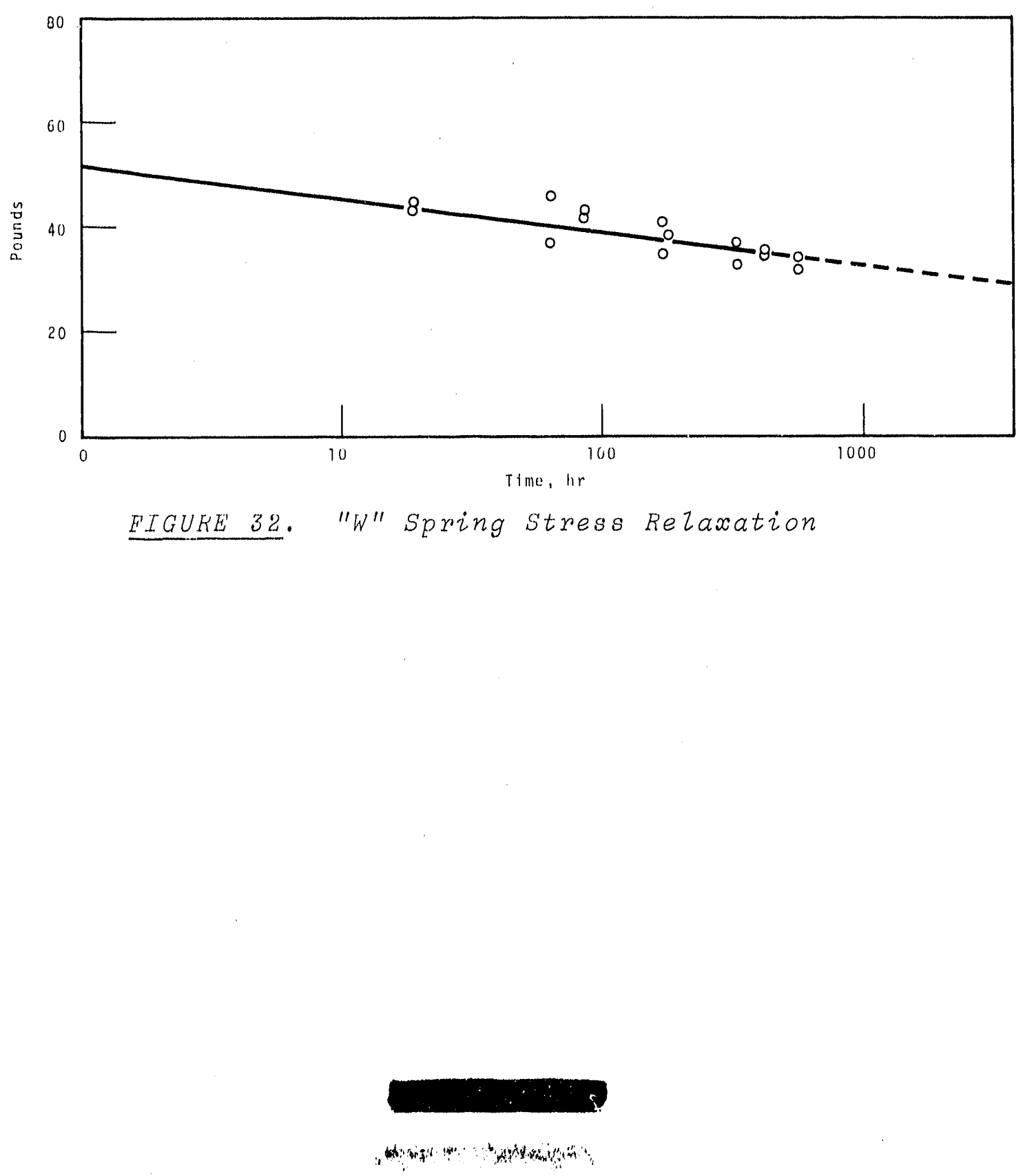


\section{REFERENCES}

1. M. C. Leverett. Technical Criteria for Coproduct Program, RL-GEN-1447. General Eleatric Company, Riohland, Washington, March 20, 1967. (Secret)

2. C. H. Shaw, Coproduct Target Element Fabrication Operating Procedures RL-GEN-1559. General Electric Company, Richland, Washington, April 6, 1967. (confidential)

3. Quality Control operations. Quality Control StandardsCoprocilat Target, RL-GEN-1082 General Electric Company, Richlcrid. Washington, July 1966. (Confidential)

4. Specia? Products Engineering Operation. Special Products-Process Specifications, $R L-G E N-933$. General Electric Company, Richland, Washington, May 1966. (Confidential)

5. N. W. McKay, D. H. Walker. N-Reactor Department Design Criteria-Coproduct Demonstration Program Fuel-Target Fabrication Equipment, RL-GEN.678: General Electric Company, Richland, Washington, December 20, 1965. (Confidential)

6. R. C. Walker. Project Proposal-Coproduct Demonstration Program - Phase I Fuel Target Fabrication Equipment, RL-GEN-679. General Electric Company, Richland, Washington, December 2\%, 1965. (Secret)

7. R. R. Studer, Specification for Lithium-Aluminate Powder, RL-GEN-696, Revision No. 1. General Electris Company, Richiand, Washington, January 5, 1966.

8. R. R. Studer. Characteristics of Lithium-Aluminate Powder, RL-GEN-1309. General Electric Company, Richland, Washington, January 3, 1967. (Confidential)

9. R. R. Studer. Fluorine Contents of Lithium-Aluminate Powder and Sintered Pellets, RL-GEN-1573.General Electric Company, Richland, Washington, Aprit 10, 1967. (Secret)

10. E. A. Smith. Coproduct Element Fabrication-Process Review, RL-GEN-1113. General Electric Company, Richland, Washington, August 8, 1966. (Confidential)

11. R. R. Studer. Analysis of Target Clad Failures, RL-GE'N1449. General Electric Company, Richland, Washington, February 28, 1967. (Unclassified) 
12. W. W. Olson. Coproduct Target Warp Evaluation (Summary PWR \#241', RL-GEN-1748. General Electric Company, Richland, Washington, June 30, 1967. (Unclassified)

13, D. H. Nyman Characteristio of the "W" Spring Coproduct Target Support, RL-GEN-1427. General Electrio Company, Richland, Washington, February 7, 1967, iUnclassified!

14. J E. Hunsen. Developmeint of N-Reactor Coproduct Target Ll.thium-Aluminate Pilet Pabrication Process For PTNR-75, RL-GEN-179?, Rorteraz, Electric Company, Richtand, Washington, June ibly $6 \%$ Corfidential?

15. W. E. Gurwe 22 Eabrication of Ceramic Target Coses by the Peliet Process for PT-NR-5?, BNWL-CC-428, Pacific Northwest Laboratory, Richland, Washington, January 11 , 1066 , iconfidential:

16. W. E. Gurwel. D. Discussion of Some Aluminate Pellet Fabrication Variables Related to PT-NR-66, BNWL-CC-641. Pacifia Northwest Laboratory, Richland, Washington, April 28, 1966. (Confidential)

17. B. i. Brazier, J. E. Hansen, D. H. Walker, and R. R. Studer. Summary Report PT-66 Coproduct Target Element fiabrication Details and Prooess Development Status, RL-GEN-1021. General Electric Company, Richiand, Washington, June 3, 1966. iConfidential.!

18. W. E Gurwe22. Characterization of Lithium-Aluminate powders in J.0. 909 and J. 0.911, RL-GEN-1142, General Eleotric Company, Richland, Washington, July $13,4966$. (Confidentiali

19. W E. Gurwe IZ and E. A. Smith. Studies of Abnormal Peliet Powder. Behavior, RL-GEN-1084. General Electric Company, Richland, Washington, July i3, 1966.

(Confidentral)

20. E A. Smith. Pellet powder Characterization for Process Contro!, RL-GEN-109\%. General Electric Company, Richland, Washington, July 28, 1966. Confidential:

21. Handbook of Balz and Pebble Mizzing, Eauz o. Abbe Company.

22. T B. Correy Target Material Closure Developmeint, BNWL-CC-496. Paoific Northwest Laboratory, Richiand, Washington, F'ebruary is, 1956. iConfidential.

UNCLASS IFIED 
23. D. H. Walker, Vent Hole Seal Weld Coproduct TargetAluminum, RL-GEN-1020. General Eilectria Company, Richland, Washington, August 23, 1966. (Confidential)

24. B. E. Dozer. Neutron Adsorption Lithium Detector, BNWL-C'C-397, Pacific Northwest Laboratory, Richland, Washington, December 21, 1965. (Unclassified)

25. D. W. Leiby and H. M. Pinkerton. "W" Spring in situ Preload Gauge Development - Interim Report \#1-Basic Target Structural Characteristias, EM-CISA-66-8. Douglas United Nuclear, Richiland, Washington, october 13, 1966. (Confidential)

26. D. W. Leiby and J. M. Pinkerton. "W" Spring in Situ Preload Gauge Development Interim Report \#2-Statistical Variations of Beam Characteristics From TargetSimulated Driver Bench Tests, EM-CISA-66-9. Douglas United Nuclear, Richland, Washington, November 3, 1966. (Confidentiaz)

27. D. W. Leiby and J.M. Pinkerton. "W" spring in situ Preload Gauge Development - Interim Report \#3 - "W" Spring in Situ Force Gauge Design Mark I and Mark I I Models, EM-CISA-66-10. Douglas United Nuclear, Richland, Washington, October 31, 1966. (Confidential) 


\section{acuraratarcar}

RL - GEN- 1773

APPENDIX A

TARGET ELEMENT IDENTIFICATION AND MATERIAL CONTROL SYSTEM

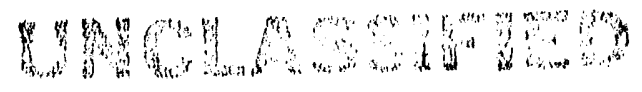




\section{APPENDIX A}

\section{TARGET ELEMENT IDENTIFICATION AND MATERIAL CONTROL SYSTEM}

Material in process was controlled by use of Manufacturing Lot Record formats. Samples of formats used are presented as Exhibits I, II, and III. The "A" Format (Exhibit I) was used to control lots of material until pellets were formed into stack units. The "C" Format (Exhibit II) was used to control lots of material from sta:k sawing to assembly into zircaloy cladding. The "E" Format (Exhibit III) was used to control lots of material from the zircaloy cladding operation to final assembly with driver fuel.

The material identification system was based on a powder lot numbering system, an aluminum subassembly numbering system, and a finished target numbering system. The three systems were crosis referenced in the respective Lot Record Formats.

The powder lot number was of the Form: A-123-123-78. A11 characters in a routine production lot were numerical except the first. The first letter identified the isotope leve1. The first set of numbers identified lithium-aluminate powder 10t. The second set of numbers identified the sintering run within a powder 1ot. The third set of numbers was the sintered density attained as percent of theoretical. Significant deviations from the operating procedures in any of the powder processing operations required notation on the manufacturing record card. The powder affected by a deviation from procedures was coded with an alpha suffix on the appropriate set of numbers. The portion of a powder lot which was processed outside the operating procedures or was otherwise suspect for any reason, therefore, became a new lot

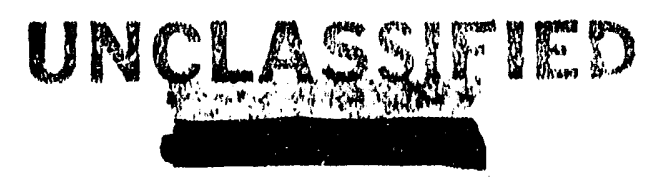


starting at that point where the deviation occurred. This system minimized the problem of holding large powder lots for evaluation due to nonstandard processing of small portion of a $10 t$.

The aluminum subassemblies were numbered sequentialiy with an alpha-numeric code of the following Form: AH $1 \rightarrow \mathrm{AH}-$ 9999. The first alpha character identified the isotope level. $A, C, D$, and $E$ were available for use on base material and $S$ and $P$ for spike and poison material respectively. The second alpha character $(H, K, M, N, R, T$, and $U)$ was used on $1 y$ to minimize the number of characters used. The aluminum subassembly identification was referenced to a specific powder 1ot on the "C" Format.

The zircaloy clad target elements were numbered sequentially with an alph-numeric code of the following Form: $A-1 \rightarrow$ A-999999. The alpha character identified the isotope level. Letters for use were identical to those used on aluminum subassemblies. Short target elements (standard length = 26.440 in.) for use with reworked driver fuel elements were further identified by an $\mathrm{L}$ or $\mathrm{N}$ following the number series for 24.740 and 21.820 in. lengths respectively, i.e., A-267-3L was a base leve1 24.740 in. target element. The zircaloy clad element was referenced to the two aluminum subassemblies contained on the "E" Format. 


\section{EXHIBIT I}

A. FORMAT

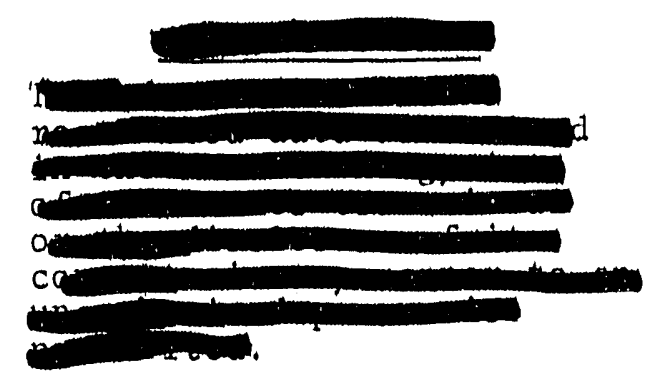

1. Number of pellets

2. Isotope content

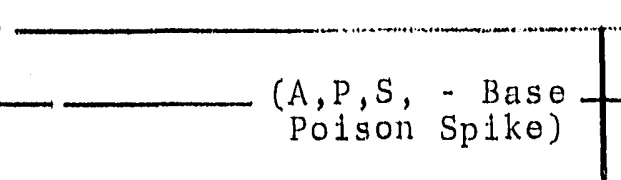

3. Cond, furnace

T'emp .

Time In

Temp . Time Out

4. Pebble mil1: Hours

5. Blender 8 steric acid,

Other additives

6. Pellet press psi

7. Binder Bakeout Furnace

Temp. Time-In

Temp. Time-Out

8. Sintering furnace\#

Time - In

Time furnace reaches $1325^{\circ} \mathrm{C}$

Time furnace is turned down

9. Inspection density: _otheoretical

10. Inspection sorting waiver diam reject diam TOTAL

No, to be Waived Rejects

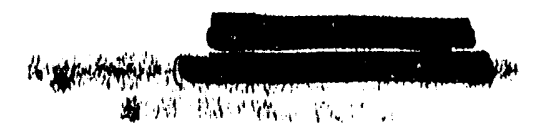

Date

$\mathrm{L}_{\mathrm{AlO}}$

Lot\#

LOT RECORD Oper Date Comments 


\section{EXHIBIT II}

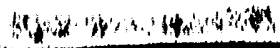

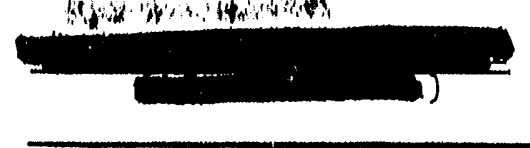

RES'T'RI C'I'BD DA'T'A

This document contains restricted data as defined in the Atomic Energy Act of 1954. Its transmittal or the disclosure of its contents in any manner to an unauthorlzed person is prohibited.

1. Centerless grind pe11et(1.075.002)

2. Grinding inspection

3. Stack longth $(12.640+/-.010)$

4. Drying furnaco: Time in. I'Ime out

Temp.

5. Subassemb1y:

Time enter. chamber

Time into glove box -

'Tlme capped (max.)

Time leav.glove box -

6. A.1. top cap wold timo: Start

7. Moisture sample\# Finish

8. Presizing inspection

9. Sizing oper. :Time at $2500 \mathrm{psi}$ \& $150^{\circ} \mathrm{C}$

10. Warp check and straightening

11. Sizing inspection

12. Finish OD (grind or machine to size)

13. Leak test

14. Blackness test

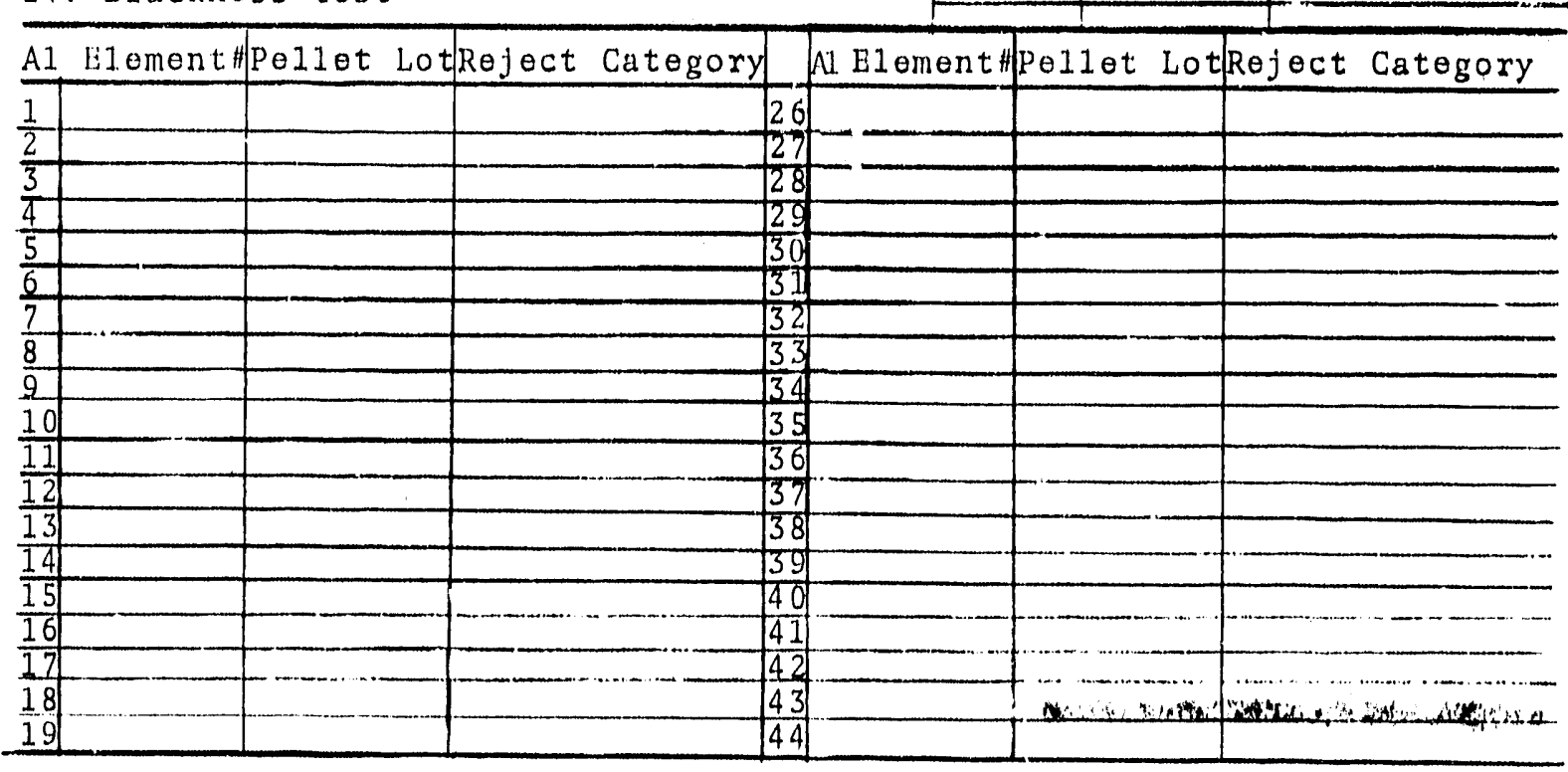

\section{FORMAT WHA}

CATION
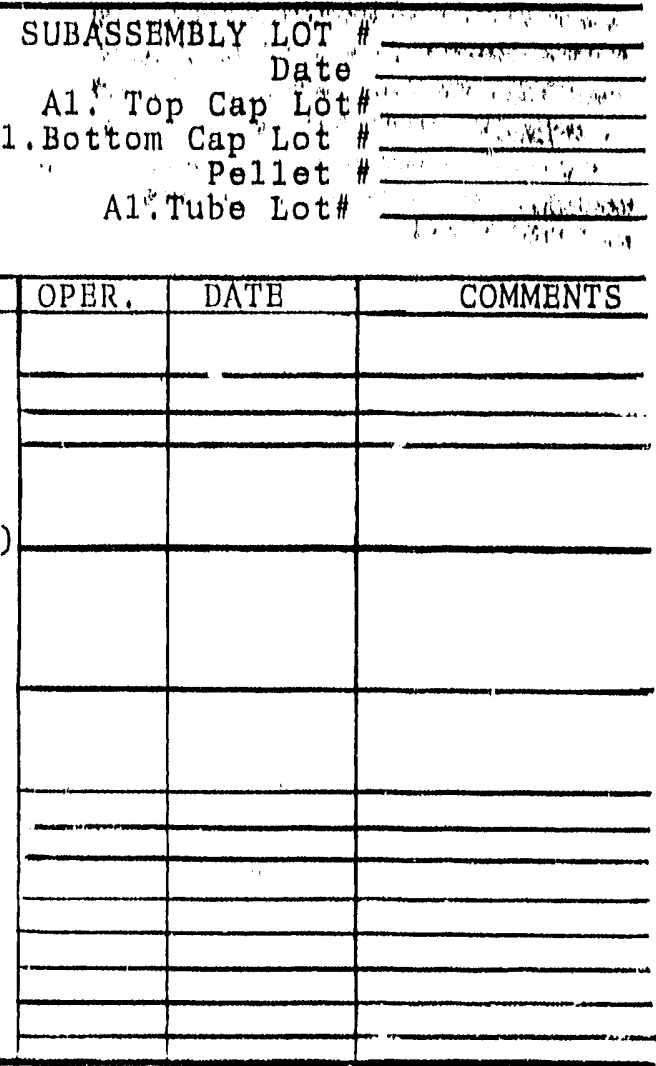

(After fill-in) 


\section{EXHIBIT III}

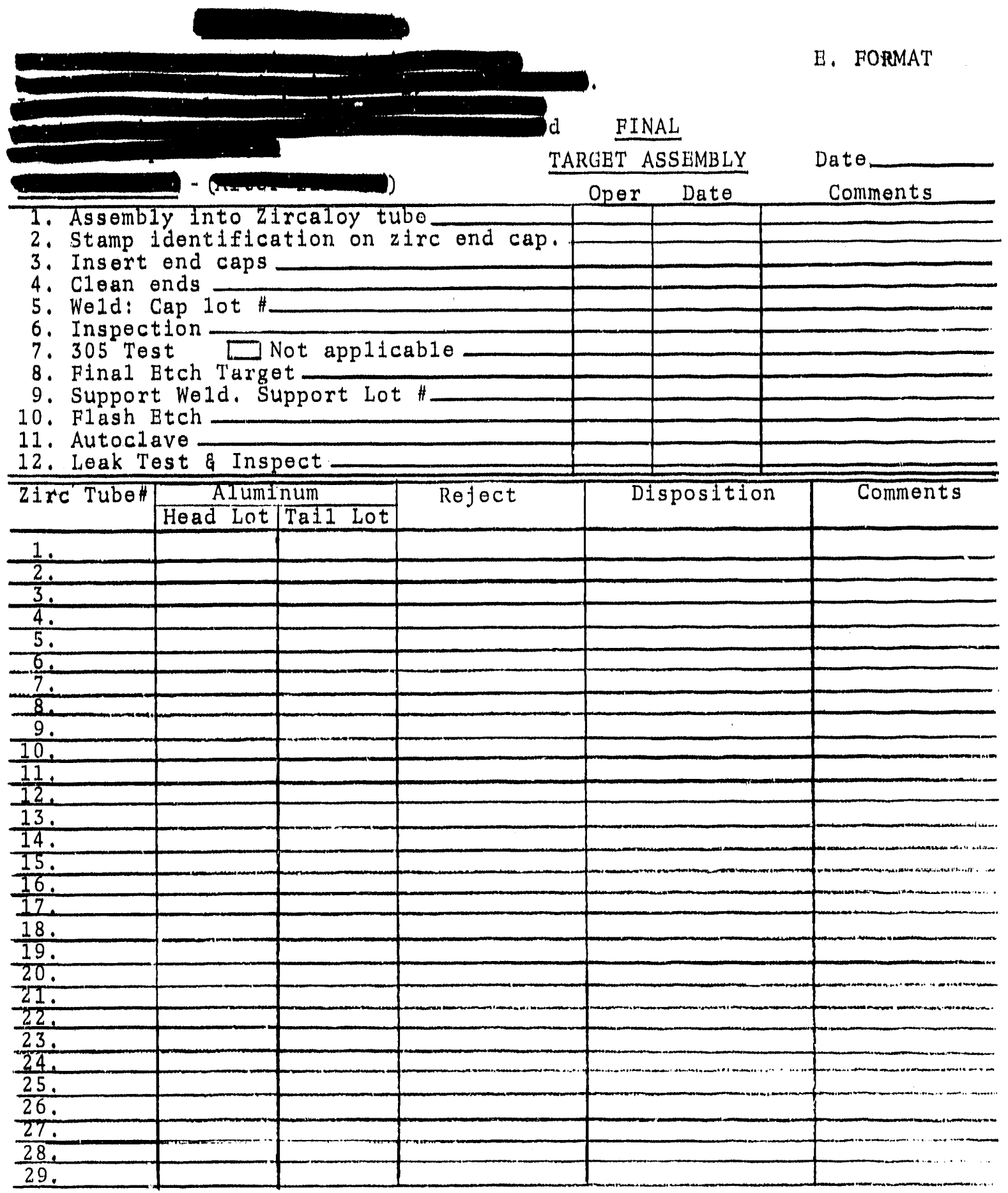

\section{UNCLASSIFIED}




\section{UVCLASSIFIED \\ APPENDIX B}

MAJOR EQUIPMENT ITEMS: TARGET ELEMENT FABRICATION PROCESS

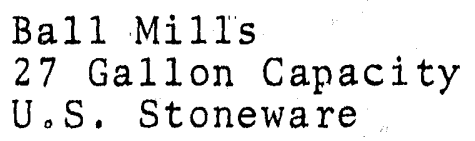

Bal1 Mills

27 Gallon Capacity

U.S. Stoneware

Blenders

60 pound capacity

Pau1 0. Abbe Inc.

Pellet Press - Automatic

Mode $1 \mathrm{HC}-30$

Hydromet Division, Olsen Mfg., Co.

Bakeout Furnace

Model L TE

Size $48 \times 48 \times 48$

$1250^{\circ} \mathrm{F}$ Rating

Lindberg Hevi-Duty

Sintering Furnaces

2 each, Sargeant \& Wilbur, Inc.

Size 12 in. $x 16$ in。 $x 96$ in.

$2500^{\circ} \mathrm{F}$ Rating

1 each, Lindberg Mode1 G-24

Size 20 in, $x 24$ in. $x 48$ in. $-2500^{\circ} \mathrm{F}$ Rating

Drying Furnace

C.I. Hayes, Inc.

Size 24 in. $x 24$ in. $x 48$ in.

$600^{\circ} \mathrm{F}$ Rating

Centerless Belt Grinders - Pellets

4 inch belt

Engelberg Huller

Cutoff Saw

Mode 10

Pistorium

Glovebox, Controlled Atmosphere

Engineered Item

Aluminum End Closure Welder

Miller - ac

BWC - 300 -MAPA

Reactivity Tester

Engineered Item 


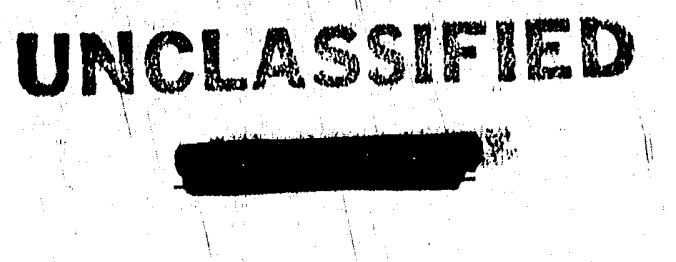

Centerless Belt Grinder - Aluminum 8 Inch Belt

Enge1berg-Huller

Zircaloy End Closure Welder

Sciaky Power Supply

Mode1 C-ZLR-Z, dc

Helium Leak Detector

Consolidated Electrodynamics Corp.

Support Welder

Mode1 1OHF. 2

Wel dex

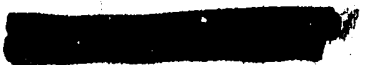


DATE FILMED $3 / 18 / 92$ 
